\title{
Quantitatively Fine-Tuning the Physicochemical and Biological Properties of Peptidic Polymers through Monodisperse PEGylation
}

Xuemeng Wang, ${ }^{\dagger}$ Yu Li, ${ }^{\S}$ Tingjuan Wu, ${ }^{\ddagger}$ Zhigang Yang, ${ }^{\dagger}$ Xing Zheng, ${ }^{\ddagger}$ Shizhen Chen, ${ }^{\S}$ Xin Zhou, $^{*, \$}$ and Zhong-Xing Jiang ${ }^{*,+}$

${ }^{\dagger}$ Hubei Province Engineering and Technology Research Center for Fluorinated Pharmaceuticals, School of Pharmaceutical Sciences, Wuhan University, Wuhan 430071, China

Institute of Pharmacy \& Pharmacology, University of South China, Hengyang 421001, China

${ }^{\S}$ State Key Laboratory for Magnetic Resonance and Atomic and Molecular Physics, National Center for Magnetic Resonance in Wuhan, Wuhan Institute of Physics and Mathematics, Chinese Academy of Sciences, Wuhan 430071, China

\section{Table of contents}

1. General information

2. Synthesis of compounds

3. Solvent-dependent ${ }^{19} \mathrm{~F}$ NMR

4. Determination of $n$-octanol/water partition coefficients

5. Turbidity test

6. Dynamic light scattering

7. Transmission electron microscopy

8. UV and fluorescent property of $\mathbf{P}_{\mathbf{7}-8}$

9. Biocompatibility assay 


\section{General information}

Unless otherwise indicated, all reagents were obtained from commercial supplier and used without prior purification. All solvents were analytical or HPLC grade. DCM, DMF, Et ${ }_{3} \mathrm{~N}, \mathrm{DIPEA}$ and THF were dried and freshly distilled prior to use. Flash chromatography was performed on silica gel (200-300 mesh) with eluents as indicated in procedures. Chemical shifts are expressed in ppm and coupling constants $(J)$ are in Hertz $(\mathrm{Hz})$. The splitting patterns for ${ }^{1} \mathrm{H}$ NMR spectra are denoted as follows: s (singlet), d (doublet), dd (double doublet), $\mathrm{t}$ (triplet), q (quartet), and m (multiplet). LC-MS mass spectra were recorded on Bruker UltiMate 3000 \& Compact mass spectrometer. MALDI-TOF mass spectra were recorded on a Bruker Ultraflex III TOF/TOF spectrometer using the reflection mode for positive ions with $\alpha$-cyano-4-hydroxylcinnamic acid or 2,5-dihydroxybenzoic acid as matrix.

All HPLC analysis were performed on SHIMADZU SIL-20A. For M-PEGylated peptidic polymers HPLC analysis: SPD-20A UV detector $(254 \mathrm{~nm}), \mathrm{RP}$ C18 column $(5 \mu \mathrm{m}, 4.6 \times 100 \mathrm{~mm})$, a gradient elution of $70 \%$ methanol in water to $100 \%$ methanol over $15 \mathrm{~min}$ (flow rate $0.7 \mathrm{~mL} / \mathrm{min}$ ) then $100 \%$ methanol for $5 \mathrm{~min}$. For DOX HPLC analysis: SPD-20A UV detector (480 nm), RP C18 column $(5 \mu \mathrm{m}, 4.6 \times 100 \mathrm{~mm})$, a gradient elution of solvent A (ammonium dihydrogen phosphate buffer, water containing $0.5 \% \mathrm{v} / \mathrm{v}$ acetic acid and $0.01 \mathrm{M}$ of ammonium dihydrogen phosphate, 0.35 $\mathrm{mL} / \mathrm{min}$ ) and solvent $\mathrm{B}$ (acetonitrile, $0.35 \mathrm{~mL} / \mathrm{min}$ ) over $20 \mathrm{~min}$.

\section{Synthesis of compounds}

\section{1) Synthesis of amino acid 1c}
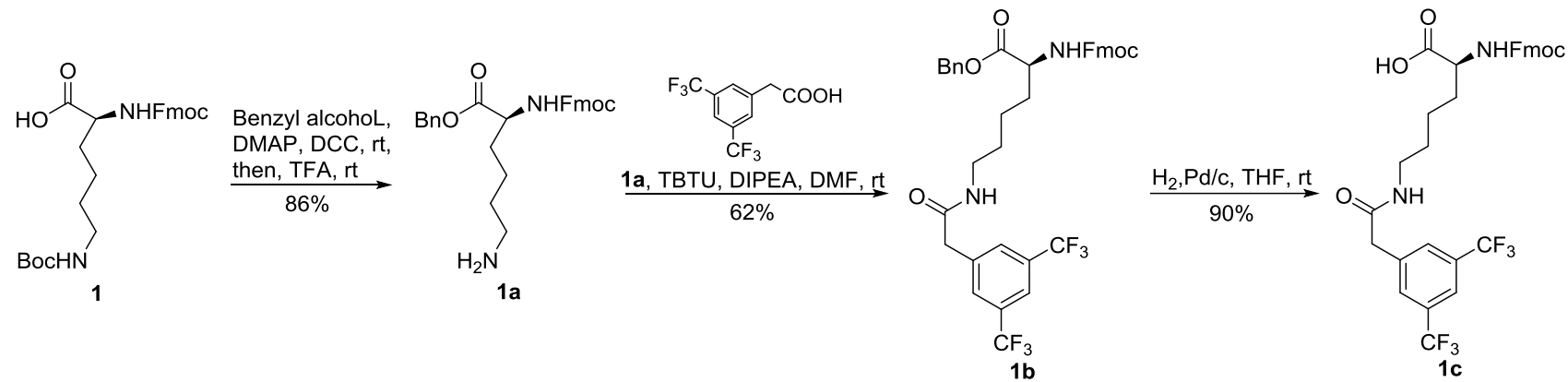

Compound 1a was prepared according to a literature method. ${ }^{[1]}{ }^{1} \mathrm{H}$ NMR $\left(400 \mathrm{MHz}, \mathrm{CDCl}_{3}\right) \delta$ 1.25-1.43 (m, 2H), $1.64(\mathrm{~s}, 3 \mathrm{H}), 1.81(\mathrm{~s}, 1 \mathrm{H}), 2.87(\mathrm{~s}, 2 \mathrm{H}), 4.02-4.26(\mathrm{~m}, 2 \mathrm{H}), 4.36$ (d, J = $7.4 \mathrm{~Hz}$, 2H), 5.01-5.25 (m, 2H), $7.29-7.66(\mathrm{~m}, 9 \mathrm{H}), 7.75(\mathrm{~d}, J=7.4 \mathrm{~Hz}, 2 \mathrm{H}), 7.93(\mathrm{~s}, 2 \mathrm{H})$. 
Compound 1b. TBTU and DIPEA were added to a solution of 2-(3,5-bis(trifluoromethyl)phenyl) acetic acid $(1.0 \mathrm{~g}, 3.7 \mathrm{mmol})$ in dry DMF $(35 \mathrm{~mL})$ at $\mathrm{rt}$. Then, a solution of $1 \mathbf{a}(1.9 \mathrm{~g}, 4.0 \mathrm{mmol})$ in dry DMF (15 mL) was added to the reaction, and the resulting mixture was stirred overnight at rt. Then DMF was evaporated under vacuum and the residue was washed with $\mathrm{H}_{2} \mathrm{O}$ and extracted with DCM. The combined organic layers were dried over anhydrous $\mathrm{Na}_{2} \mathrm{SO}_{4}$ and concentrated to give a residue. The residue was purified with flash chromatography on silica gel (PE:EA $=6: 1$ to $2: 1)$ to give the desired product $\mathbf{1 b}(1.6 \mathrm{~g}, 62 \%$ yield $)$ as white solid. ${ }^{1} \mathrm{H}$ NMR (400 MHz, $\left.\mathrm{CDCl}_{3}\right) \delta 1.31-1.46(\mathrm{~m}, 2 \mathrm{H}), 1.53(\mathrm{~d}, J=6.8 \mathrm{~Hz}, 2 \mathrm{H}), 1.65-1.78(\mathrm{~m}, 1 \mathrm{H}), 1.88(\mathrm{~d}, J$ $=7.1 \mathrm{~Hz}, 1 \mathrm{H}), 3.16-3.32(\mathrm{~m}, 2 \mathrm{H}), 3.49-3.64(\mathrm{~m}, 2 \mathrm{H}), 4.24(\mathrm{t}, J=6.9 \mathrm{~Hz}, 1 \mathrm{H}), 4.33-4.53(\mathrm{~m}, 3 \mathrm{H})$, $5.21(\mathrm{q}, J=12.2 \mathrm{~Hz}, 2 \mathrm{H}), 7.28-7.48(\mathrm{~m}, 9 \mathrm{H}), 7.60(\mathrm{~d}, J=7.3 \mathrm{~Hz}, 2 \mathrm{H}), 7.71-7.86(\mathrm{~m}, 5 \mathrm{H})$.

Compound 1c was prepared by employing the a literature method. ${ }^{[1]}{ }^{1} \mathrm{H} \mathrm{NMR}(400 \mathrm{MHz}$, DMSO-d $d_{6} \delta 1.29-1.43(\mathrm{~m}, 4 \mathrm{H}), 1.54-1.71(\mathrm{~m}, 2 \mathrm{H}), 3.02-3.07(\mathrm{~m}, 2 \mathrm{H}), 3.66(\mathrm{~s}, 2 \mathrm{H}), 3.85-3.92(\mathrm{~m}$, 1H), 4.18-4.32 (m, 3H), $7.32(\mathrm{t}, J=7.4 \mathrm{~Hz}, 2 \mathrm{H}), 7.41(\mathrm{t}, J=7.4 \mathrm{~Hz}, 2 \mathrm{H}), 7.72(\mathrm{~d}, J=7.4 \mathrm{~Hz}, 2 \mathrm{H})$, $7.89(\mathrm{~d}, J=7.5 \mathrm{~Hz}, 2 \mathrm{H}), 7.96(\mathrm{~d}, J=9.0 \mathrm{~Hz}, 3 \mathrm{H})$. 


\section{2) Synthesis of M-PEGylated $L$-lysine $2 \mathrm{e}, 3 \mathrm{e}, \mathbf{4 g}$}
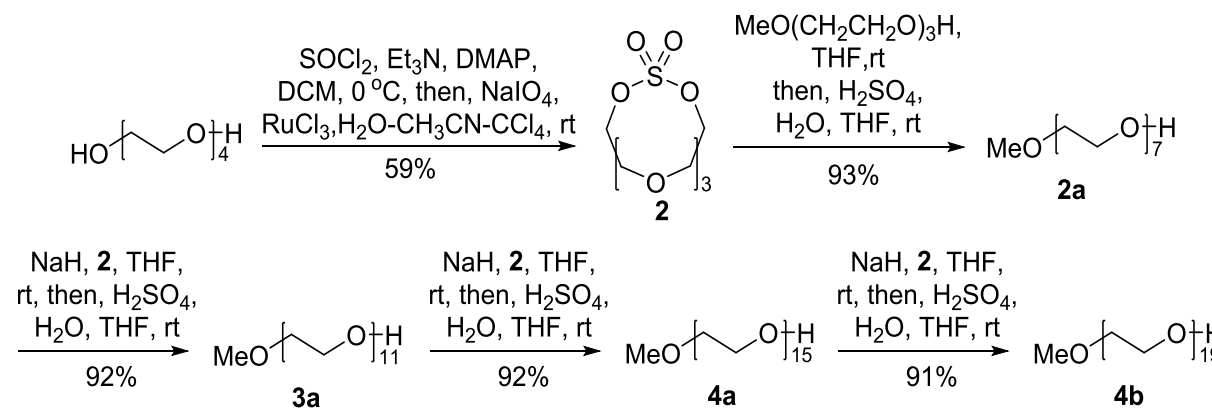

$3 a$

$4 b$

$\mathrm{NaH}, 2$, THF,

rt, then, $\mathrm{H}_{2} \mathrm{SO}_{4}$,

$\underset{90 \%}{\stackrel{\mathrm{H}_{2} \mathrm{O}, \mathrm{THF}, \mathrm{rt}}{\longrightarrow}} \mathrm{MeO} \underbrace{\mathrm{O}}_{4 \mathbf{c}} \mathrm{H}_{23}^{\mathrm{H}}$
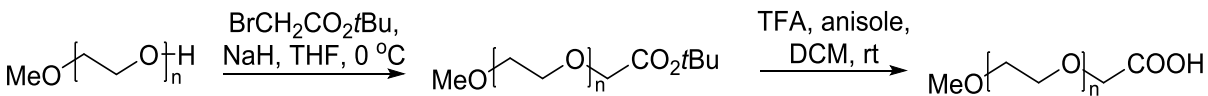

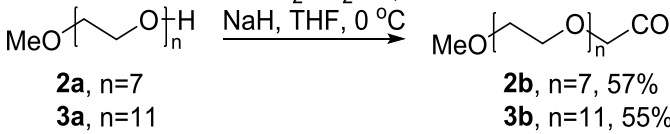

3b, $n=11,55 \%$

2c, $n=7,100 \%$

3c, $n=11,100 \%$

4c, $n=23$

4d, $n=23,55 \%$

$4 e, n=23,98 \%$

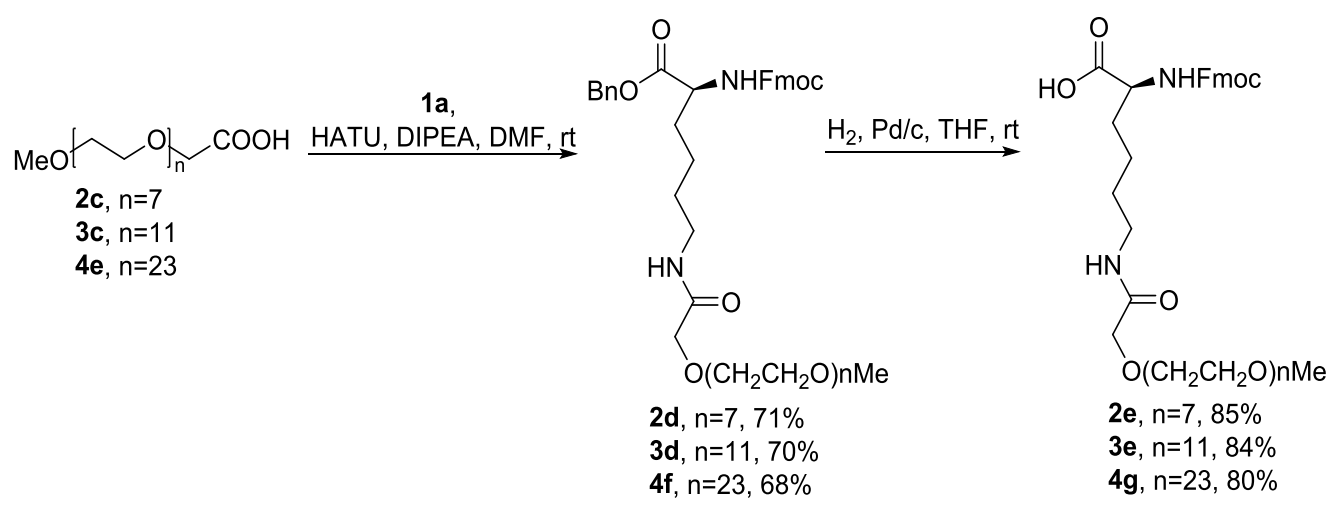

Compound 2. Cyclic sulfate 2 was prepared by employing the a literature method. ${ }^{[1]}$

Compound 2a. Under an atmosphere of Ar, to a suspension of $\mathrm{NaH}(1.8 \mathrm{~g}, 60 \%$ in mineral oil, 45.7 $\mathrm{mmol})$ in dry THF $(40 \mathrm{~mL})$ was added a solution of triethylene glycol monomethyl ether $(5.0 \mathrm{~g}, 30.5$ mmol) in dry THF $(15 \mathrm{~mL})$ at $0{ }^{\circ} \mathrm{C}$. After stirring for $2 \mathrm{~h}$, a solution of macrocyclic sulfate $2(10.1 \mathrm{~g}$, $39.6 \mathrm{mmol})$ in dry THF $(15 \mathrm{~mL})$ was added to the reaction, and the resulting mixture was stirred overnight at rt. Then, $\mathrm{H}_{2} \mathrm{O}(1.4 \mathrm{~mL}, 76.1 \mathrm{mmol})$ was added and the $\mathrm{pH}$ was adjusted to 3 with $\mathrm{H}_{2} \mathrm{SO}_{4}$. After stirring at $\mathrm{rt}$ for $3 \mathrm{~h}$, the reaction was quenched with saturated $\mathrm{NaHCO}_{3}$ solution and concentrated under vacuum, the residue was purified with flash chromatography on silica gel with $\mathrm{MeOH} / \mathrm{DCM}(1 / 20)$ as eluents to give 2a (9.6 g, yield: 93\%) as clear oil. ${ }^{1} \mathrm{H}$ NMR $\left(400 \mathrm{MHz}, \mathrm{CDCl}_{3}\right)$ $\delta 3.40(\mathrm{~s}, 3 \mathrm{H}), 3.55-3.80(\mathrm{~m}, 28 \mathrm{H})$.

Compound 3a was prepared from 2a by following the same procedure for $\mathbf{2 a}$ as light yellow oil (12.9 g, 92\% yield). ${ }^{1} \mathrm{H}$ NMR (400 MHz, $\left.\mathrm{CDCl}_{3}\right) \delta 3.40(\mathrm{~s}, 3 \mathrm{H}), 3.55-3.76(\mathrm{~m}, 44 \mathrm{H})$. 
Compound 4a was prepared from 3a by following the same procedure for $\mathbf{2 a}$ as light yellow oil (14.5 g, 92\% yield). ${ }^{1} \mathrm{H}$ NMR (400 MHz, $\left.\mathrm{CDCl}_{3}\right) \delta 3.40$ (s, 3H), 3.54-3.77 (m, 60H).

Compound $4 \mathbf{b}$ was prepared from $4 \mathbf{a}$ by following the same procedure for $\mathbf{2 a}$ as light yellow oil (23 g, 91\% yield). ${ }^{1} \mathrm{H}$ NMR (400 $\left.\mathrm{MHz}, \mathrm{CDCl}_{3}\right) 3.40$ (s, 3H), 3.49-3.80 (m, 76H). ${ }^{13} \mathrm{C}$ NMR $\left(100 \mathrm{MHz} \mathrm{CDCl}_{3}\right) \delta 77.5,77.2,76.9,72.6,71.9,70.5,70.2,61.6,59.0$. HRMS (ESI) calcd for $\mathrm{C}_{39} \mathrm{H}_{80} \mathrm{NaO}_{20}{ }^{+}[\mathrm{M}+\mathrm{Na}]^{+} 891.5141$, found 891.5126.

Compound $4 \mathbf{c}$ was prepared from $\mathbf{4 b}$ by following the same procedure for $2 \mathbf{a}$ as light yellow oil (6.6 g, 90\% yield). ${ }^{1} \mathrm{H}$ NMR $\left(400 \mathrm{MHz}, \mathrm{CDCl}_{3}\right) \delta 3.40(\mathrm{~s}, 3 \mathrm{H}), 3.47-3.90(\mathrm{~m}, 92 \mathrm{H}) .{ }^{13} \mathrm{C}$ NMR (100 MHz, $\left.\mathrm{CDCl}_{3}\right) \delta 77.60,77.28,76.96,72.47,71.81,70.40,70.29,61.38,58.91$. HRMS (ESI) calcd for $\mathrm{C}_{47} \mathrm{H}_{96} \mathrm{NaO}_{24}{ }^{+}[\mathrm{M}+\mathrm{Na}]^{+} 1067.6189$, found 1067.6182.

Compound 2b. Under an atmosphere of Ar, to a suspension of $\mathrm{NaH}(0.2 \mathrm{~g}, 60 \%$ in mineral oil, $5.1 \mathrm{mmol})$ in dry THF (3 mL) was added a solution of $2 \mathbf{a}(0.5 \mathrm{~g}, 1.5 \mathrm{mmol})$ in dry THF $(10 \mathrm{~mL})$ at $0{ }^{\circ} \mathrm{C}$ and the mixture was stirred at this temperature for $2 \mathrm{~h}$. Then tert-butyl bromoacetate $(1.0 \mathrm{~g}, 0.8 \mathrm{~mL}, 5.1 \mathrm{mmol})$ was added to the reaction, and the resulting mixture was stirred overnight at rt. The reaction was neutralized with saturated $\mathrm{NH}_{4} \mathrm{Cl}$, dried over anhydrous $\mathrm{Na}_{2} \mathrm{SO}_{4}$ and concentrated. The residue was purified with flash chromatography on silica gel with MeOH/DCM (1/20) as eluents to give $2 \mathbf{b}(0.4 \mathrm{~g}, 57 \%$ yield $)$ as light yellow oil. ${ }^{1} \mathrm{H}$ NMR (400 MHz, $\left.\mathrm{CDCl}_{3}\right) \delta 1.49(\mathrm{~s}, 9 \mathrm{H}), 3.40(\mathrm{~s}, 3 \mathrm{H}), 3.48-3.80(\mathrm{~m}, 28 \mathrm{H}), 4.04(\mathrm{~s}, 2 \mathrm{H})$.

Compound 2c. A solution of compound $2 \mathbf{b}(7.8 \mathrm{~g}, 19.3 \mathrm{mmol})$, anisole $(3.1 \mathrm{~mL}, 28.9 \mathrm{mmol})$ and TFA $(35.8 \mathrm{~mL}, 481.8 \mathrm{mmol})$ in DCM $(100 \mathrm{~mL})$ was stirred overnight at $30{ }^{\circ} \mathrm{C}$. After concentrated under vacuum, the residue was dissolved in water and washed with $\mathrm{Et}_{2} \mathrm{O}$, then the water phase was extracted with DCM. The combined organic layers were dried over anhydrous $\mathrm{Na}_{2} \mathrm{SO}_{4}$, concentrated under vacuum to give $2 \mathrm{c}(7.7 \mathrm{~g}, 100 \%$ yield) as yellow oil. Compound 2d. HATU and DIPEA were added to a solution of $2 \mathbf{c}(7.0 \mathrm{~g}, 17.6 \mathrm{mmol})$ in dry DMF $(130 \mathrm{~mL})$ at $\mathrm{rt}$. Then, a solution of $\mathbf{1 a}(6.2 \mathrm{~g}, 13.5 \mathrm{mmol})$ in dry DMF $(30 \mathrm{~mL})$ was added to the reaction, and the resulting mixture was stirred overnight at rt. Then DMF was evaporated and the residue was washed with $\mathrm{H}_{2} \mathrm{O}$, extracted with $\mathrm{DCM}$ and dried over anhydrous $\mathrm{Na}_{2} \mathrm{SO}_{4}$. The combined organic layers were purified with flash chromatography on silica gel with MeOH/DCM (1/20) as eluents to give $2 \mathbf{d}\left(8.1 \mathrm{~g}, 71 \%\right.$ yield) as clear oil. ${ }^{1} \mathrm{H} \mathrm{NMR}\left(400 \mathrm{MHz},\left(\mathrm{CD}_{3}\right)_{2} \mathrm{CO}\right) \delta$ 1.44-1.60 (m, 4H), 1.78-1.92 (m, 2H), 3.22-3.27 (m, 2H), $3.29(\mathrm{~s}, 3 \mathrm{H}), 3.47(\mathrm{dd}, J=5.8,3.8 \mathrm{~Hz}, 2 \mathrm{H})$, 
3.53-3.73 (m, 28H), 4.07-4.30 (m, 3H), 4.30-4.51 (m, 3H), 5.14-5.25(m, 2H), 7.32-7.45 (m, 9H), $7.74(\mathrm{~d}, J=7.4 \mathrm{~Hz}, 2 \mathrm{H}), 7.89(\mathrm{~d}, J=7.5 \mathrm{~Hz}, 2 \mathrm{H}) .{ }^{13} \mathrm{C} \mathrm{NMR}\left(126 \mathrm{MHz}, \mathrm{CDCl}_{3}\right) \delta 172.4,170.1,156.1$, $143.9,141.3,135.4,128.6,128.4,127.7,127.1,125.1,120.0,71.9,70.9,70.3$, 70.0, 67.0, 59.0, 53.9, 47.2, 31.9, 29.7, 29.4, 22.5. HRMS (ESI) calcd for $\mathrm{C}_{45} \mathrm{H}_{62} \mathrm{~N}_{2} \mathrm{NaO}_{13}{ }^{+}[\mathrm{M}+\mathrm{Na}]^{+} 861.4150$, found 861.4131.

Compound 2e. A mixture of $2 \mathbf{d}(5.2 \mathrm{~g}, 6.2 \mathrm{mmol})$ and $\mathrm{Pd} / \mathrm{C}(0.6 \mathrm{~g}, 10 \%$ on carbon) in $\mathrm{MeOH}(50$ $\mathrm{mL})$ was stirred at $\mathrm{rt}$ under $\mathrm{H}_{2}(1 \mathrm{~atm})$ for $5 \mathrm{~h}$. The mixture was filtered through Cite and purified with flash chromatography on silica gel with $\mathrm{MeOH} / \mathrm{DCM}(1 / 20)$ as eluents to give $2 \mathrm{e}$ (3.9 g, 85\% yield) as clear oil. ${ }^{1} \mathrm{H}$ NMR (400 MHz, $\left.\mathrm{CDCl}_{3}\right) \delta 1.33-1.66(\mathrm{~m}, 4 \mathrm{H}), 1.69-2.00(\mathrm{~m}, 2 \mathrm{H}), 3.29-3.42(\mathrm{~m}$, $5 \mathrm{H}), 3.54-3.70(\mathrm{~m}, 28 \mathrm{H}), 4.02(\mathrm{~d}, J=16.5 \mathrm{~Hz}, 2 \mathrm{H}), 4.09-4.58(\mathrm{~m}, 4 \mathrm{H}), 7.33(\mathrm{t}, J=7.4 \mathrm{~Hz}, 2 \mathrm{H}), 7.41$ $(\mathrm{t}, J=7.4 \mathrm{~Hz}, 2 \mathrm{H}), 7.63(\mathrm{dd}, J=7.3,3.4 \mathrm{~Hz}, 2 \mathrm{H}), 7.78(\mathrm{~d}, J=7.5 \mathrm{~Hz}, 2 \mathrm{H}) .{ }^{13} \mathrm{C} \mathrm{NMR}(100 \mathrm{MHz}$, $\left.\mathrm{CDCl}_{3}\right) \delta 173.9,170.5,156.1,143.9,141.3,127.7,127.1,125.1,120.0,71.9,70.9,70.4,66.8,59.0$, 53.6, 47.2, 38.3, 31.6, 28.7, 22.0. HRMS (ESI) calcd for $\mathrm{C}_{38} \mathrm{H}_{55} \mathrm{~N}_{2} \mathrm{O}_{13}{ }^{-}[\mathrm{M}-\mathrm{H}]^{-}$747.3704, found 747.3725 .

Compound $\mathbf{3 b}$ was prepared from $\mathbf{3 a}$ by following the same procedure for $\mathbf{2 b}$ as light yellow oil (15.4 g, 55\% yield). ${ }^{1} \mathrm{H}$ NMR (400 MHz, $\left.\mathrm{CDCl}_{3}\right) \delta 1.50(\mathrm{~s}, 9 \mathrm{H}), 3.40(\mathrm{~s}, 3 \mathrm{H}), 3.57$ (dd, $J$ $=5.7,3.5 \mathrm{~Hz}, 2 \mathrm{H}), 3.64-3.76(\mathrm{~m}, 42 \mathrm{H}), 4.05(\mathrm{~s}, 2 \mathrm{H}) .{ }^{13} \mathrm{C} \mathrm{NMR}\left(100 \mathrm{MHz}, \mathrm{CDCl}_{3}\right) \delta 169.6$, 81.5, 71.9, 70.6, 69.0, 59.0, 28.1. HRMS (ESI) calcd for $\mathrm{C}_{29} \mathrm{H}_{58} \mathrm{NaO}_{14}{ }^{+}[\mathrm{M}+\mathrm{Na}]^{+} 653.3724$, found 653.3702 .

Compound $3 \mathbf{c}$ was prepared from $\mathbf{3 b}$ by following the same procedure for $\mathbf{2 c}$ as light yellow oil (13.3 g, 100\% yield). ${ }^{1} \mathrm{H}$ NMR (400 $\left.\mathrm{MHz} \mathrm{CDCl}_{3}\right) \delta 3.40(\mathrm{~s}, 3 \mathrm{H}), 3.48-3.87$ (m, 44H), $4.18(\mathrm{~s}, 2 \mathrm{H})$.

Compound 3d was prepared from $3 \mathbf{c}$ by following the same procedure for $\mathbf{2} \mathbf{d}$ as light yellow oil (6.6 g, 70\% yield). ${ }^{1} \mathrm{H}$ NMR (400 MHz, $\left.\left(\mathrm{CD}_{3}\right)_{2} \mathrm{CO}\right) \delta 1.48(\mathrm{~d}, J=7.3 \mathrm{~Hz}, 2 \mathrm{H}), 1.54(\mathrm{~d}, J=$ $7.7 \mathrm{~Hz}, 2 \mathrm{H}), 1.80-1.91(\mathrm{~m}, 2 \mathrm{H}), 3.23-3.28(\mathrm{~m}, 2 \mathrm{H}), 3.31(\mathrm{~s}, 3 \mathrm{H}), 3.48-3.51(\mathrm{~m}, 2 \mathrm{H}), 3.55-3.69$ $(\mathrm{m}, 42 \mathrm{H}), 3.94(\mathrm{~s}, 2 \mathrm{H}), 4.26(\mathrm{~d}, J=7.1 \mathrm{~Hz}, 2 \mathrm{H}), 4.34-4.41(\mathrm{~m}, 2 \mathrm{H}), 5.20(\mathrm{~d}, J=3.6 \mathrm{~Hz}, 2 \mathrm{H})$, 7.35-7.47 (m, 9H), $7.74(\mathrm{~d}, J=7.4 \mathrm{~Hz}, 2 \mathrm{H}), 7.89(\mathrm{~d}, J=7.2 \mathrm{~Hz}, 2 \mathrm{H}) .{ }^{13} \mathrm{C} \mathrm{NMR}(126 \mathrm{MHz}$, $\left.\mathrm{CDCl}_{3}\right) \delta 172.3,170.2,156.1,143.9,141.3,135.36,128.8,128.5,128.3,127.7,127.1$, $125.1,120.0,71.8,70.8,70.2,67.1,66.8,59.0,54.0,47.2,38.3,31.7,29.7,22.5$. HRMS (ESI) calcd for $\mathrm{C}_{53} \mathrm{H}_{78} \mathrm{~N}_{2} \mathrm{NaO}_{17}{ }^{+}[\mathrm{M}+\mathrm{Na}]^{+}$1037.5198, found 1037.5203. 
Compound 3e was prepared from 3d by following the same procedure for $2 \mathbf{e}$ as light yellow oil (5.0 g, 84\% yield). ${ }^{1} \mathrm{H}$ NMR (400 $\left.\mathrm{MHz}, \mathrm{CDCl}_{3}\right) \delta 1.33-1.66(\mathrm{~m}, 4 \mathrm{H}), 1.72-2.01(\mathrm{~m}, 2 \mathrm{H})$, $3.32(\mathrm{~d}, J=5.1 \mathrm{~Hz}, 2 \mathrm{H}), 3.38(\mathrm{~s}, 3 \mathrm{H}), 3.50-3.79(\mathrm{~m}, 44 \mathrm{H}), 4.00(\mathrm{~s}, 2 \mathrm{H}), 4.22$ (t, $J=6.7 \mathrm{~Hz}$, $1 \mathrm{H}), 4.30-4.55(\mathrm{~m}, 3 \mathrm{H}), 7.23-7.36(\mathrm{~m}, 2 \mathrm{H}), 7.40(\mathrm{t}, J=7.4 \mathrm{~Hz}, 2 \mathrm{H}), 7.62(\mathrm{~s}, 2 \mathrm{H}), 7.77(\mathrm{~d}, J=$ $7.5 \mathrm{~Hz}, 2 \mathrm{H}) .{ }^{13} \mathrm{C} \mathrm{NMR}\left(100 \mathrm{MHz}, \mathrm{CDCl}_{3}\right) \delta 174.0,170.5,156.1,143.9,141.3,127.7,127.1$, $125.1,120.0,71.9,71.0,70.4,69.9,66.8,59.0,53.6,47.2,38.3,31.6,28.7,22.1$. HRMS (ESI) calcd for $\mathrm{C}_{46} \mathrm{H}_{71} \mathrm{~N}_{2} \mathrm{O}_{17^{-}}[\mathrm{M}-\mathrm{H}]^{-}$923.4753, found 923.4750.

Compound $4 \mathbf{d}$ was prepared from $\mathbf{4 c}$ by following the same procedure for $\mathbf{2 b}$ as light yellow oil (14.0 g, 55\% yield). ${ }^{1} \mathrm{H}$ NMR (400 MHz, $\left.\mathrm{CDCl}_{3}\right) \delta 1.49$ (s, 9H), 3.40 (s, 3H), 3.56-3.59 (m, 2H), 3.64-3.75 (m, 90H), 4.04 (s, 2H). $\left.{ }^{13} \mathrm{C} \mathrm{NMR} \mathrm{(100} \mathrm{MHz,} \mathrm{CDCl}_{3}\right) \delta 169.5,81.3,71.79$, 70.5, 68.9, 58.9, 28.09. HRMS (ESI) calcd for $\mathrm{C}_{53} \mathrm{H}_{106} \mathrm{NaO}_{26}{ }^{+}[\mathrm{M}+\mathrm{Na}]^{+} 1181.6870$, found 1181.6873.

Compound $4 \mathbf{e}$ was prepared from $4 \mathbf{d}$ by following the same procedure for $2 \mathbf{c}$ as light yellow oil (10.8 g, 98\% yield). ${ }^{1} \mathrm{H}$ NMR (400 MHz, $\left.\left(\mathrm{CD}_{3}\right)_{2} \mathrm{CD}\right) \delta 3.31$ (s, 3H), 3.47-3.51 (m, 2H), 3.53-4.00 (m, 90H), $4.14(\mathrm{~s}, 2 \mathrm{H}) .{ }^{13} \mathrm{C} \mathrm{NMR}\left(100 \mathrm{MHz}, \mathrm{CDCl}_{3}\right) \delta 171.8,71.8,70.6,70.4,68.4$, 58.8. HRMS (ESI) calcd for $\mathrm{C}_{49} \mathrm{H}_{97} \mathrm{O}_{26}{ }^{-}[\mathrm{M}-\mathrm{H}]^{-} 1101.6268$, found 1101.6237.

Compound $\mathbf{4 f}$ was prepared from $\mathbf{4 e}$ by following the same procedure for $\mathbf{2 d}$ as light yellow oil (5.8 g, 68\% yield). ${ }^{1} \mathrm{H}$ NMR (400 MHz, $\left.\mathrm{CDCl}_{3}\right) \delta 1.27$ (d, J=7.1 Hz, 2H), $1.56(\mathrm{~s}, 2 \mathrm{H}), 2.07$ (s, 2H), 3.27 (s, 2H), 3.40 (s, 3H), 3.41-3.97 (m, 92H), 4.12-4.18 (m, 2H), 4.24 (s, 2H), 4.38-4.46 (m, 3H), $5.20(\mathrm{~d}, J=4.3 \mathrm{~Hz}, 2 \mathrm{H}), 7.31-7.45(\mathrm{~m}, 9 \mathrm{H}), 7.62(\mathrm{~s}, 2 \mathrm{H}), 7.79$ (d, $J=7.8 \mathrm{~Hz}, 2 \mathrm{H}) .{ }^{13} \mathrm{C}$ NMR $(126$ $\left.\mathrm{MHz}, \mathrm{CDCl}_{3}\right) \delta 172.3,170.1,156.1,143.8,141.2$, 135.4, 129.1, 128.5, 128.2, 127.7, 127.0, 125.1, $119.9,71.8,70.8,70.1,69.3,68.3,67.1,66.8,59.0,54.0,47.2,38.3,31.6,29.3,22.5$. HRMS (ESI) calcd for $\left(\mathrm{C}_{73} \mathrm{H}_{128} \mathrm{~N}_{2} \mathrm{Na}_{4} \mathrm{O}_{29}{ }^{2+}\right) / 2[(\mathrm{M}+\mathrm{Na}) / 2]^{+} 794.4097$, found 794.4108 .

Compound $\mathbf{4 g}$ was prepared from $4 \mathbf{f}$ by following the same procedure for $2 \mathrm{e}$ as light yellow oil (4.4 g, 80\% yield). ${ }^{1} \mathrm{H}$ NMR (400 $\left.\mathrm{MHz} \mathrm{CDCl}_{3}\right) \delta 1.45-1.69(\mathrm{~m}, 4 \mathrm{H}), 1.97-1.79(\mathrm{~m}, 2 \mathrm{H})$, $3.32(\mathrm{~d}, J=5.6 \mathrm{~Hz}, 2 \mathrm{H}), 3.40(\mathrm{~s}, 3 \mathrm{H}), 3.59-3.54(\mathrm{~m}, 2 \mathrm{H}), 3.76-3.60(\mathrm{~m}, 90 \mathrm{H}), 3.99(\mathrm{~s}, 2 \mathrm{H})$, $4.24(\mathrm{t}, J=6.6 \mathrm{~Hz}, 1 \mathrm{H}), 4.35-4.48(\mathrm{~m}, 3 \mathrm{H}), 7.34(\mathrm{t}, J=7.3 \mathrm{~Hz}, 2 \mathrm{H}), 7.42(\mathrm{t}, J=7.4 \mathrm{~Hz}, 2 \mathrm{H})$, $7.63(\mathrm{~d}, J=6.9 \mathrm{~Hz}, 2 \mathrm{H}), 7.78(\mathrm{~d}, J=7.5 \mathrm{~Hz}, 2 \mathrm{H}) .{ }^{13} \mathrm{C} \mathrm{NMR}\left(100 \mathrm{MHz}, \mathrm{CDCl}_{3}\right) \delta 169.3,81.0$, $71.7,70.7,70.3,70.2,70.1,69.6,69.0,58.7,51.6,45.2,27.9$. HRMS (ESI) calcd for $\mathrm{C}_{70} \mathrm{H}_{119} \mathrm{~N}_{2} \mathrm{O}_{29}{ }^{-}[\mathrm{M}-\mathrm{H}]^{-}$1451.7899, found 1451.7940 . 
Peptide P7-8. ${ }^{1} \mathrm{H}$ NMR (400 MHz, CD $\left.{ }_{3} \mathrm{CO}\right) \delta$ 1.76-1.22 (m, 48H), 3.05-3.28 (m, 16H), 3.36 $(\mathrm{d}, J=3.2 \mathrm{~Hz}, 15 \mathrm{H}), 3.75-3.52(\mathrm{~m}, 146 \mathrm{H}), 4.06-4.53(\mathrm{~m}, 17 \mathrm{H}), 7.81-7.89(\mathrm{~m}, 5 \mathrm{H}), 7.90-8.00$ $(\mathrm{m}, 9 \mathrm{H}) .{ }^{19} \mathrm{~F}$ NMR $\left(376 \mathrm{MHz}, \mathrm{D}_{3} \mathrm{O}\right) \delta-63.40,-63.41,-63.43,-63.48,-63.51 . \mathrm{MS}$ (MALDI) $\mathrm{m} / \mathrm{z}$ calcd for $\mathrm{C}_{173} \mathrm{H}_{275} \mathrm{~F}_{18} \mathrm{~N}_{17} \mathrm{KO}_{57}{ }^{+}[(\mathrm{M}+\mathrm{K})]^{+} 3883.8$, found 3882.4.

Peptide P7-12. ${ }^{1} \mathrm{H}$ NMR (400 MHz, $\left.\mathrm{CDCl}_{3}\right) \delta$ 1.16-1.37 (m, 24H), 1.38-1.69 (m, 48H), 3.21 $(\mathrm{s}, 24 \mathrm{H}), 3.38(\mathrm{~s}, 21 \mathrm{H}), 3.43-3.75(\mathrm{~m}, 206 \mathrm{H}), 3.79-4.12(\mathrm{~m}, 25 \mathrm{H}), 7.66-7.74(\mathrm{~m}, 7 \mathrm{H})$, 7.75-7.89 (m, 15H). ${ }^{19} \mathrm{~F}$ NMR (376 MHz, D 30$) \delta-63.41,-63.43$. MS (MALDI) m/z calcd for $\mathrm{C}_{251} \mathrm{H}_{394} \mathrm{~F}_{30} \mathrm{~N}_{25} \mathrm{Na}_{2} \mathrm{O}_{81}{ }^{+}[(\mathrm{M}+2 \mathrm{Na}-\mathrm{H})]^{+}$5670.6, found 5669.9.

Peptide P11-8. ${ }^{1} \mathrm{H}$ NMR (400 MHz, $\left.\mathrm{CDCl}_{3}\right) \delta$ 1.82-1.01 (m, 48H), 3.12-3.32 (m, 16H), 3.39 $(\mathrm{s}, 15 \mathrm{H}), 3.94-3.43(\mathrm{~m}, 226 \mathrm{H}), 5.35-3.99(\mathrm{~m}, 17 \mathrm{H}), 7.67-7.76(\mathrm{~m}, 5 \mathrm{H}), 7.77-7.93(\mathrm{~m}, 9 \mathrm{H}) .{ }^{19} \mathrm{~F}$ NMR (376 MHz, D 3 O) $\delta-63.29,-63.36,-63.37,-63.44,-63.48$. MS (MALDI) m/z calcd for $\mathrm{C}_{215} \mathrm{H}_{359} \mathrm{~F}_{18} \mathrm{~N}_{18} \mathrm{O}_{77}{ }^{+}[(\mathrm{M}+\mathrm{ACN}+\mathrm{H})]^{+}$4767.4, found 4766.5 .

Peptide P11-12. ${ }^{1} \mathrm{H}$ NMR (400 $\left.\mathrm{MHz}, \mathrm{CDCl}_{3}\right) \delta$ 1.31-1.68 (m, 48H), 1.72-2.05 (m, 24H), 3.00-3.35 (m, 24H), 3.39 (d, $J=3.2 \mathrm{~Hz}, 21 \mathrm{H}), 3.77-3.53(\mathrm{~m}, 318 \mathrm{H}), 4.21-4.42(\mathrm{~m}, 25 \mathrm{H})$, 7.67-7.74 (m, 7H), 7.77-7.89 (s, 15H). ${ }^{19} \mathrm{~F}$ NMR (376 MHz, D 30$) \delta-63.38,-63.40 . \mathrm{MS}$ (MALDI) $\mathrm{m} / \mathrm{z}$ calcd for $\mathrm{C}_{308} \mathrm{H}_{512} \mathrm{~F}_{30} \mathrm{~N}_{25} \mathrm{O}_{110}{ }^{+}\left[\left(\mathrm{M}+\mathrm{CH}_{3} \mathrm{OH}+\mathrm{H}\right)\right]^{+}$6895.5, found 6896.9.

Peptide P23-8. ${ }^{1} \mathrm{H}$ NMR (400 MHz, $\left.\mathrm{CDCl}_{3}\right) \delta$ 1.38-1.07 (m, 16H), 1.40-1.69 (m, 32H), 3.01-3.34 (m, 16H), $3.40(\mathrm{~s}, 15 \mathrm{H}), 3.98-3.48(\mathrm{~m}, 466 \mathrm{H}), 4.02-4.47(\mathrm{~m}, 17 \mathrm{H}), 7.68-7.77(\mathrm{~m}$, 5H), 7.79-7.88 (m, 9H). ${ }^{19} \mathrm{~F}$ NMR (376 MHz, D $\left.3 \mathrm{O}\right) \delta-63.24,-63.32,-63.40,-63.43 . \mathrm{MS}$ (MALDI) $\mathrm{m} / \mathrm{z}$ calcd for $\mathrm{C}_{335} \mathrm{H}_{598} \mathrm{~F}_{18} \mathrm{~N}_{18} \mathrm{O}_{137}{ }^{+}[(\mathrm{M}+\mathrm{ACN}+\mathrm{H})]^{+} 7411.9$, found 7407.2.

\section{Solvent-dependent ${ }^{19}$ F NMR}

${ }^{19} \mathrm{~F}$ NMR spectra of peptidic polymers in mixed solvents of methanol and water in different proportions were measured by a Bruker NMR $376 \mathrm{MHz}$ spectrometer and referenced to 2\% perfluorobenzene (s, -164.90 ppm) in $\mathrm{CDCl}_{3}$ and $73 \mathrm{mM}$ sodium trifluomethanesulfonate (s, -79.61 ppm) in $\mathrm{D}_{2} \mathrm{O}$. 


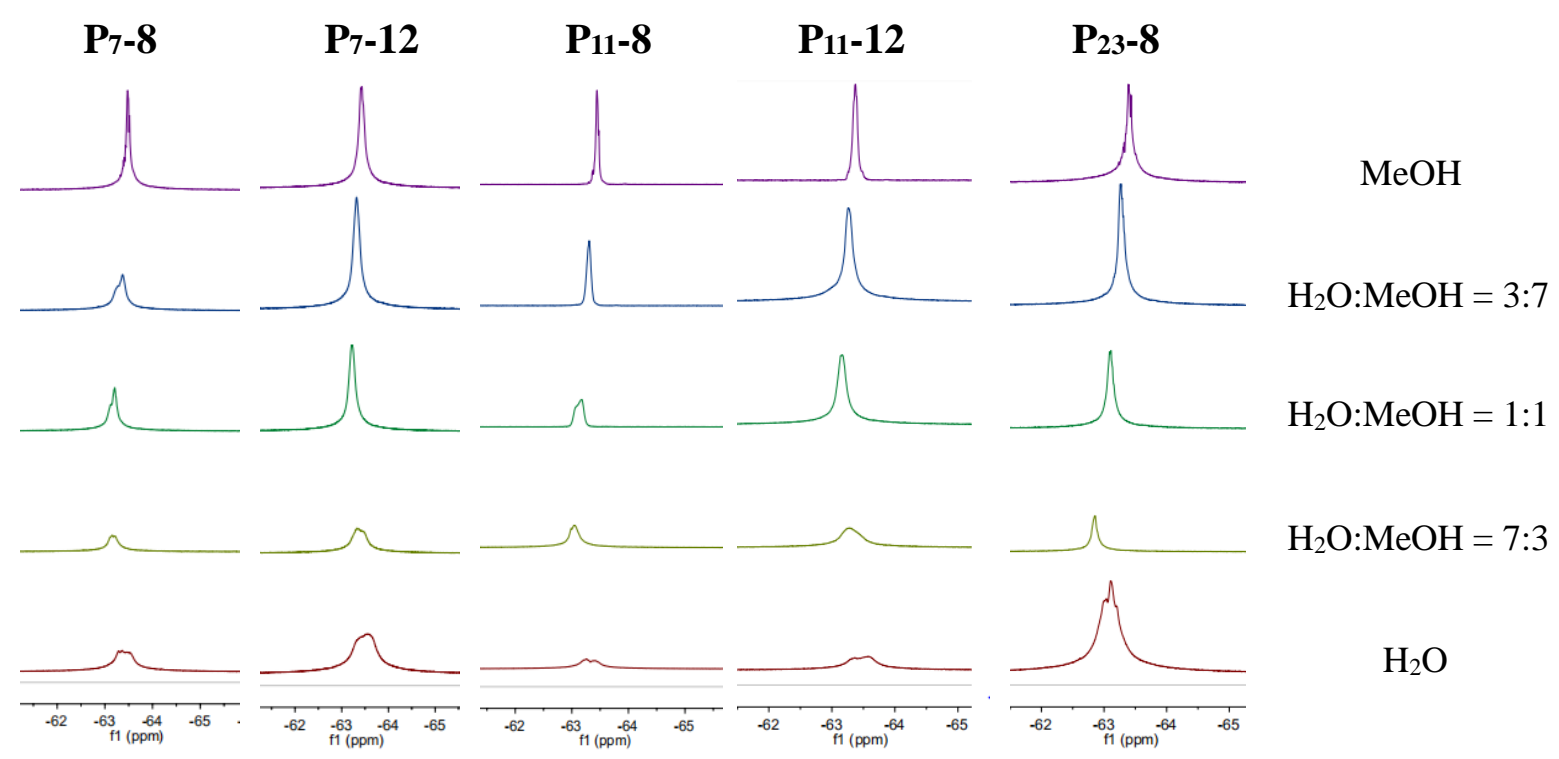

Figure S1. Solvent-dependent ${ }^{19}$ F NMR spectra of the M-PEGs peptidic polymers

\section{Determination of n-octanol/water partition coefficients}

The $\log P$ values of peptidic polymers were detected by a shake-flask method. Specifically, a peptide was dissolved in distilled water saturated with $n$-octanol. Then $1.5 \mathrm{~mL}$ of this solution was mixed with an equal volume of $n$-octanol saturated with distilled water and the mixture was shock overnight, then the $n$-octanol phase was separated by centrifugation. Equal-volume samples of the shaken water phase and the starting solution were subsequently taken and analyzed by HPLC. The peak area was measured at $\lambda=254 \mathrm{~nm}$, and compared with calibration curve to obtain the concentration of the peptide. $\log P$ values were determined from: $\log \left[\left(\mathrm{C}_{\mathrm{s}}-\mathrm{C}_{\mathrm{w}}\right) / \mathrm{C}_{\mathrm{w}}\right]$, where $\mathrm{C}_{\mathrm{s}}$ and $\mathrm{C}_{\mathrm{w}}$ are the concentrations of the starting water solution and the water phase of the compound, respectively.

\section{Turbidity Test}

The turbidity tests were recorded by a UV-visible Lambda 35 spectrometer (Perkin Elmer, USA) at $700 \mathrm{~nm}$. All peptidic polymers with 3 concentrations were dissolved in water $(3.0 \mathrm{mM}, 1.2 \mathrm{mM}$ or $0.342 \mathrm{mM})$. The transmittance was measured between $30{ }^{\circ} \mathrm{C}$ and $99{ }^{\circ} \mathrm{C}$ through temperature-controlled heating and cooling cycles, and the sample was equilibrated for $10 \mathrm{~min}$ at 
each temperature before measurement.

Table S1. LCST of M-PEGs peptidic polymers at $3.0 \mathrm{mM}, 1.2 \mathrm{mM}$ and $0.342 \mathrm{mM}$

\begin{tabular}{ccccccc}
\hline Concentration & $\mathbf{P}_{\mathbf{7}-8}$ & $\mathbf{P}_{\mathbf{7}-\mathbf{- 1 2}}$ & $\mathbf{P}_{\mathbf{1 1}} \mathbf{- 8}$ & $\mathbf{P}_{\mathbf{1 1}} \mathbf{- 1 2}$ & $\mathbf{P}_{\mathbf{8}} \mathbf{- 1 2}$ & $\mathbf{P}_{\mathbf{4 + 4}-\mathbf{- 1 0}}$ \\
$0.342(\mathrm{mM})$ & $75{ }^{\circ} \mathrm{C}$ & $63{ }^{\circ} \mathrm{C}$ & $90{ }^{\circ} \mathrm{C}$ & $84{ }^{\circ} \mathrm{C}$ & $26{ }^{\circ} \mathrm{C}$ & $66{ }^{\circ} \mathrm{C}$ \\
$1.2(\mathrm{mM})$ & $71{ }^{\circ} \mathrm{C}$ & $61{ }^{\circ} \mathrm{C}$ & $87{ }^{\circ} \mathrm{C}$ & $82{ }^{\circ} \mathrm{C}$ & $24{ }^{\circ} \mathrm{C}$ & $60{ }^{\circ} \mathrm{C}$ \\
$3(\mathrm{mM})$ & $68.5{ }^{\circ} \mathrm{C}$ & $60{ }^{\circ} \mathrm{C}$ & $84{ }^{\circ} \mathrm{C}$ & $80{ }^{\circ} \mathrm{C}$ & $23{ }^{\circ} \mathrm{C}$ & $56{ }^{\circ} \mathrm{C}$ \\
\hline
\end{tabular}

\section{Dynamic light scattering}

The dynamic light scattering (DLS) analysis, including particle size and polydispersity index (PDI), was performed on DLS Analyzer (Malvern Zetasizer Nano 3690). The peptidic polymers (P7-8, $\mathbf{P}_{7-12}, \mathbf{P}_{8-12}$ and $\left.\mathbf{P}_{4+4-10}\right)$ were dissolved in water with desired concentration and measured at an angle of $90^{\circ}$ in a $10 \mathrm{~mm}$ diameter cell at the set temperatures $\left(25{ }^{\circ} \mathrm{C}\right.$, LCST and LCST $+5{ }^{\circ} \mathrm{C}$ ) and recorded by Malvern software. Each measurement was repeated 3 times.

Table S2. DLS of M-PEGs peptidic polymers $(0.9 \mathrm{mg} / \mathrm{mL})$ at room temperature

\begin{tabular}{|c|c|c|c|c|c|}
\hline & $\mathbf{P}_{7-8}$ & $P_{7-12}$ & $\mathbf{P}_{11-8}$ & $P_{11-12}$ & $\mathbf{P}_{23-8}$ \\
\hline Size(nm) & 76.85 & 84.26 & 165.0 & 153.3 & 199.0 \\
\hline PDI & 0.592 & 0.626 & 0.439 & 0.663 & 0.380 \\
\hline
\end{tabular}

Table S3. DLS of M-PEGs peptidic polymers $(0.3 \mathrm{mg} / \mathrm{mL})$ at different temperatures

\begin{tabular}{ccccccccc}
\hline & \multicolumn{2}{c}{ P7-8 } & \multicolumn{2}{c}{ P7-12 } & \multicolumn{2}{c}{ P8-12 } & \multicolumn{2}{c}{ P4+4-10 } \\
\hline & Size(nm) & PDI & Size(nm) & PDI & Size(nm) & PDI & Size(nm) & PDI \\
rt & 177.3 & 0.362 & 176.3 & 0.348 & 208.0 & 0.315 & 257.4 & 0.498 \\
LCST & 584.2 & 0.102 & 551.2 & 0.155 & 658.0 & 0.179 & 1113 & 0.464 \\
LCST+5 ${ }^{\circ} \mathrm{C}$ & 427.7 & 0.079 & 300.6 & 0.042 & 843.4 & 0.049 & 826.6 & 0.170 \\
\hline
\end{tabular}



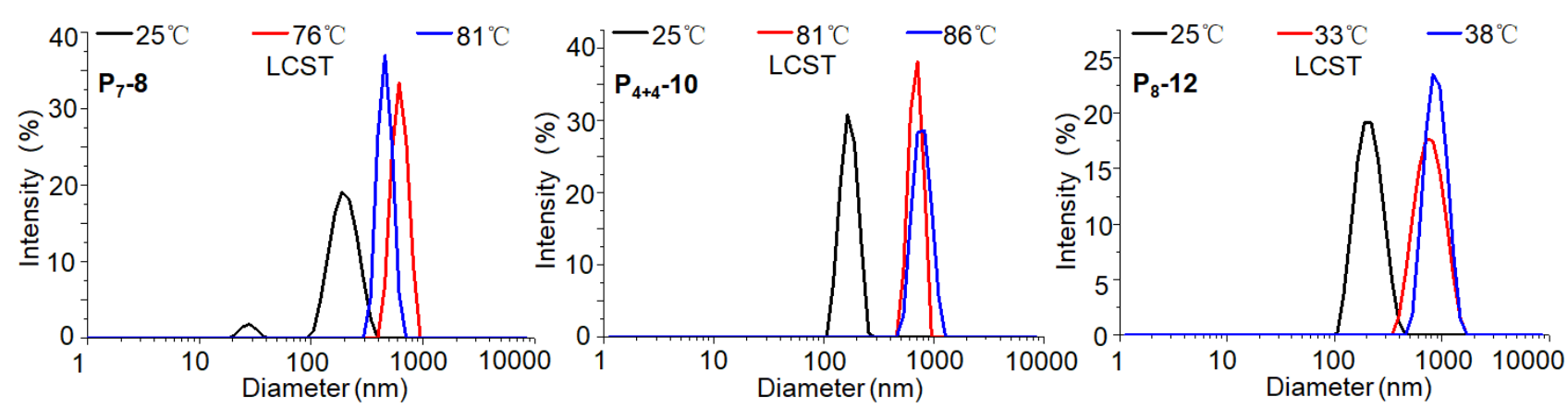

Figure S2. DLS M-PEGs peptidic polymers $(0.3 \mathrm{mg} / \mathrm{mL})$ at different temperature

\section{Transmission electron microscopy}

The M-PEGs peptidic polymers $\mathbf{P}_{\mathbf{7}} \mathbf{8}, \mathbf{P}_{\mathbf{7}} \mathbf{- 1 2}$ and drug-loaded nanoemulsion $\mathbf{P}_{\mathbf{7}-12 / D O X}$ dissolved in water at a concentration of $0.3 \mathrm{mg} / \mathrm{mL}$ were allowed to dry in the oven at $25{ }^{\circ} \mathrm{C}$ for 30 minutes and then air-dried for 2 hours. After the TEM images were taken on JEM-1230 at an acceleration voltage of $200 \mathrm{kV}$.

\section{UV and Fluorescent property of $\mathrm{P}_{7}-8$}

The UV property of $\mathbf{P}_{\mathbf{7}-8}$ was detected by UV 2400 and the fluorescent property was detected by F-4600 FL Spectrophotometer with concentration of $0.3 \mathrm{mg} / \mathrm{mL}$ at room temperature.
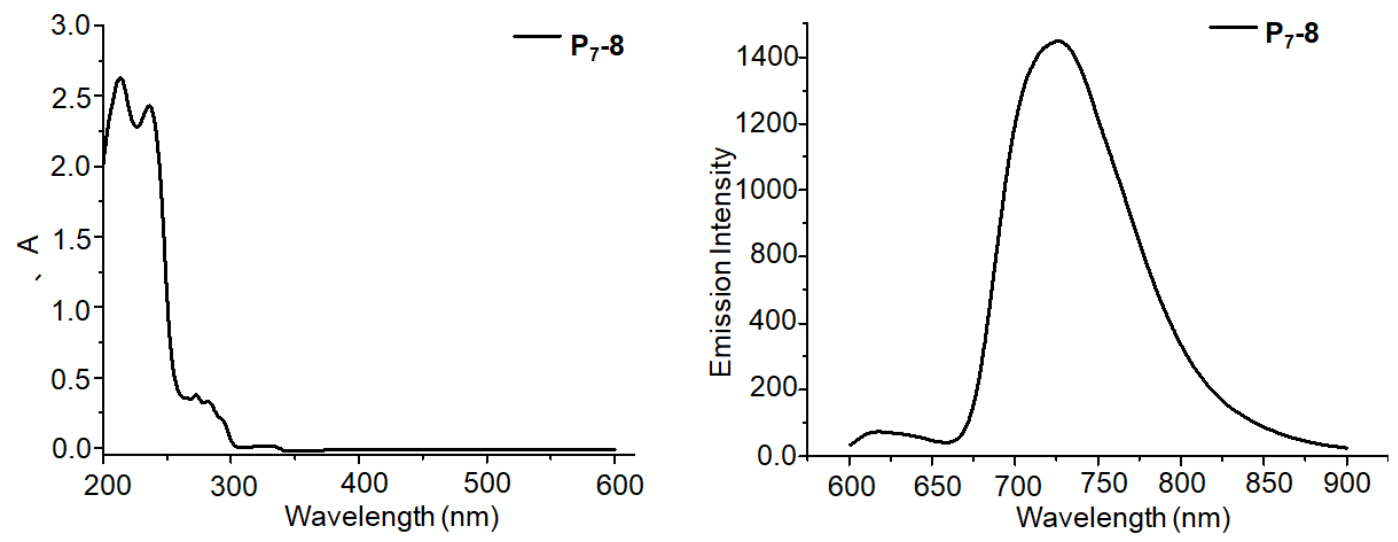

Figure S3. UV and Fluorescent spectrum of $\mathbf{P}_{\mathbf{7}} \mathbf{8}$

\section{Biocompatibility assay}

L929 cells were cultured in alpha-MEM medium containing $10 \%$ FBS. $\mathrm{HepG}_{2}$ cells were cultured in DMEM medium containing 10\% FBS. All cells were cultured at $37{ }^{\circ} \mathrm{C}$ in humidified atmosphere containing 5\% $\mathrm{CO}_{2}$ and the growth medium was replaced with fresh media every $24 \mathrm{~h}$.

The biocompatibility studies of all peptidic polymers were researched in L929 cell lines in vitro 
by MTT assay. Briefly, L929 cells were seeded into a 96-well plate and allowed for adherent culture at $37{ }^{\circ} \mathrm{C}$ for 24 hours. Afterwards, the cells were incubated with a gradient concentration of the M-PEGs peptide ranging from $8 \mu \mathrm{g} / \mathrm{mL}$ to $1000 \mu \mathrm{g} / \mathrm{mL}$. Every concentration was set with five wells at least. Cells treated with only media were used as control. After incubation 24 hours, MTT stock solution $(0.1 \mathrm{mg} / \mathrm{mL}$ in PBS, $200 \mu \mathrm{L})$ was added to each well and incubated for another $4 \mathrm{~h}$. The media were replaced by $100 \mu \mathrm{L}$ DMSO to dissolve the formazan blue crystal. The relative cell viability (\%) was determined spectrophotometrically by comparing the absorbance of each well at $490 \mathrm{~nm}$ with control well using a microplate reader (Bio Tek Instruments, USA). All of the experiments were repeated in three times at least.

\section{Stability study in rat plasma}

In the in vitro stability studies, peptidic polymers $\mathbf{P}_{\mathbf{7}} \mathbf{8}, \mathbf{P}_{\mathbf{7}} \mathbf{- 1 2}, \mathbf{P}_{\mathbf{8}} \mathbf{- 1 2}$ and $\mathbf{P}_{\mathbf{1 1}} \mathbf{- 1 2}$ were selected as experimental object to study the effects of various factors on the stability of the peptide in SD rat plasma, such as polyethylene glycol size, peptidic polymers chain length and amino acids arrangement in the peptidic polymers. In brief, $2.0 \mathrm{mg}$ of peptide was incubated with $600 \mu \mathrm{L}$ of rat plasma at $37{ }^{\circ} \mathrm{C}$ for $72 \mathrm{~h}$ with gentle stirring. After 2, 4, 8, 18, 30, 42, 54, 66 and $72 \mathrm{~h}$, a sample (20 $\mu \mathrm{L}$ ) was collected and mixed with $1.0 \mathrm{~mL}$ methanol. The mixture was filtered and analyzed by HPLC. The integrated values of these peaks were compared to those of $t=0 \mathrm{~min}$ in plasma for each peptide and expressed as a fraction of the initial compound that was remaining at the given time point.

\section{IC 50 of $\mathrm{P}_{7-12 / D O X}$ and DOX at $37{ }^{\circ} \mathrm{C}$ on $\mathrm{HepG}_{2}$ cells}

$\mathrm{HepG}_{2}$ cells were seeded into a 96-well plate and allowed for adherent culture at $37{ }^{\circ} \mathrm{C}$ for 24 hours. Subsequently, the cells were incubated with a gradient concentration of free DOX and $\mathbf{P}_{7-12} / \mathrm{DOX}$ nanoemulsion and eventual concentration is $0.1,1,5,10,20,50 \mu \mathrm{g} / \mathrm{mL}$, respectively. Every concentration was set with five wells at least. Cells treated with only media were used as control. After incubation 24 hours at $37^{\circ} \mathrm{C}$, followed by replacing the medium with $200 \mu \mathrm{L}$ MTT $(0.1$ $\mathrm{mg} / \mathrm{mL}$ in PBS) solution and incubated for another $4 \mathrm{~h}$ at $37{ }^{\circ} \mathrm{C}$. Then the medium was replaced with $100 \mu \mathrm{L}$ DMSO and the absorbance values was measured at $490 \mathrm{~nm}$ using a microplate reader (Bio Tek Instruments, USA). All of the experiments were repeated three times. 


\section{Reference}

1. Zhu, J.; Xiao, Y.; Zhang, H.; Li, Y.; Yuan, Y.; Yang, Z.; Chen, S.; Zheng, X.; Zhou, X.; Jiang, Z.-X., Peptidic monodisperse PEG “combs” with fine-tunable LCST and multiple imaging modalities. Biomacromolecules. 2019, 20, 1281-1287.

\section{Copies of ${ }^{1} \mathrm{H} /{ }^{13} \mathrm{C} /{ }^{19} \mathrm{~F}$ NMR, HRMS spectra of compounds}

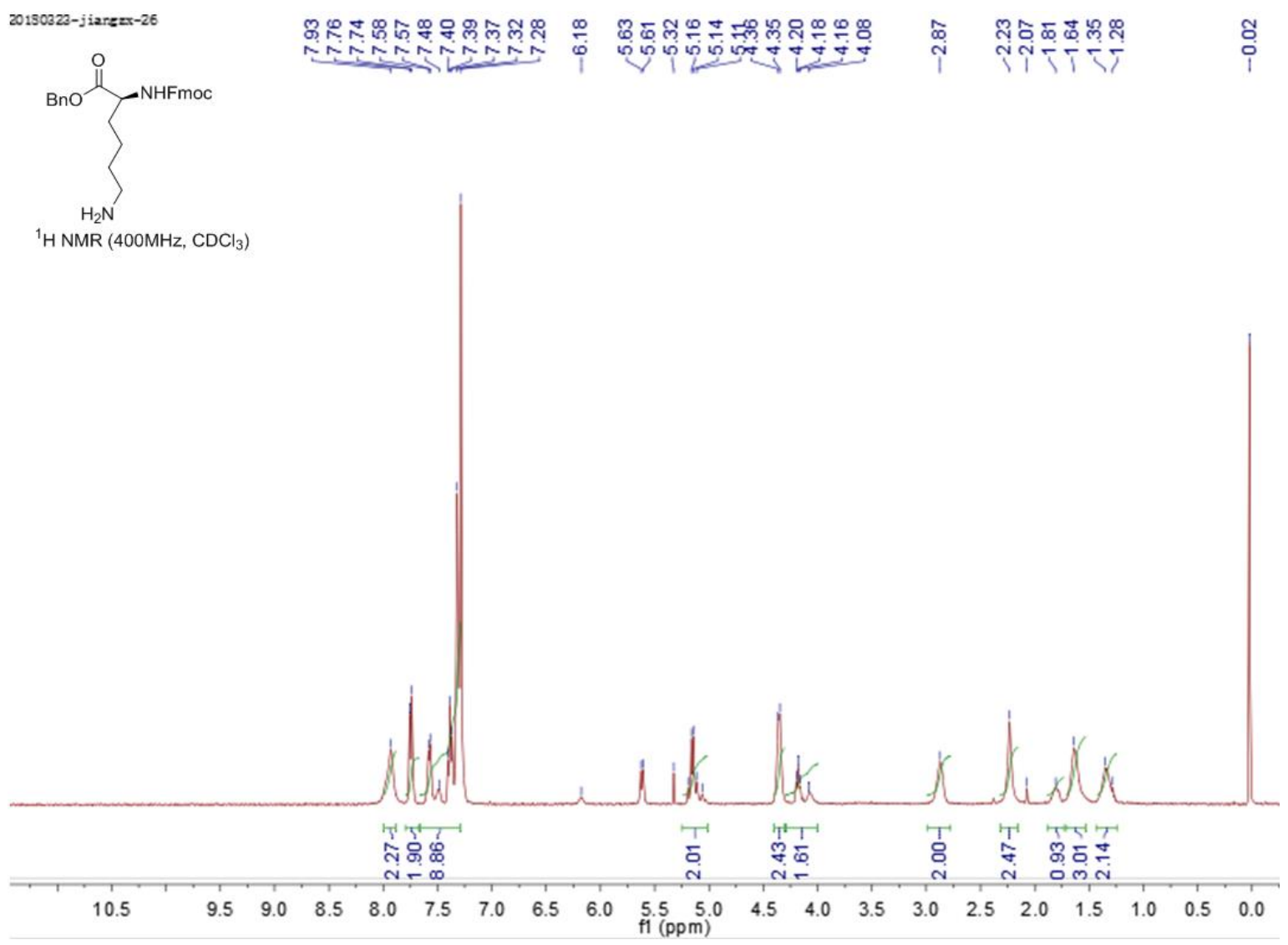




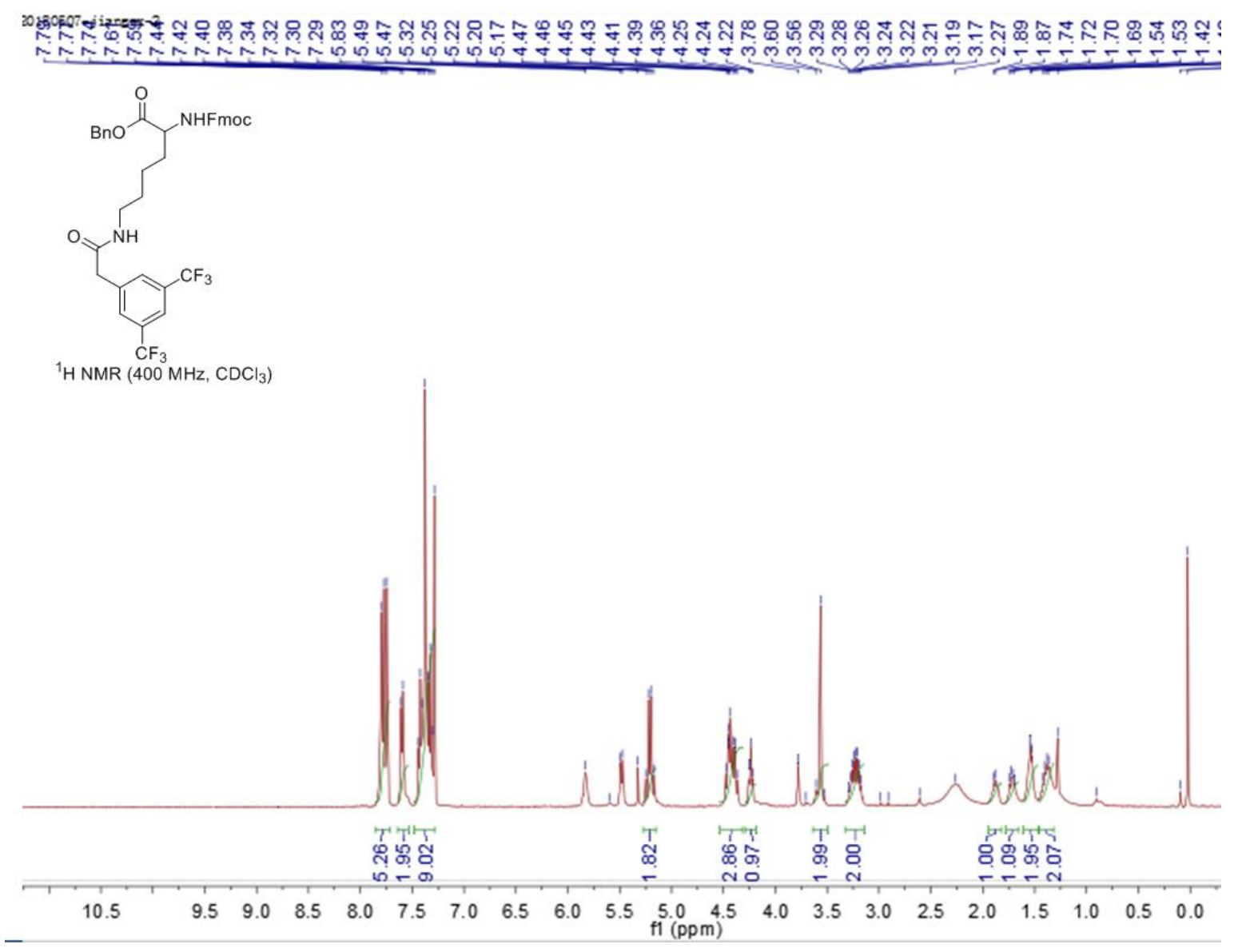

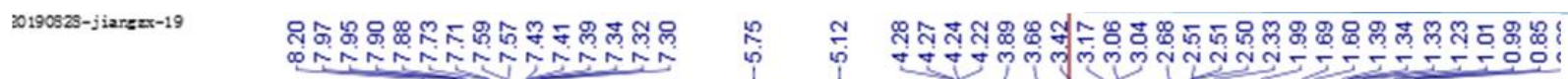

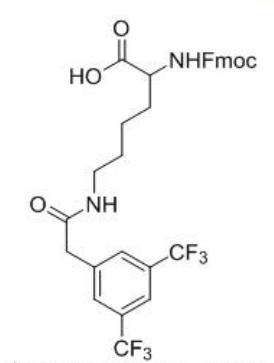

${ }^{1} \mathrm{H}$ NMR $\left(400 \mathrm{MHz}\right.$, DMSO- $\left.d_{6}\right)$

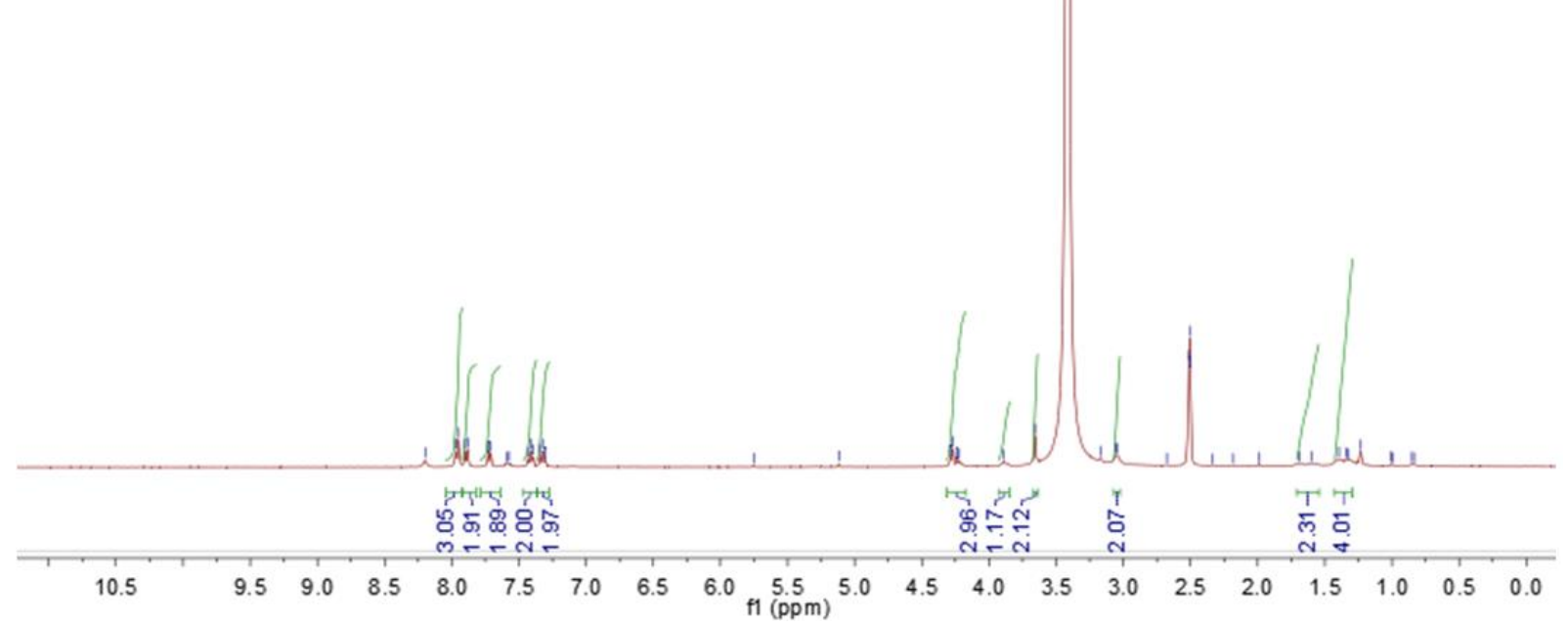




$$
\text { MeO† OOH }
$$

$\mathrm{HMR}\left(400 \mathrm{MHz}, \mathrm{CDCl}_{3}\right)$

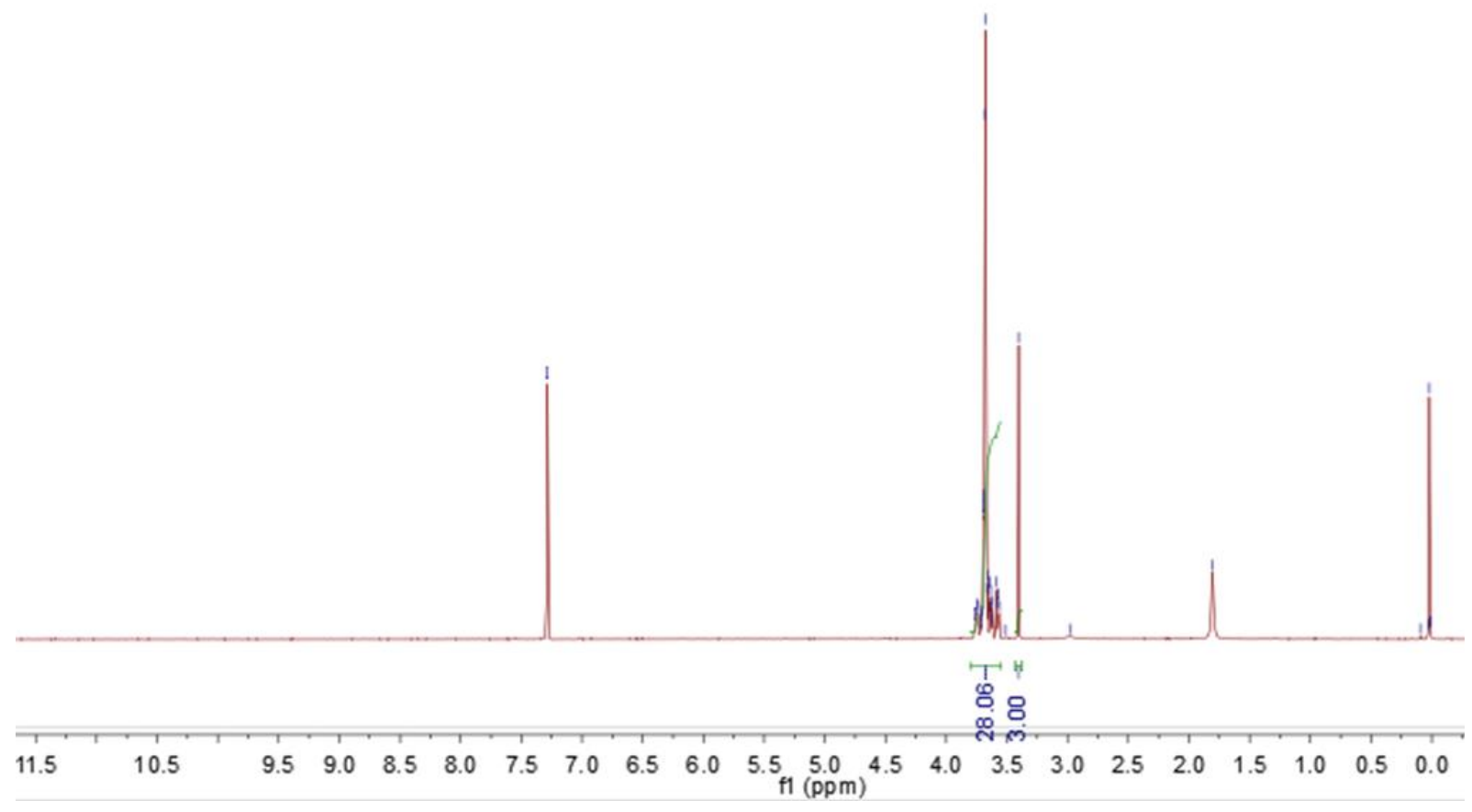




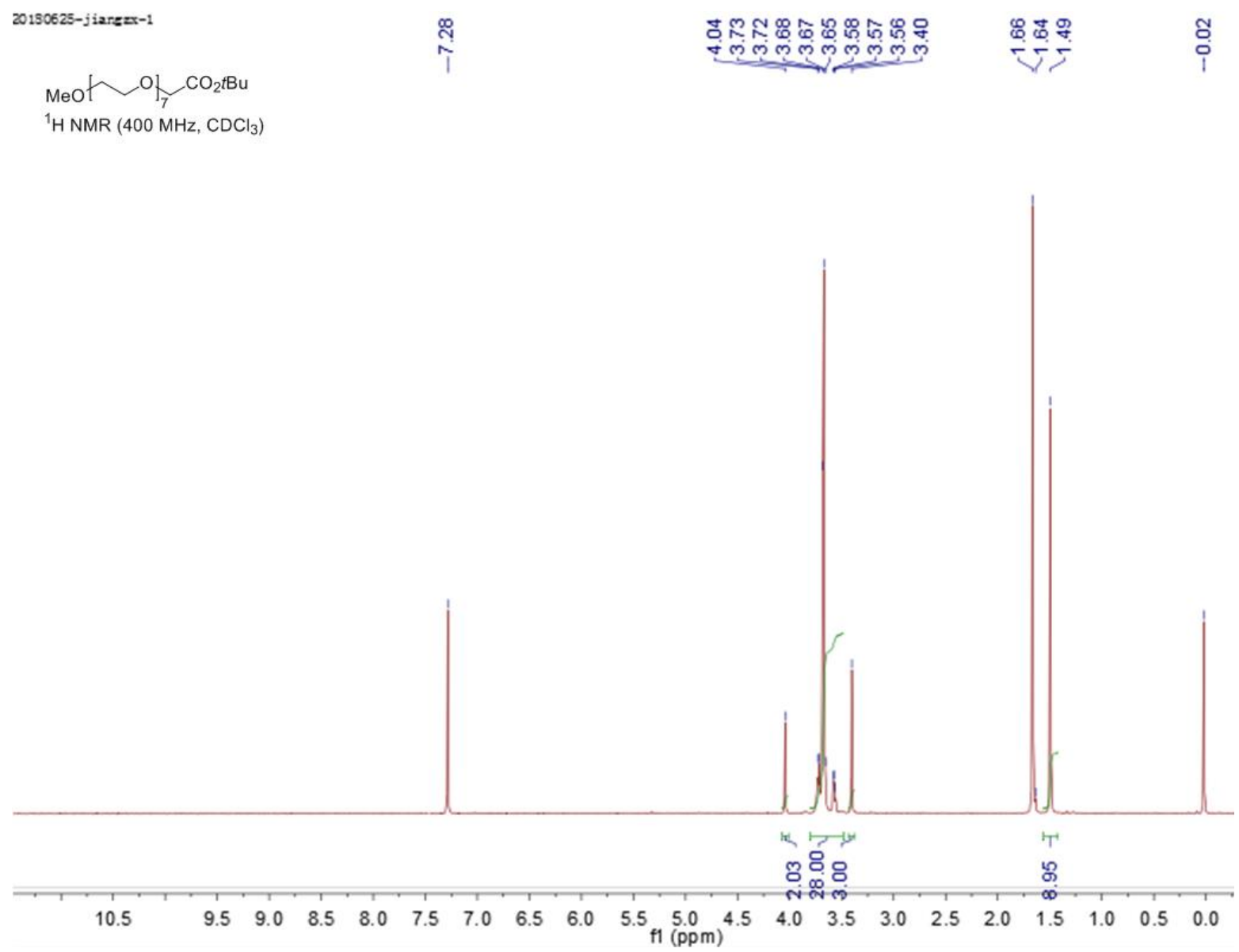

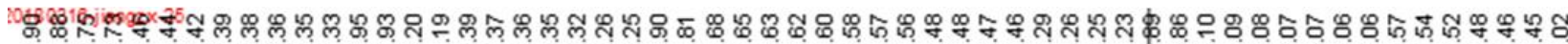

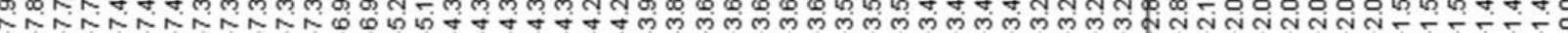

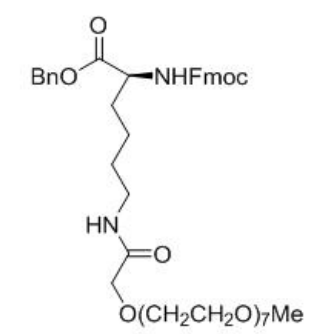

${ }^{1} \mathrm{H}$ NMR $\left(400 \mathrm{MHz},\left(\mathrm{CD}_{3}\right)_{2} \mathrm{CO}\right)$

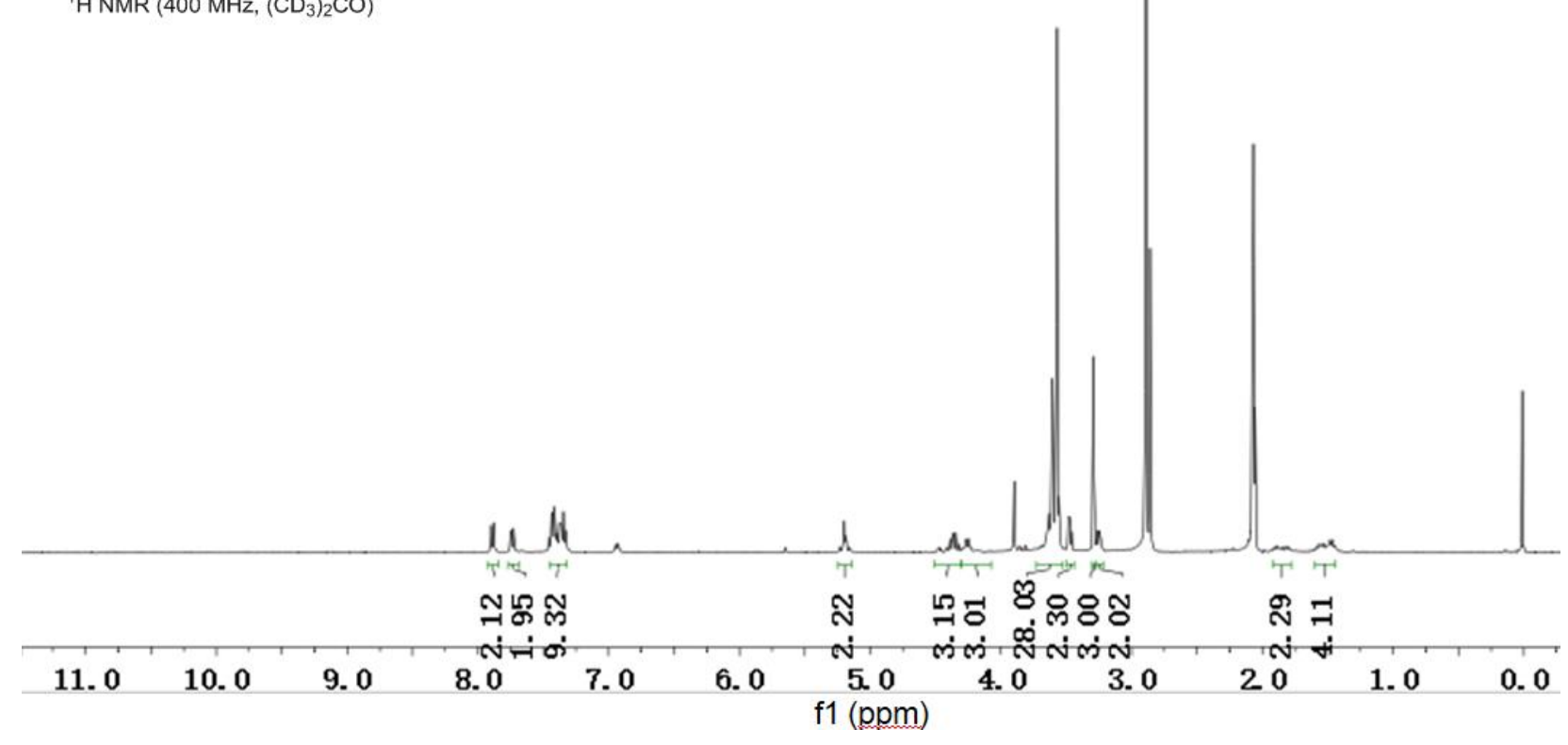




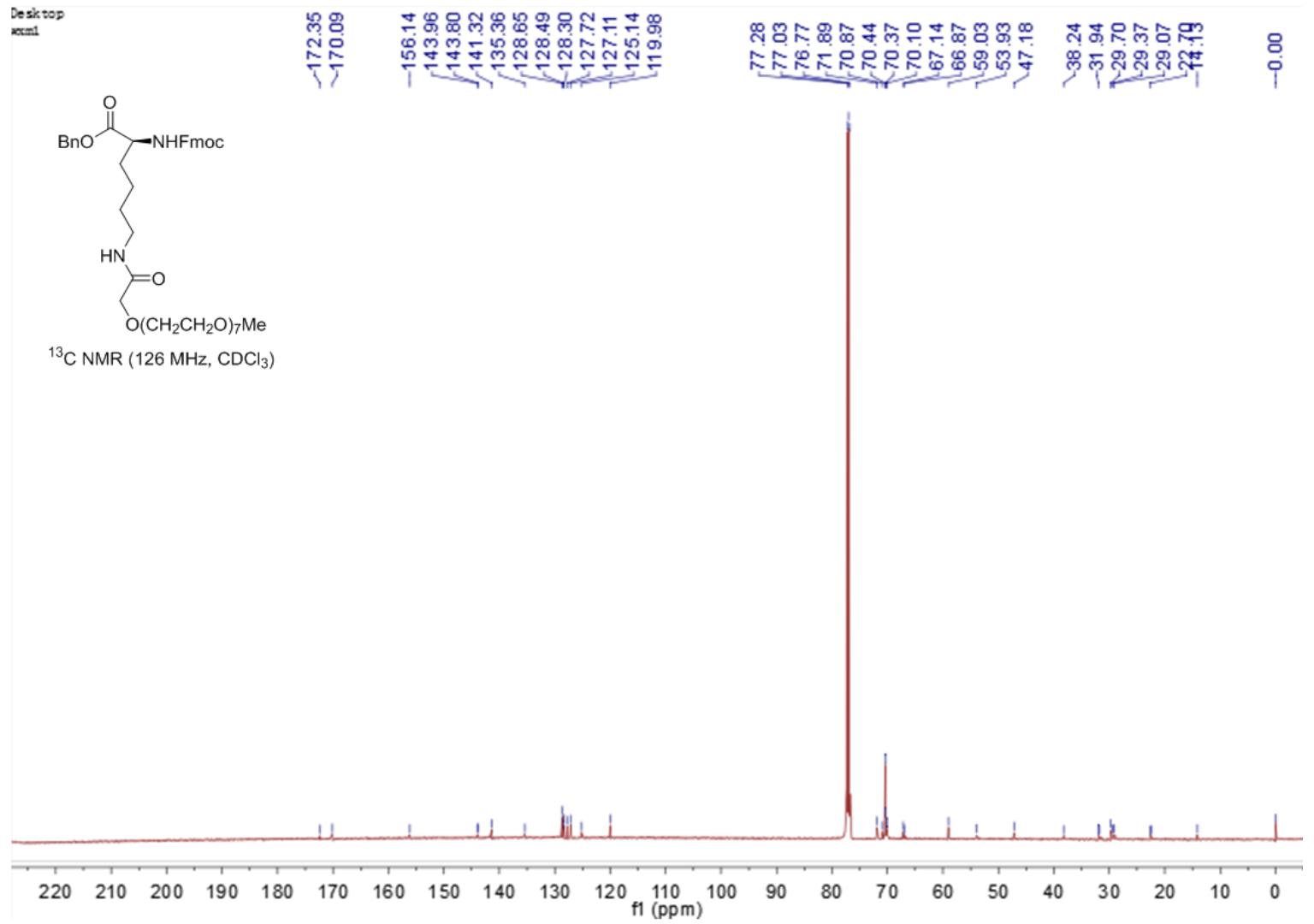

+MS, $0.3 \mathrm{~min} \# 20$

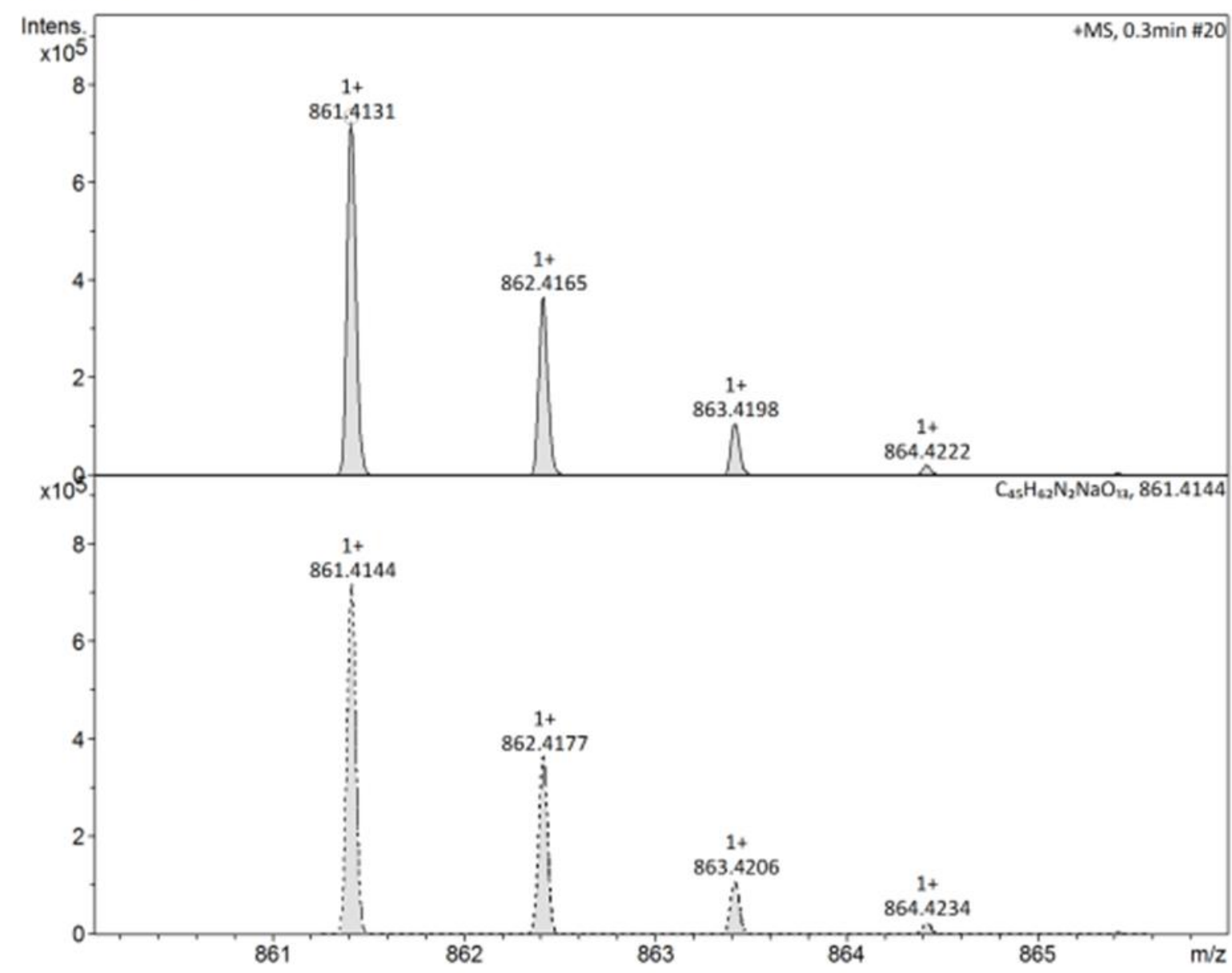




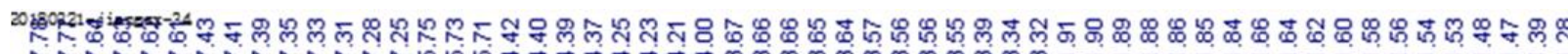

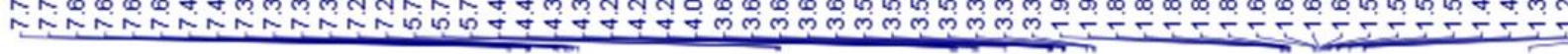<smiles>CCOCC(=O)NCCCCC(=O)OCCO</smiles>

${ }^{1} \mathrm{H} \mathrm{NMR}\left(400 \mathrm{MHz}, \mathrm{CDCl}_{3}\right)$

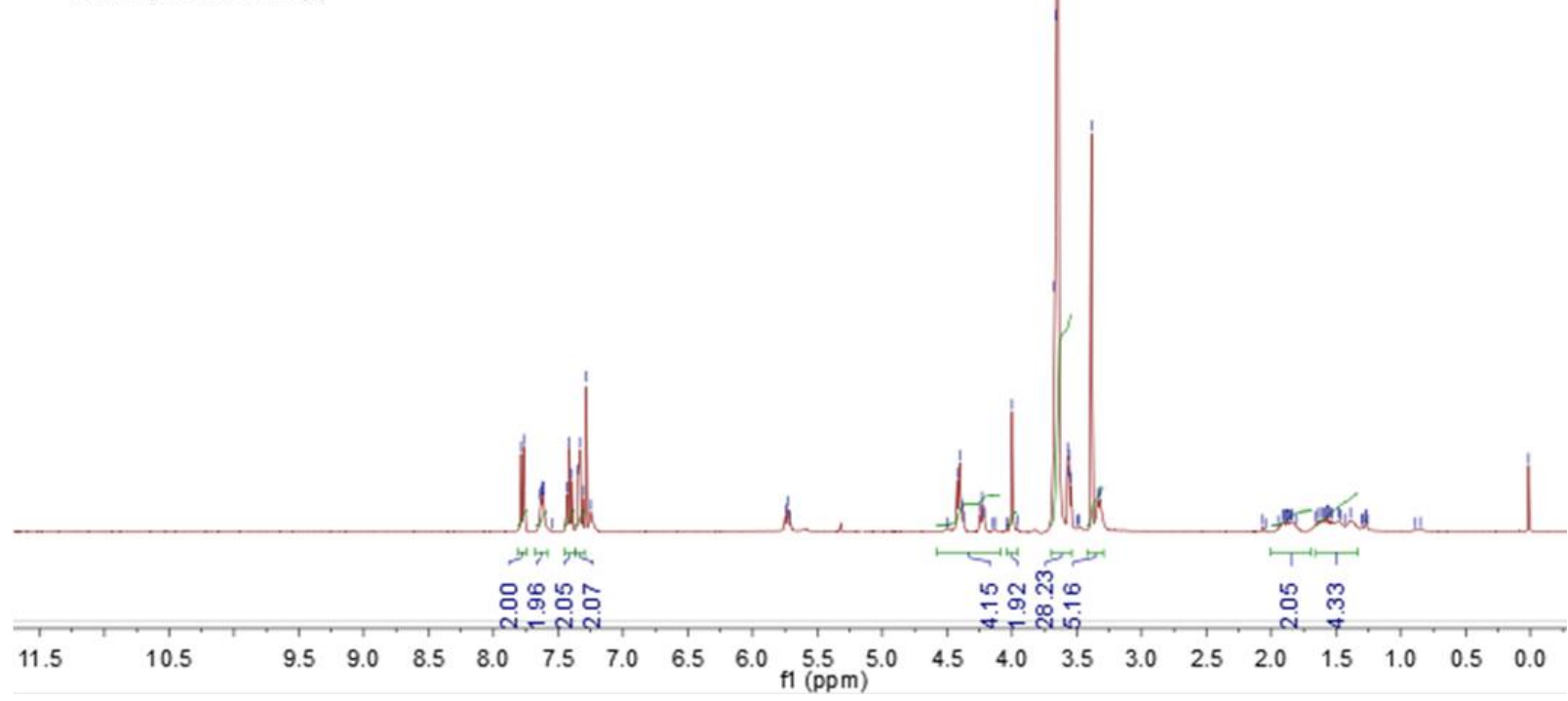

20150909-jiargex-2

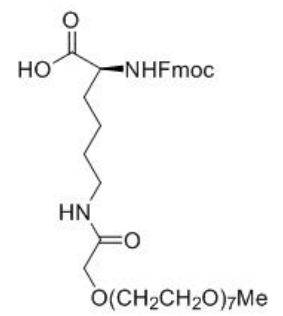

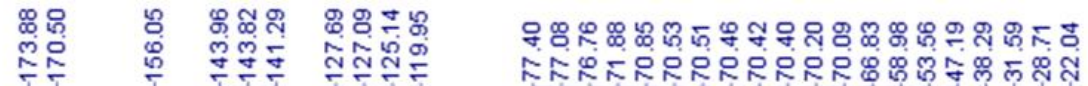

${ }^{13} \mathrm{C} \mathrm{NMR}\left(100 \mathrm{MHz}, \mathrm{CDCl}_{3}\right)$

$\begin{array}{lllllllllllllllllllllll}220 & 210 & 200 & 190 & 180 & 170 & 160 & 150 & 140 & 130 & 120 & \begin{array}{l}110 \\ \mathrm{f}(\mathrm{ppm})\end{array} & 100 & 90 & 80 & 70 & 60 & 50 & 40 & 30 & 20 & 10 & 0\end{array}$


$-\mathrm{MS}, 0.3-0.5 \mathrm{~min} \# 18-27$

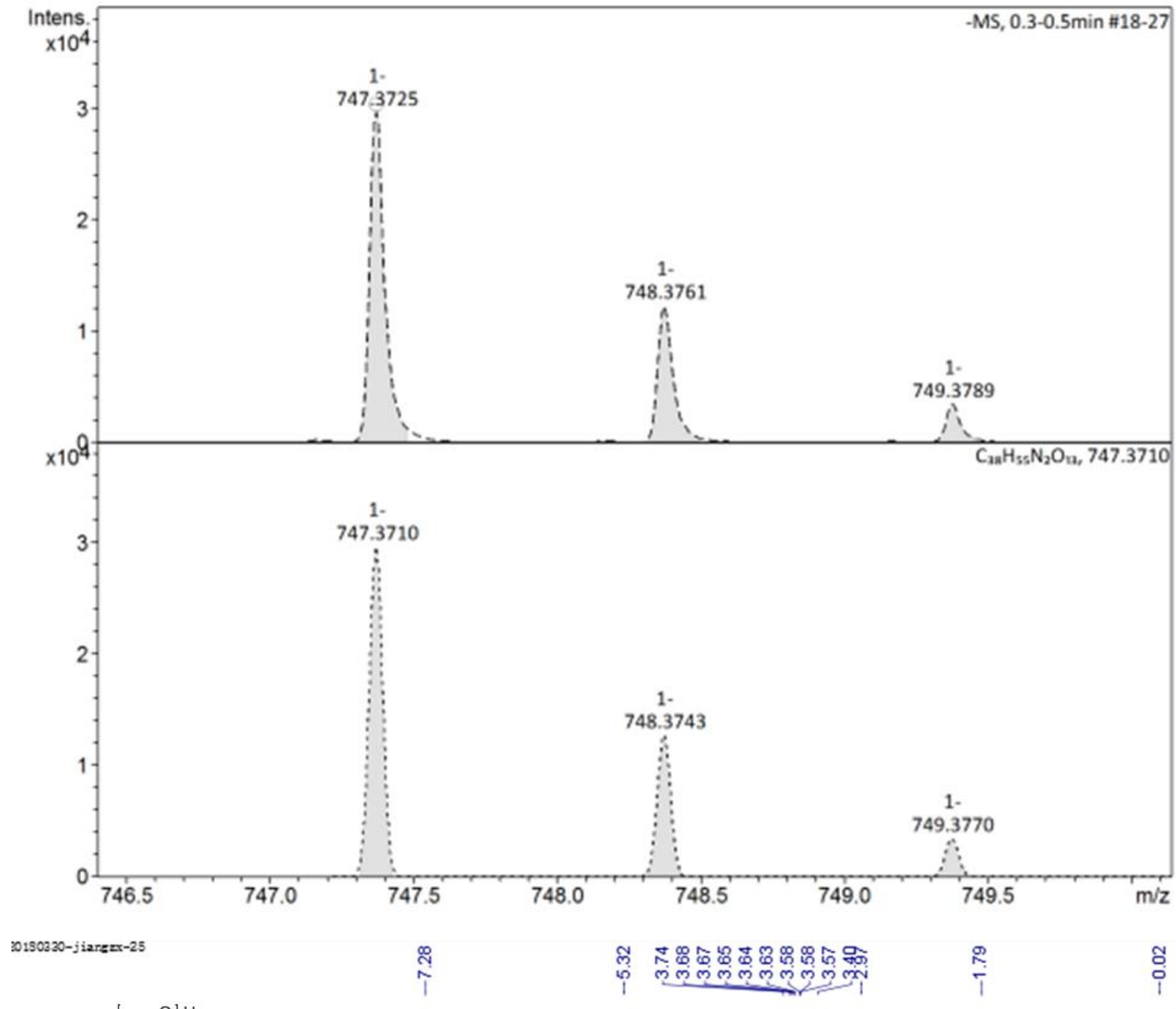

MeO†otH

${ }^{1} \mathrm{H} \mathrm{NMR} \mathrm{(400} \mathrm{MHz,} \mathrm{CDCl}_{3}$ )

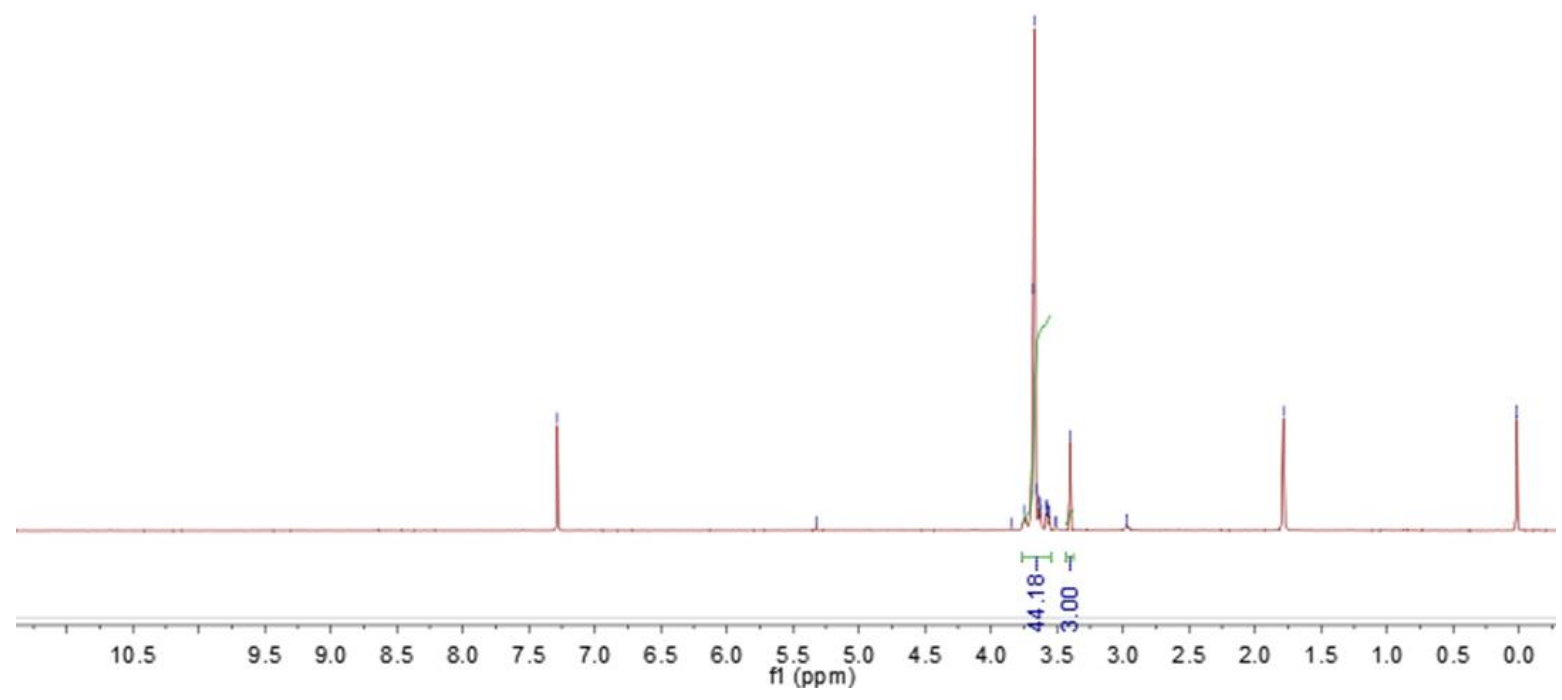



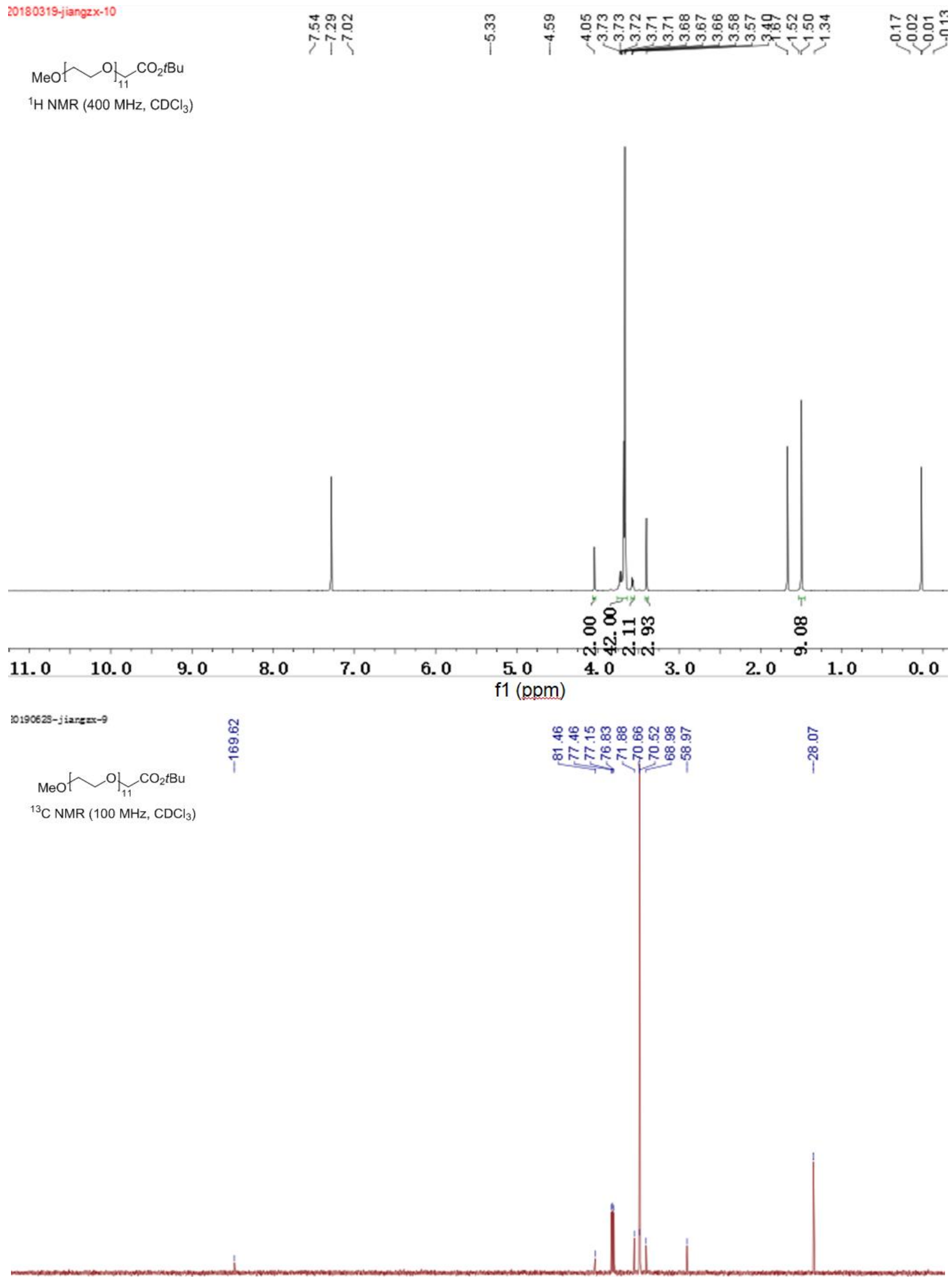

$\begin{array}{lllllllllllllllllllllllll}220 & 210 & 200 & 190 & 180 & 170 & 160 & 150 & 140 & 130 & 120 & \begin{array}{l}110 \\ \mathrm{fl}(\mathrm{ppm})\end{array} & 100 & 90 & 80 & 70 & 60 & 50 & 40 & 30 & 20 & 10 & 0\end{array}$ 
+MS, $0.3 \min \# 19$

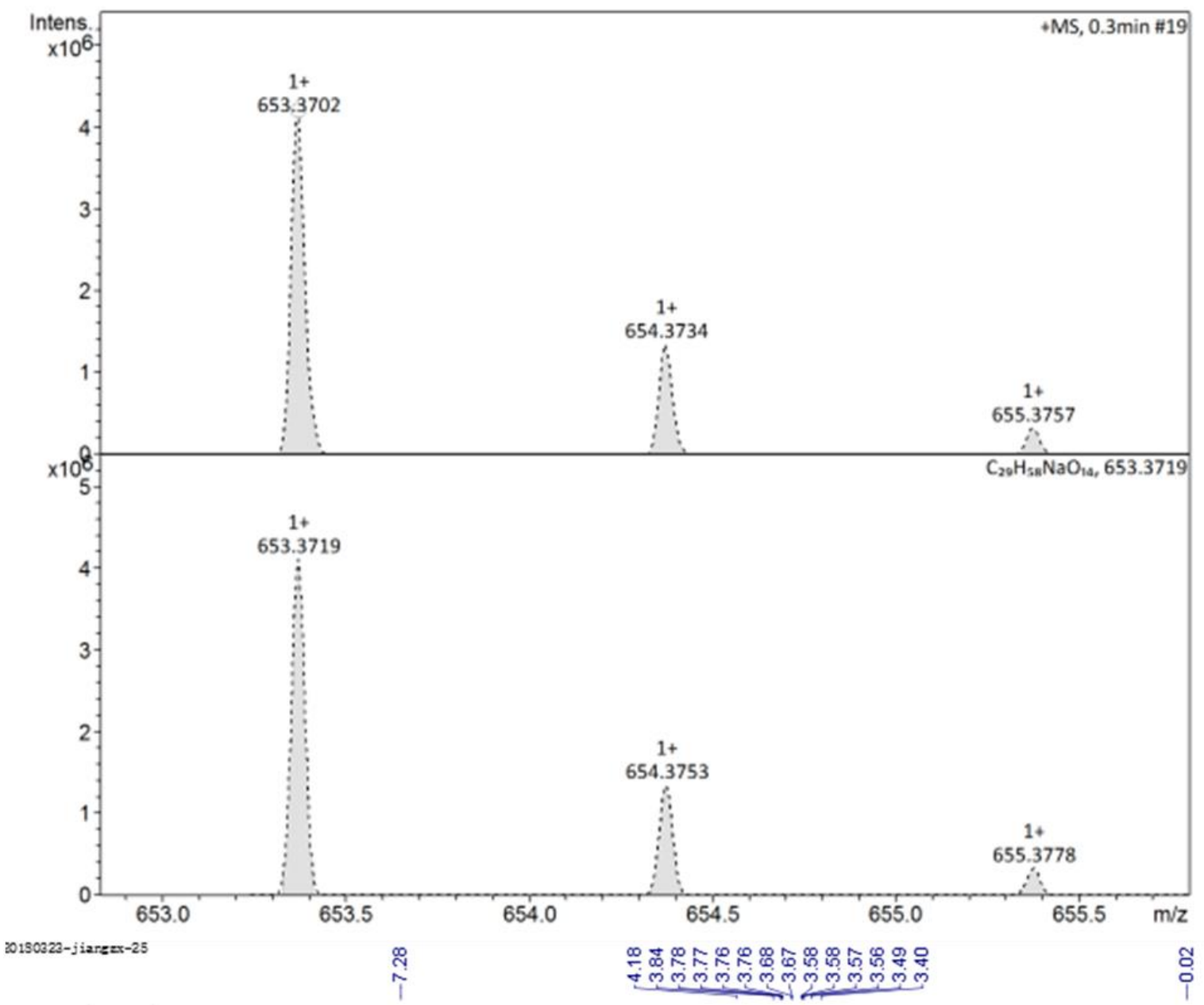

MeO $\sim \mathrm{Ol}_{11} \mathrm{COOH}$

${ }^{1} \mathrm{H} \mathrm{NMR} \mathrm{(400} \mathrm{MHz,} \mathrm{CDCl}_{3}$ )

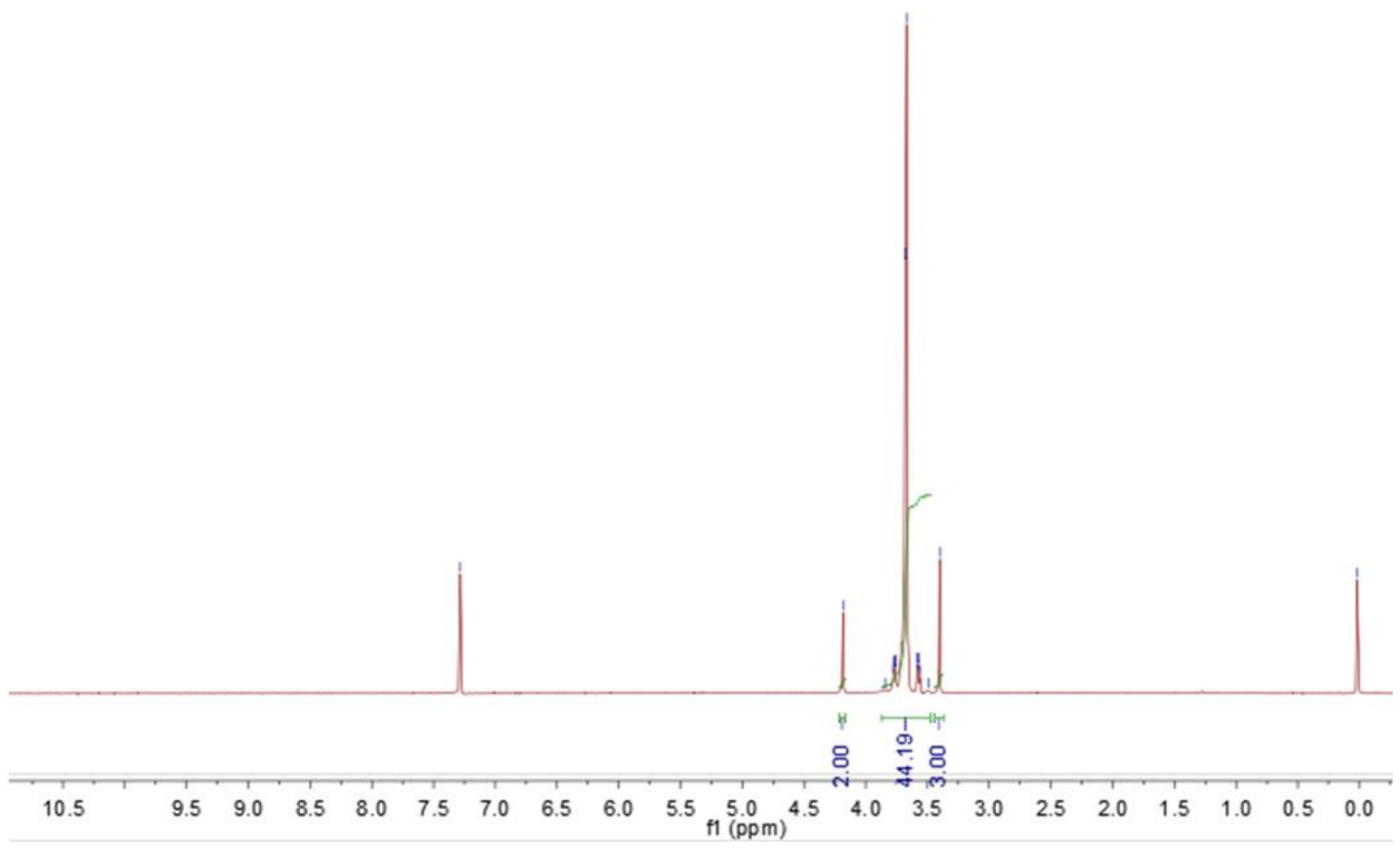



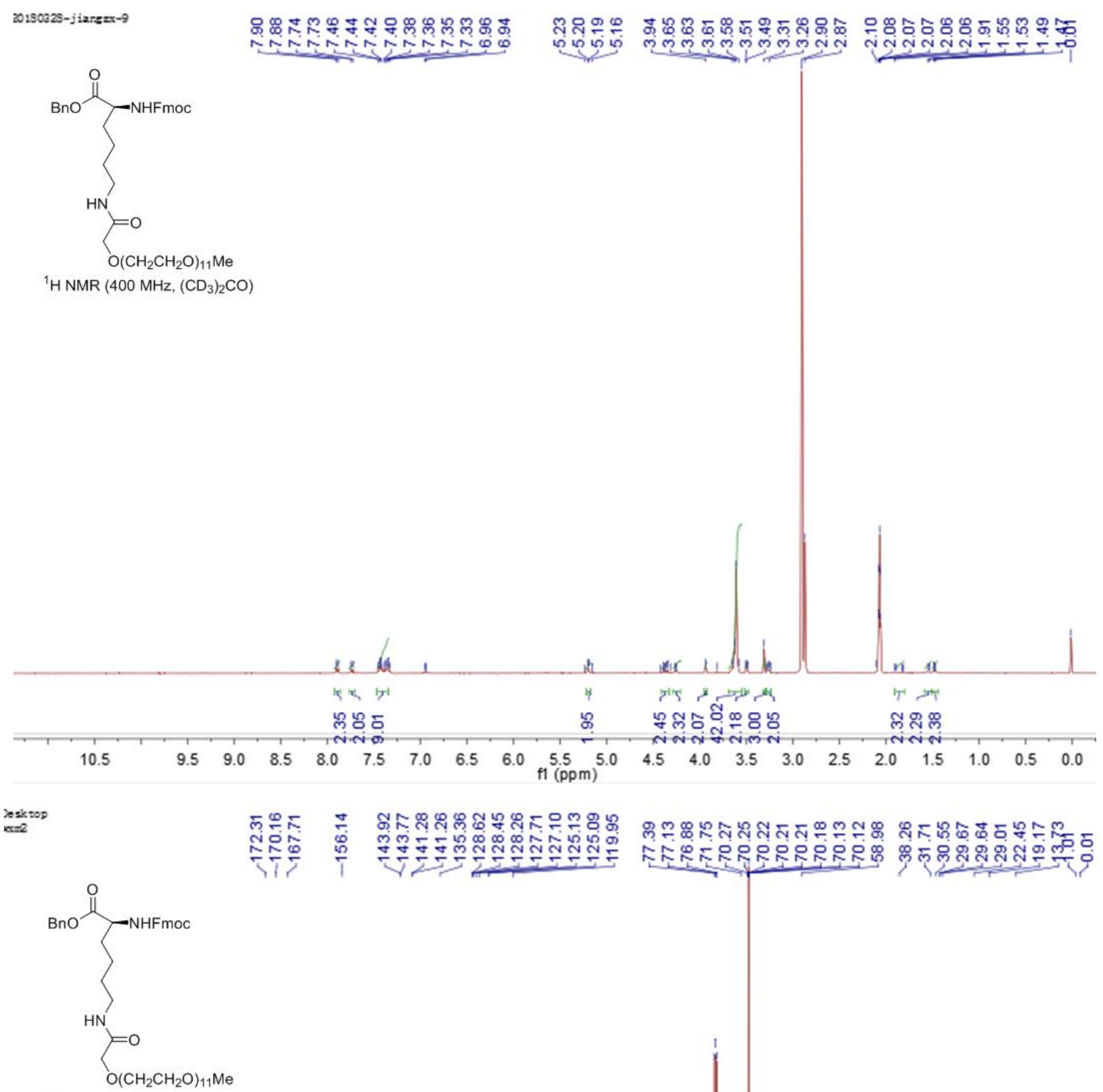

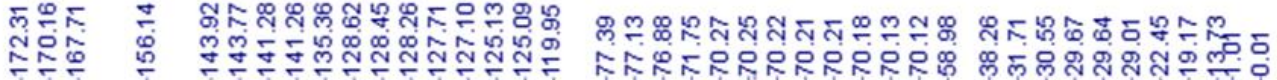

${ }^{13} \mathrm{C} \mathrm{NMR}\left(126 \mathrm{MHz} \mathrm{CDCl}_{3}\right)$

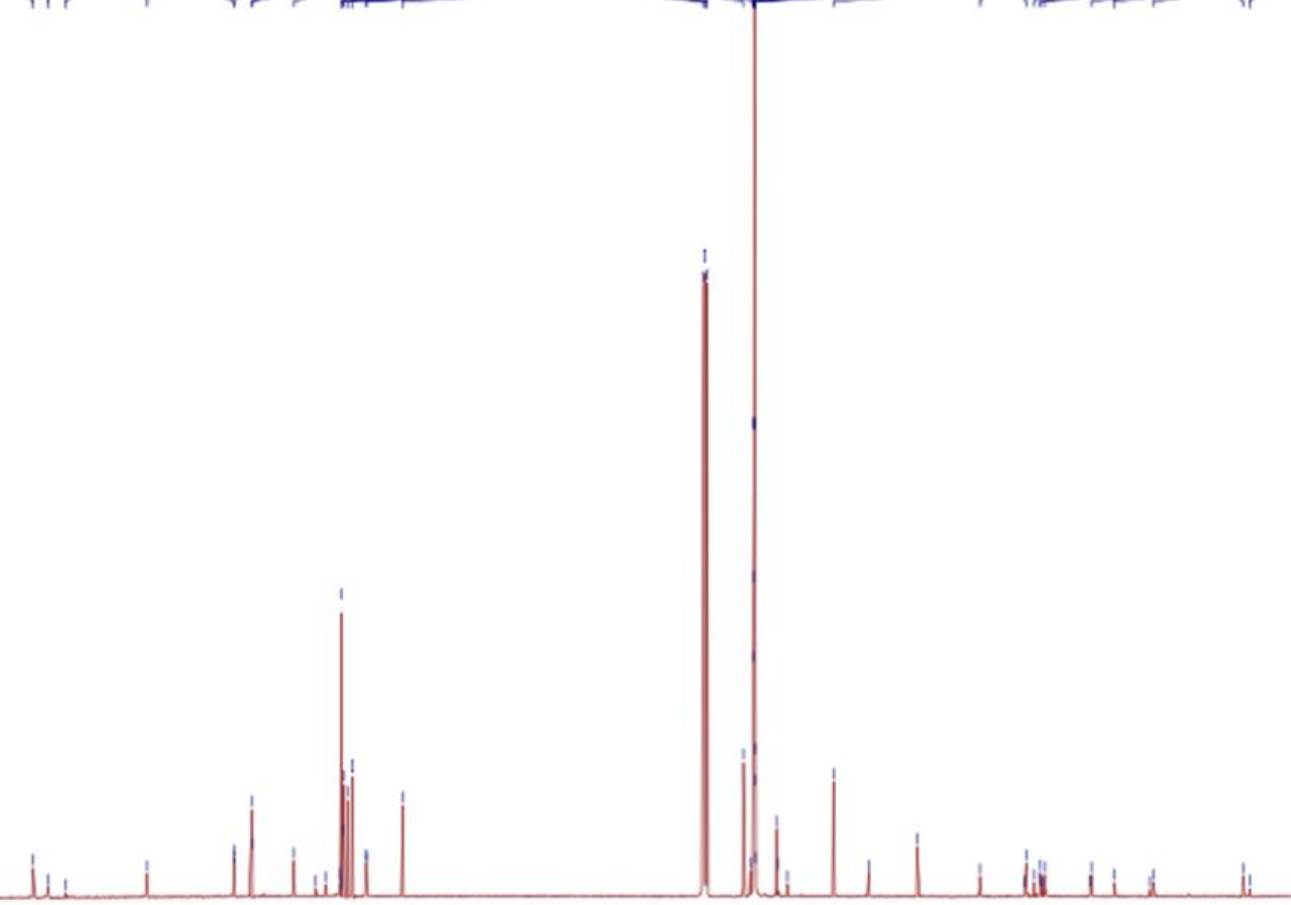

$\begin{array}{lllllllllllllllllllllll}220 & 210 & 200 & 190 & 180 & 170 & 160 & 150 & 140 & 130 & 120 & \begin{array}{l}110 \\ \mathrm{f} 1\end{array}(\mathrm{ppm}) & 100 & 90 & 80 & 70 & 60 & 50 & 40 & 30 & 20 & 10 & 0\end{array}$ 
+MS, 0.3min \#19

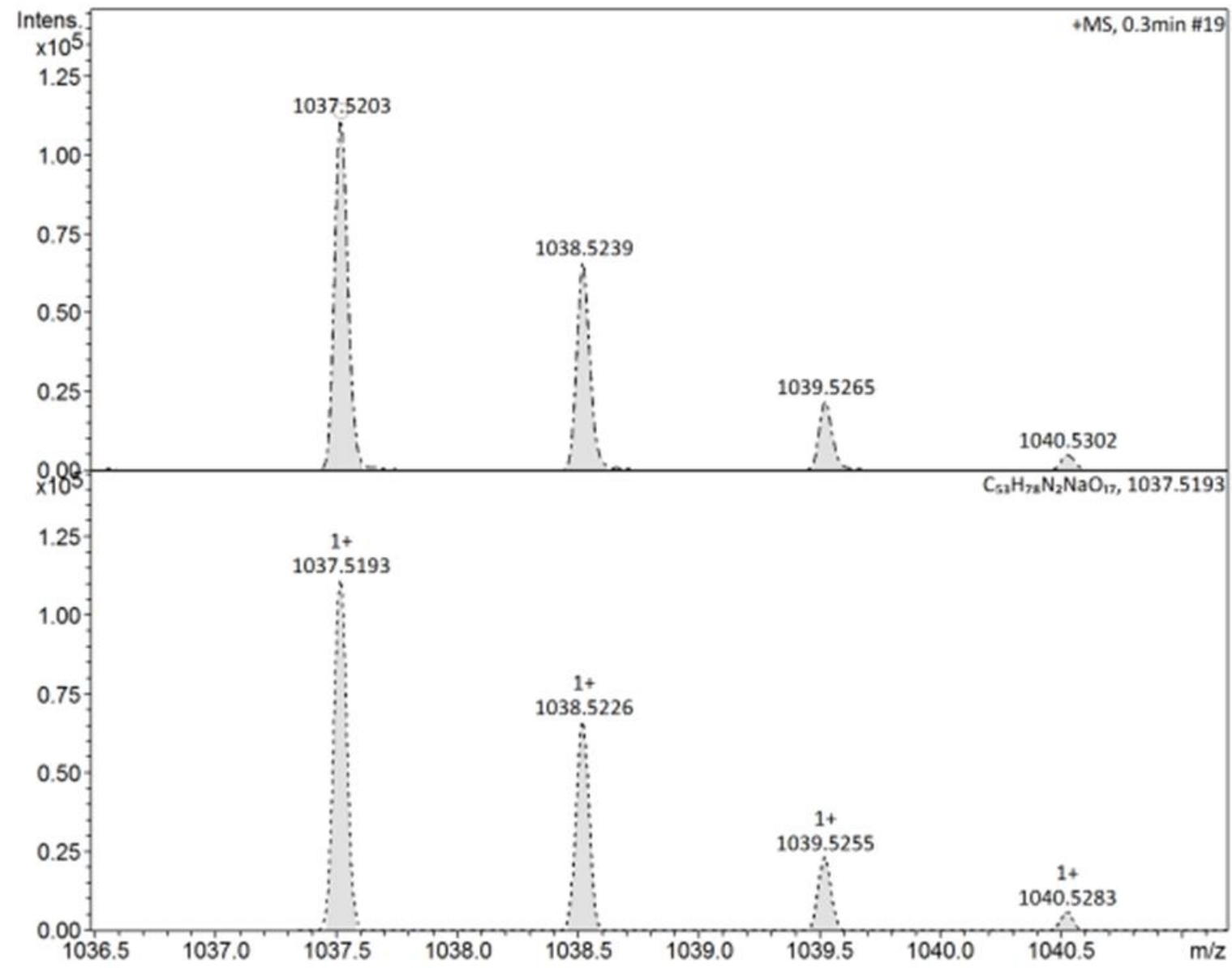

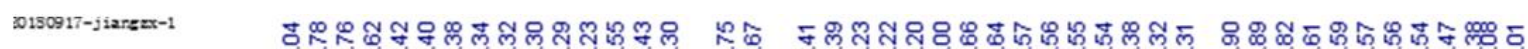

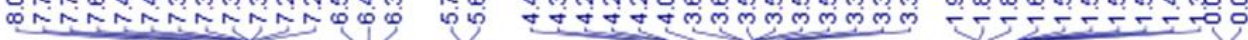

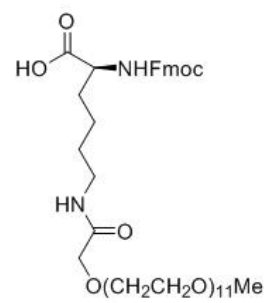

${ }^{1} \mathrm{HNMR}\left(400 \mathrm{MHz}, \mathrm{CDCl}_{3}\right)$

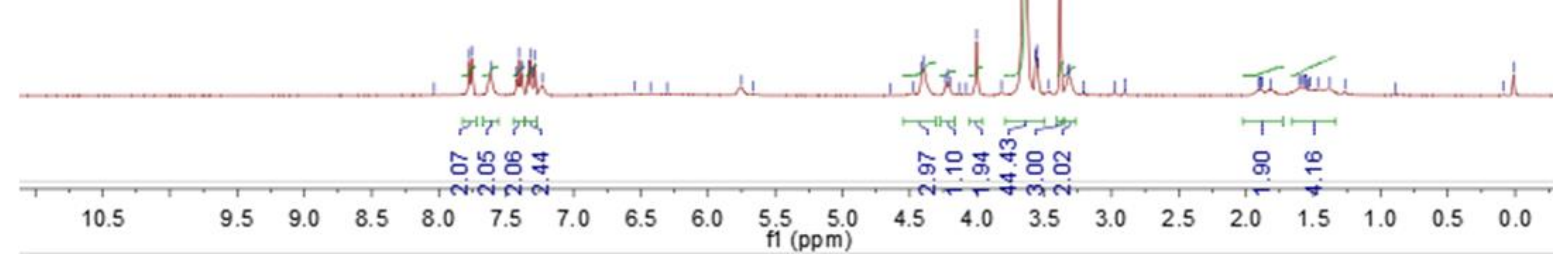



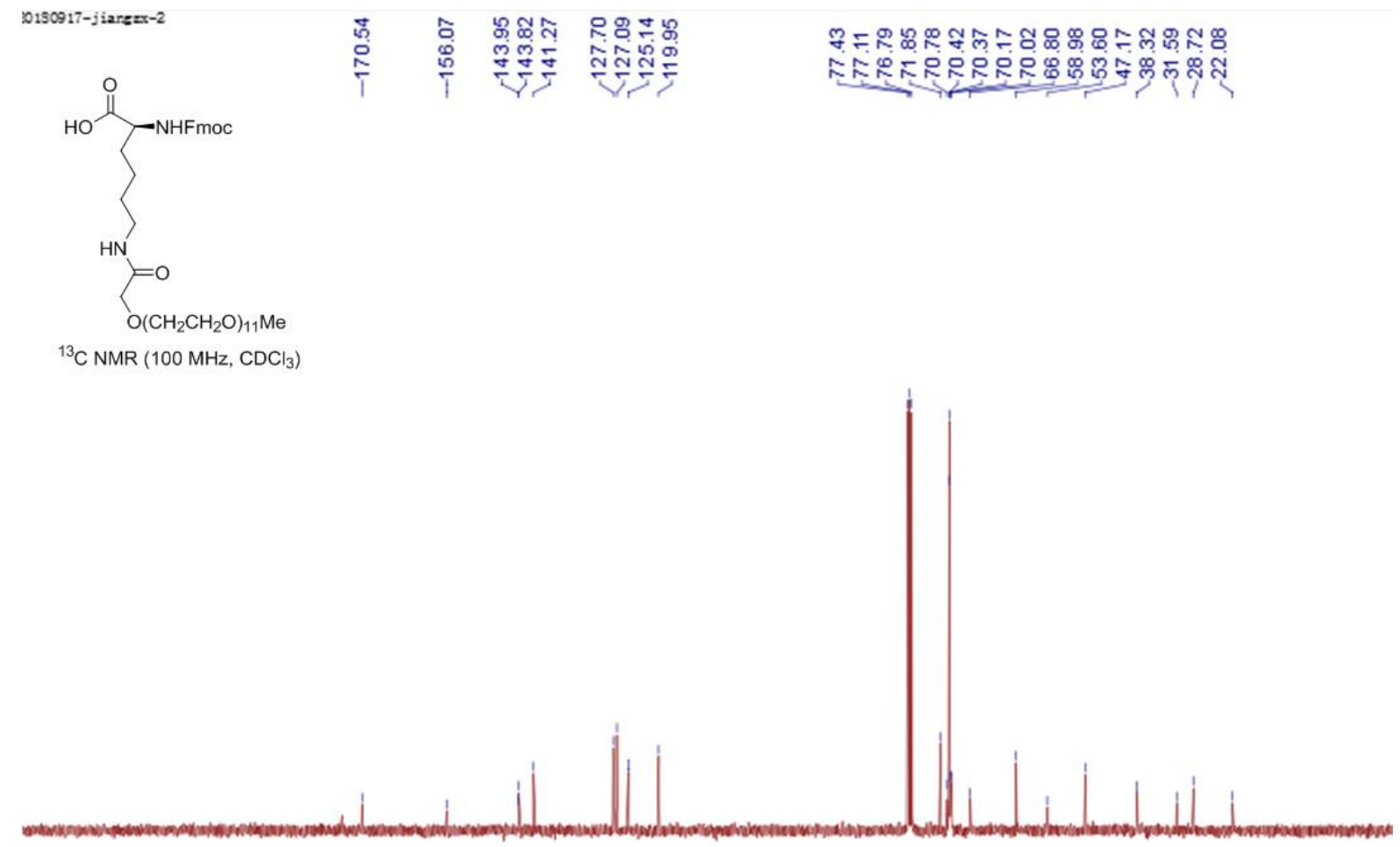

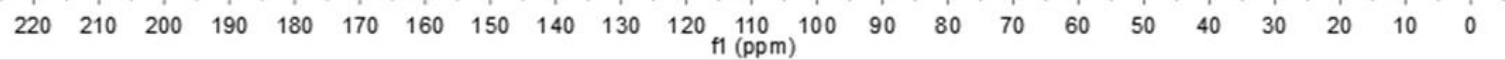

$-\mathrm{MS}, 0.3 \mathrm{~min} \# 16$

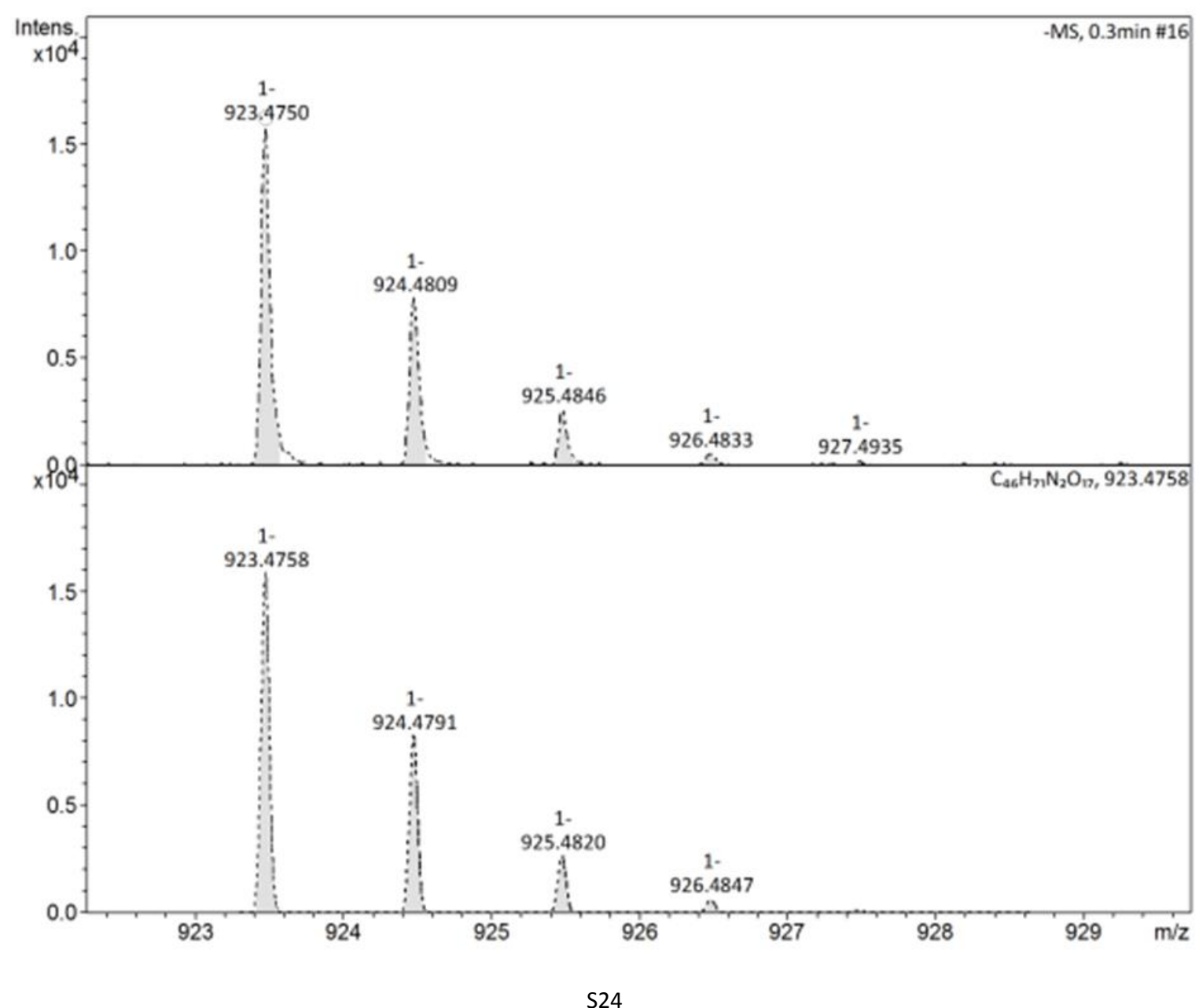


20150323-jiargex-24

MeOT OH

${ }^{1} \mathrm{H}$ NMR $\left(400 \mathrm{MHz}, \mathrm{CDCl}_{3}\right.$ )

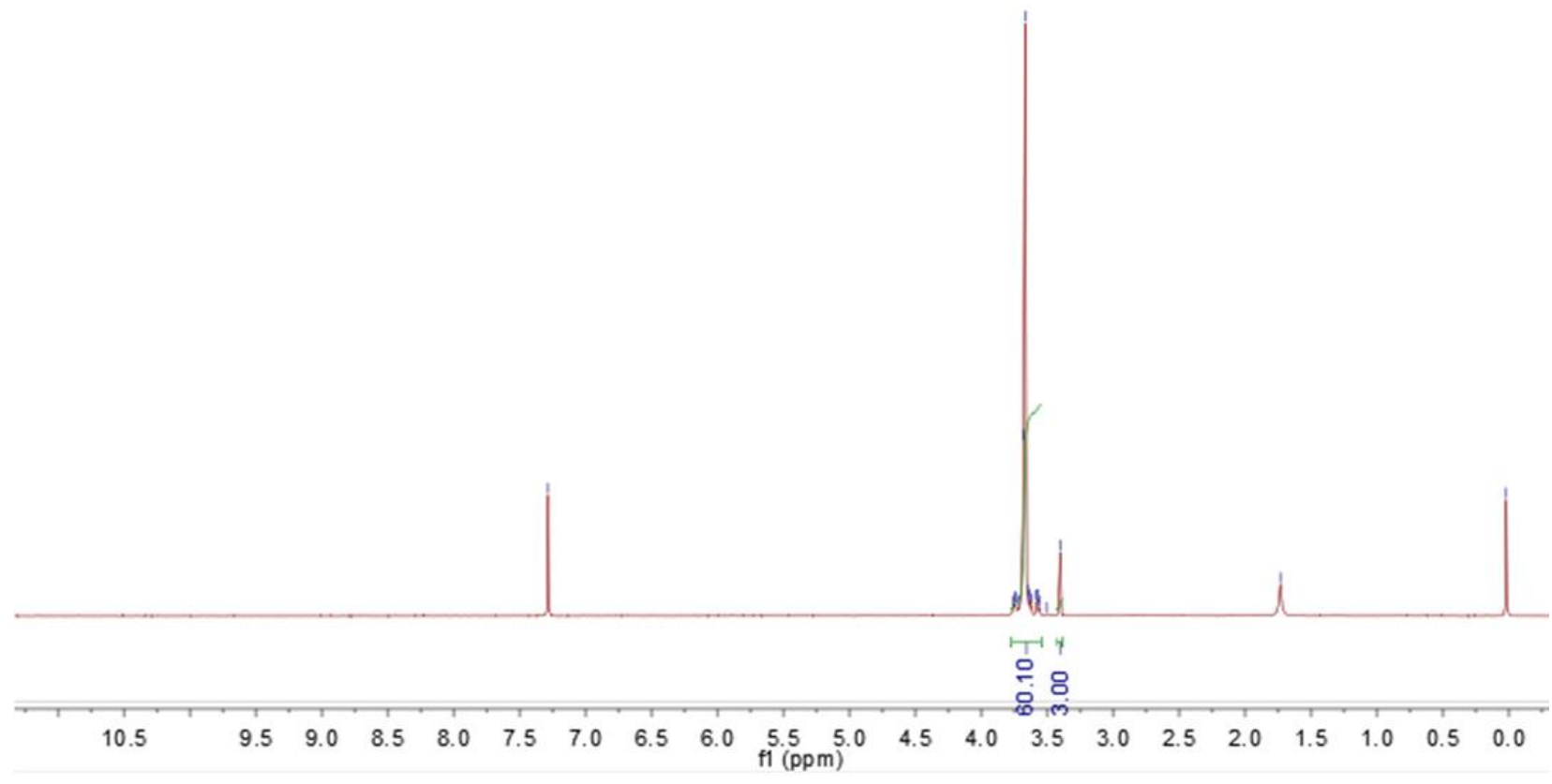

$20190404-j$ iarsax- 16

meot otH

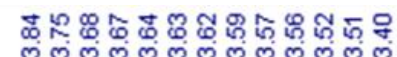

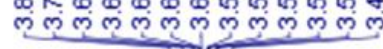

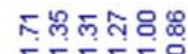
एँ

${ }^{1} \mathrm{H}$ NMR $\left(400 \mathrm{MHz}, \mathrm{CDCl}_{3}\right)$

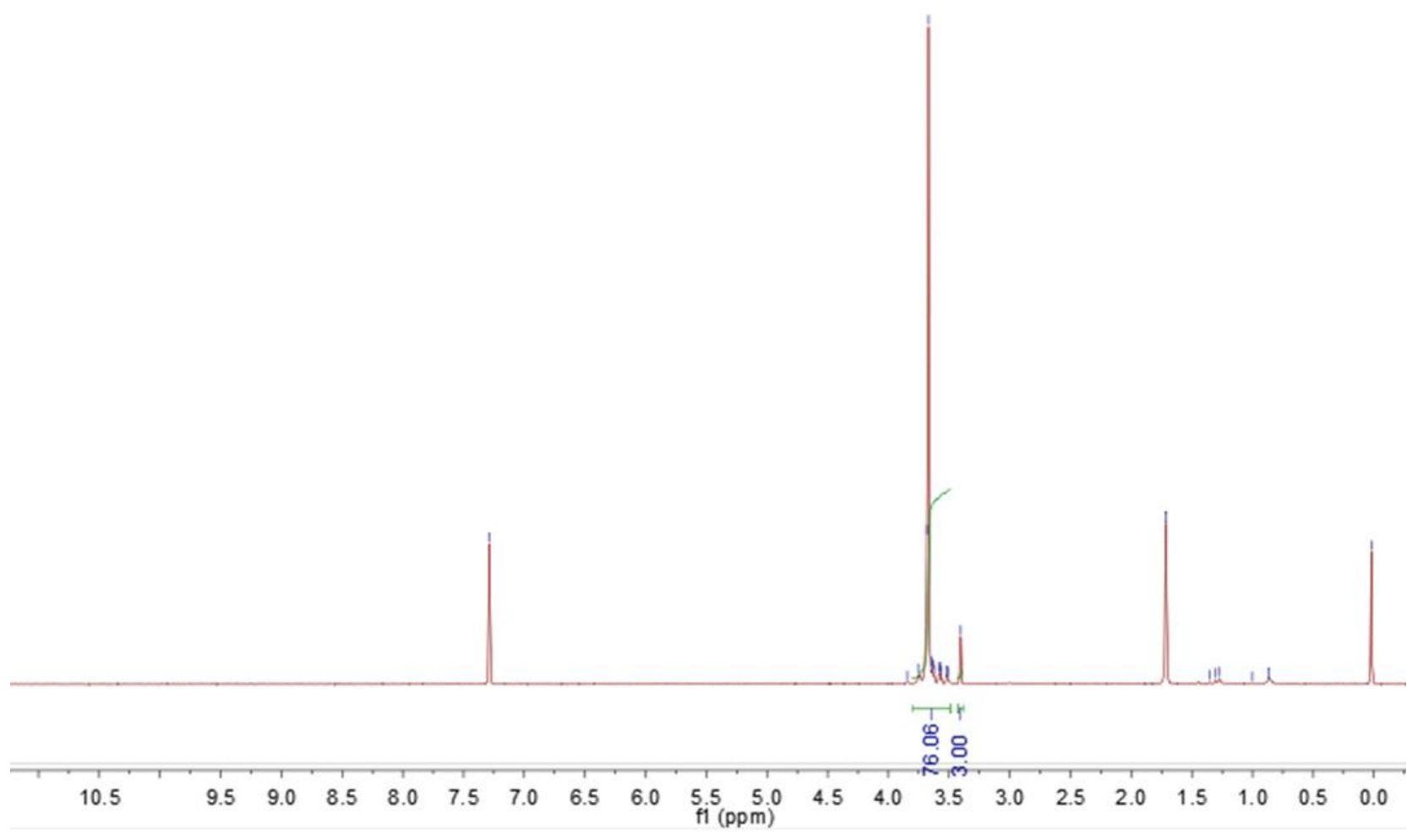


$20190628-j$ iarsex-10

$$
\text { MeotorH }
$$

${ }^{13} \mathrm{C}$ NMR $\left(100 \mathrm{MHz}, \mathrm{CDCl}_{3}\right)$
ธำ

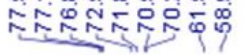

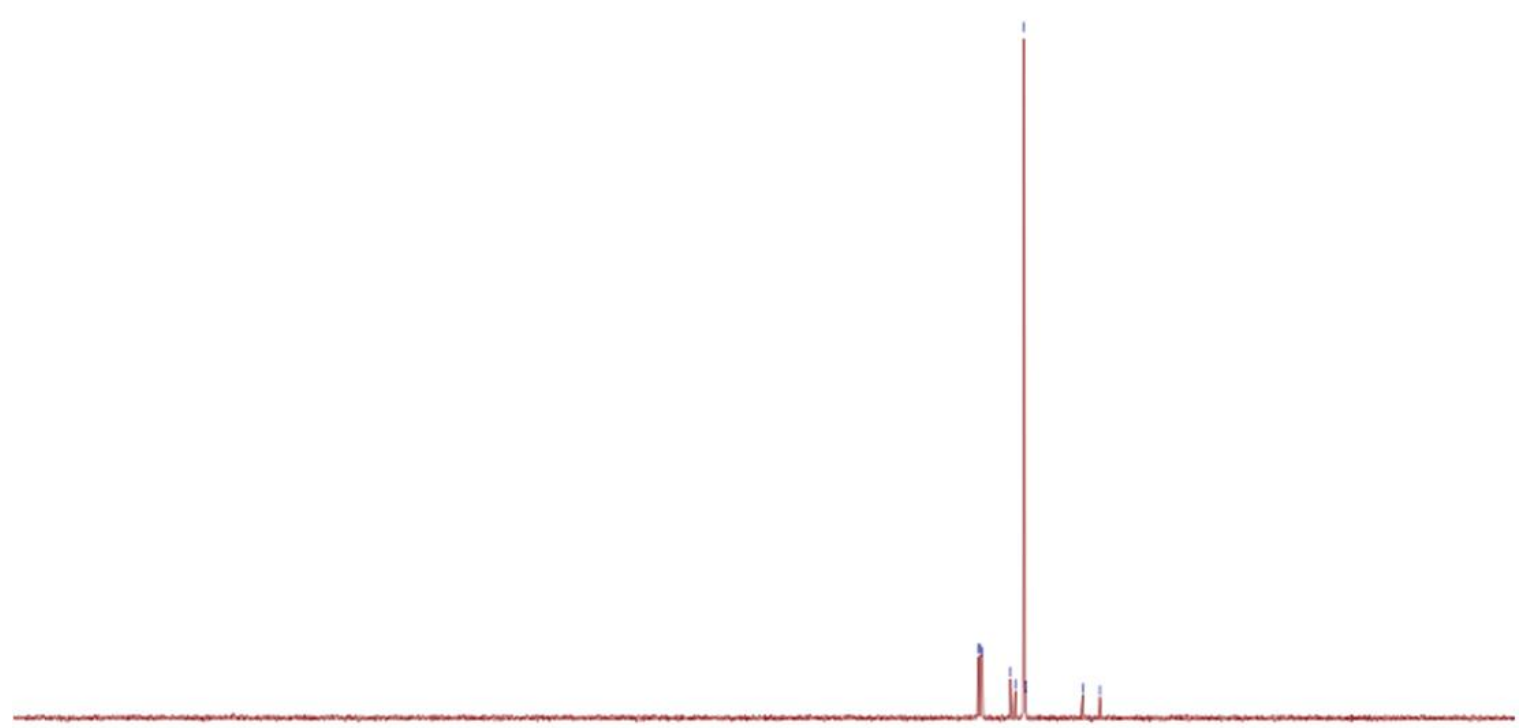

$\begin{array}{lllllllllllllllllllllllllll}220 & 210 & 200 & 190 & 180 & 170 & 160 & 150 & 140 & 130 & 120 & 110 & 100 & 90 & 80 & 70 & 60 & 50 & 40 & 30 & 20 & 10 & 0\end{array}$

+MS, 0.3min \#19

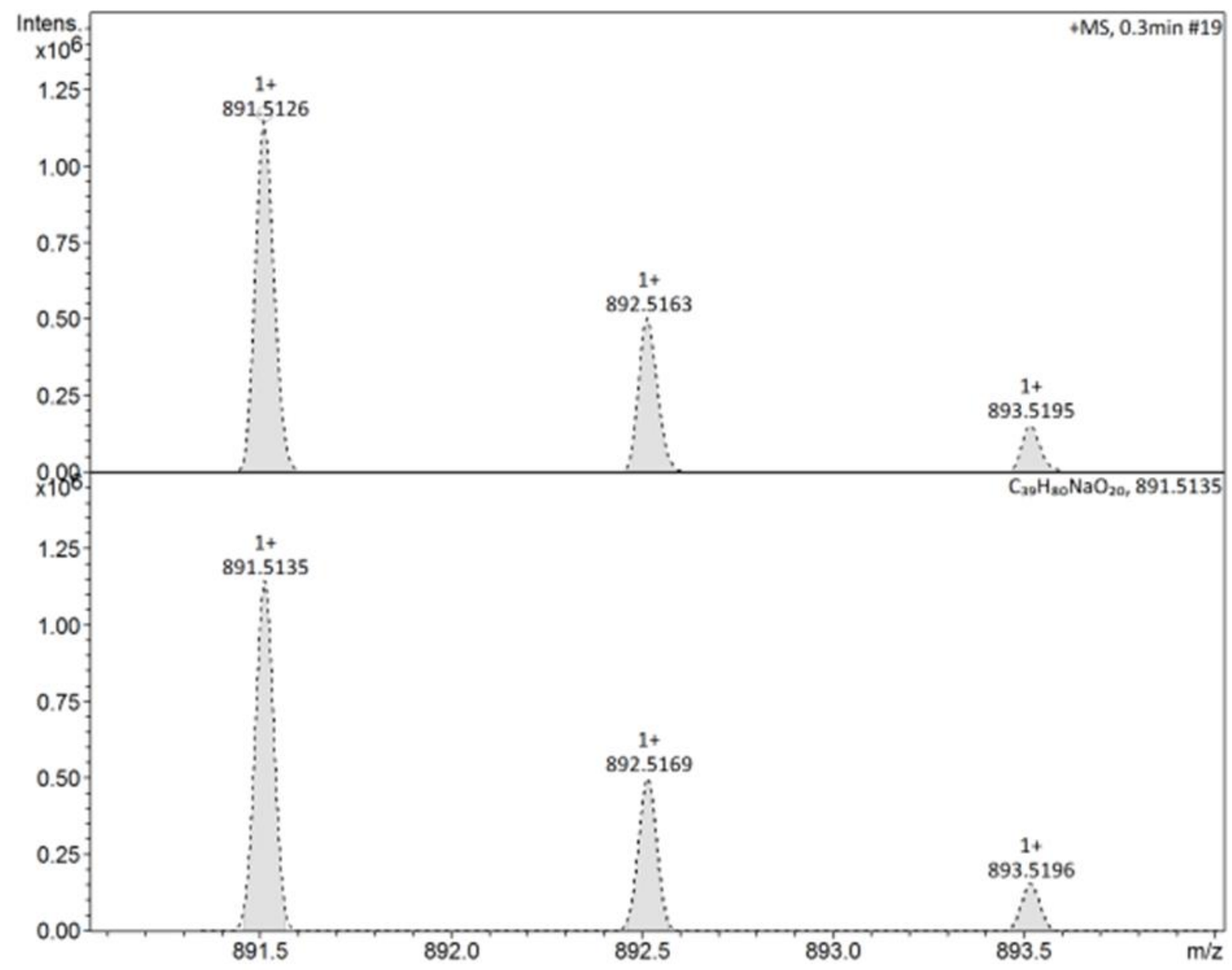




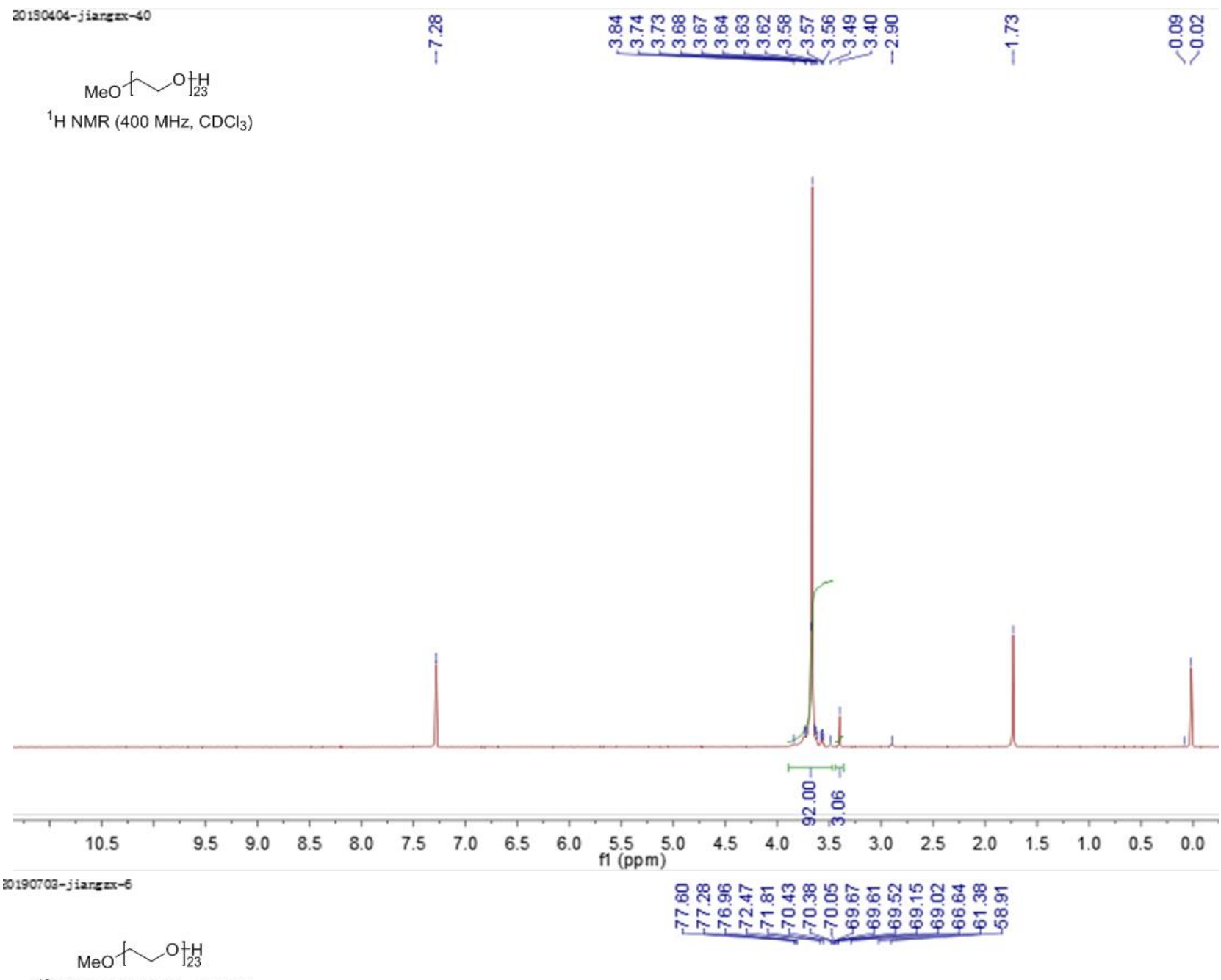

${ }^{13} \mathrm{C} \mathrm{NMR}\left(100 \mathrm{MHz}, \mathrm{CDCl}_{3}\right)$

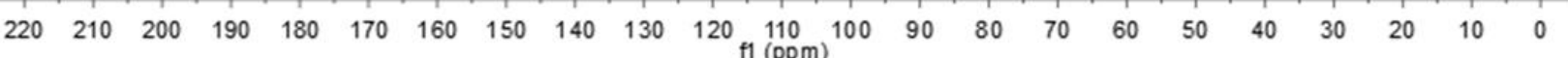


$+\mathrm{MS}, \mathbf{0 . 3 \operatorname { m i n }} \# 20$

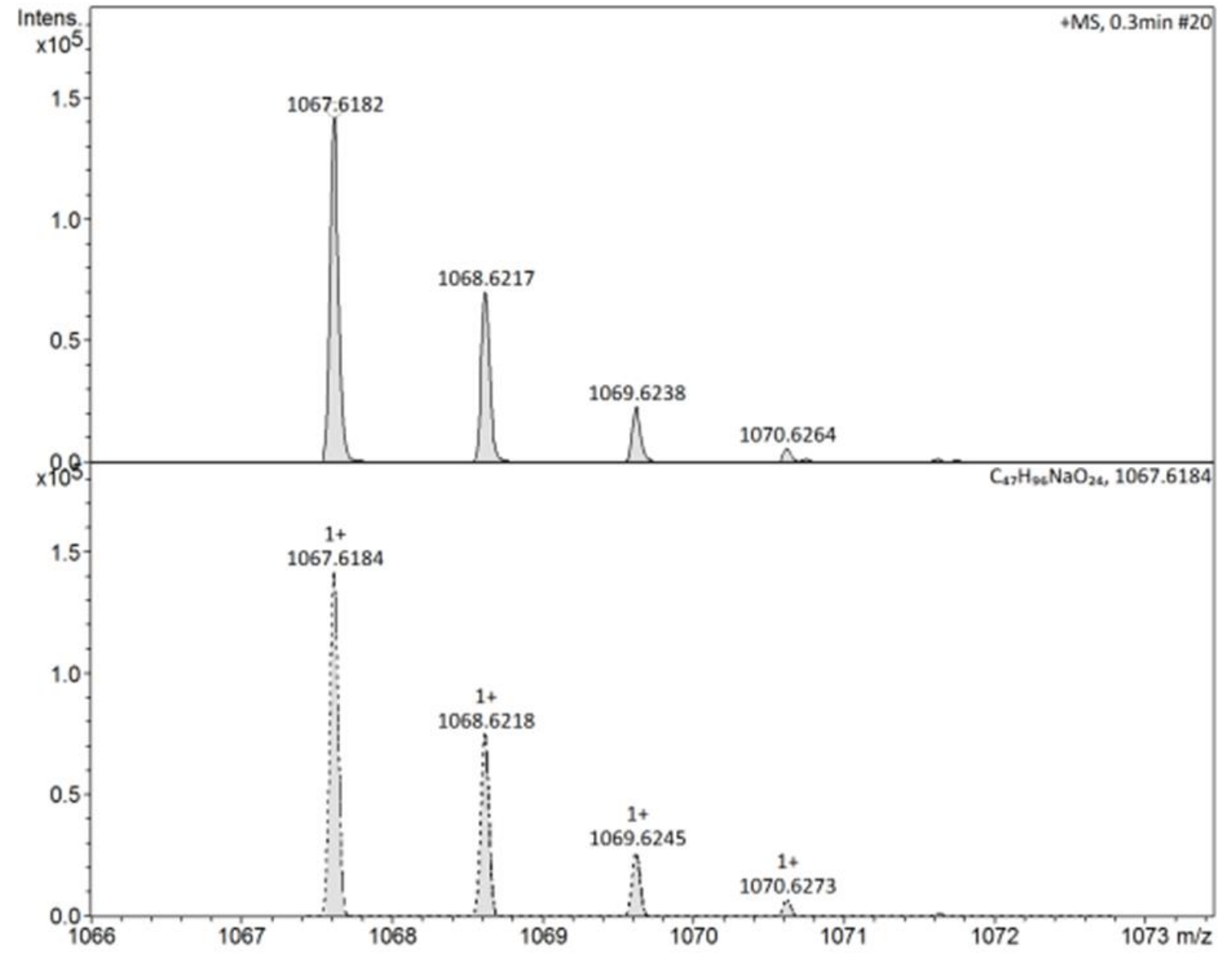

$20190409-j$ i2rszx-13

MeOł O+f $\mathrm{CO}_{23} \mathrm{tBu}$

${ }^{1} \mathrm{H} \mathrm{NMR}\left(400 \mathrm{MHz}, \mathrm{CDCl}_{3}\right)$ 

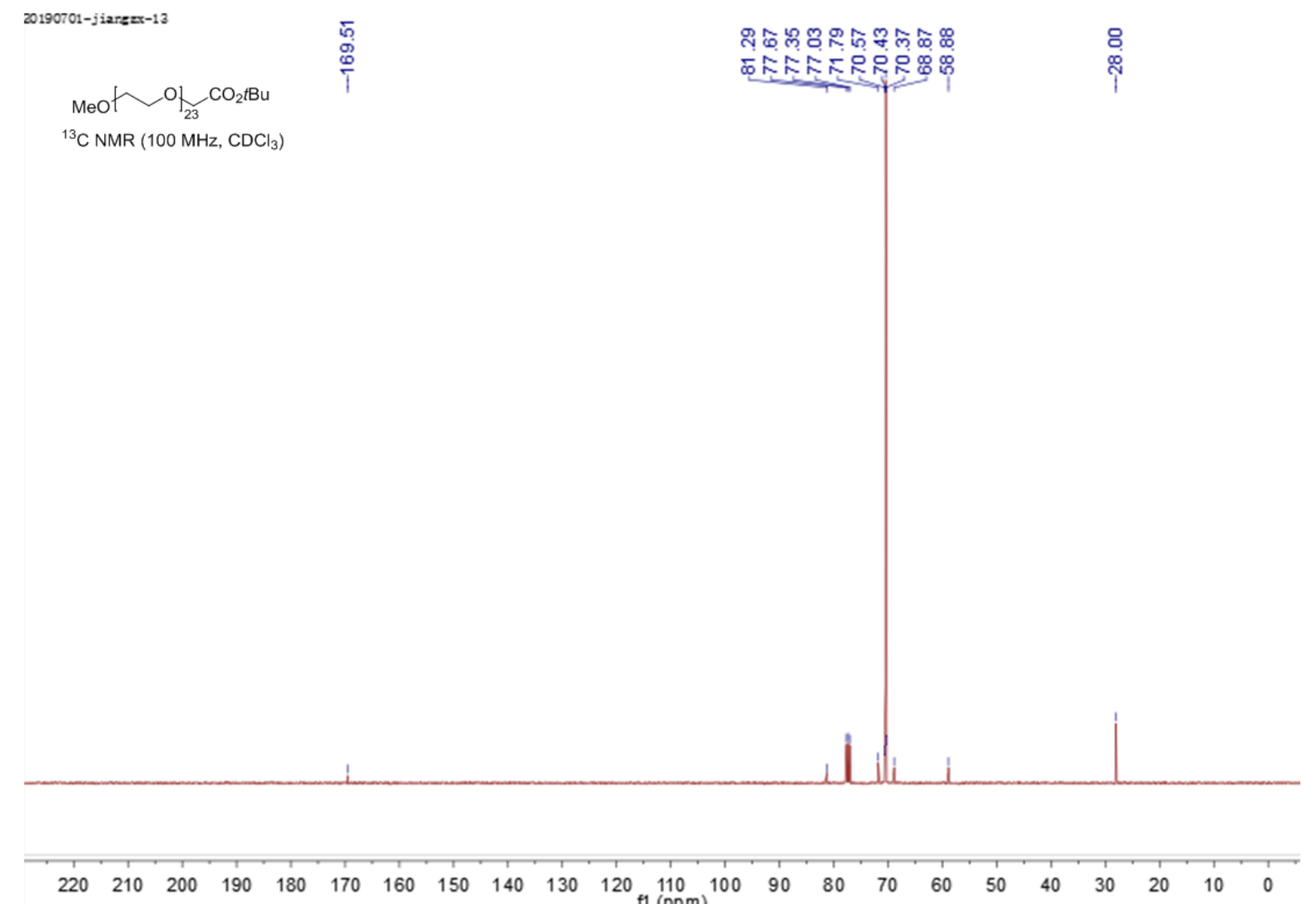

+MS, 0.3min \#18

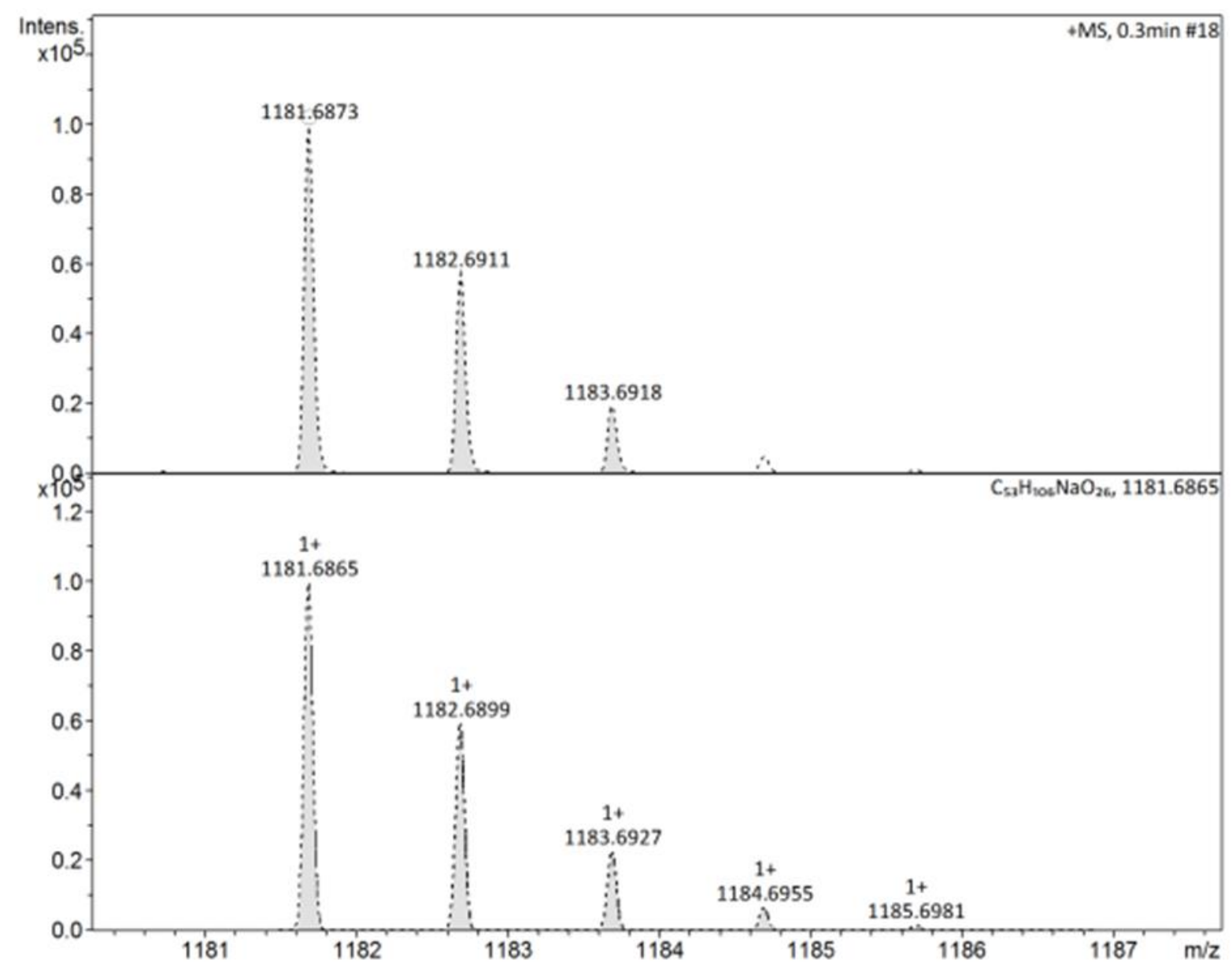




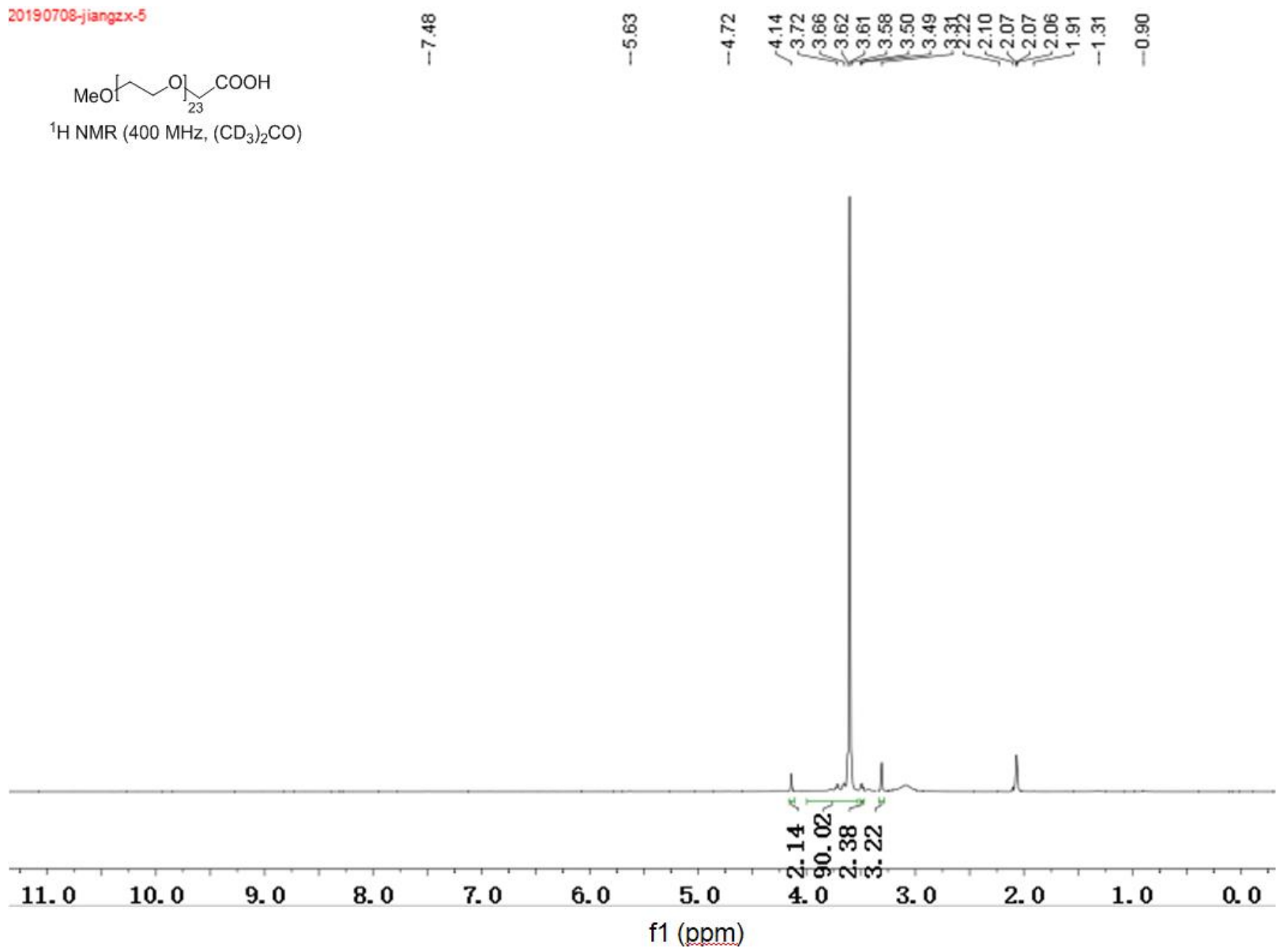

20190701-jiarsex-14

${ }^{13} \mathrm{C} \mathrm{NMR}\left(100 \mathrm{MHz}, \mathrm{CDCl}_{3}\right)$

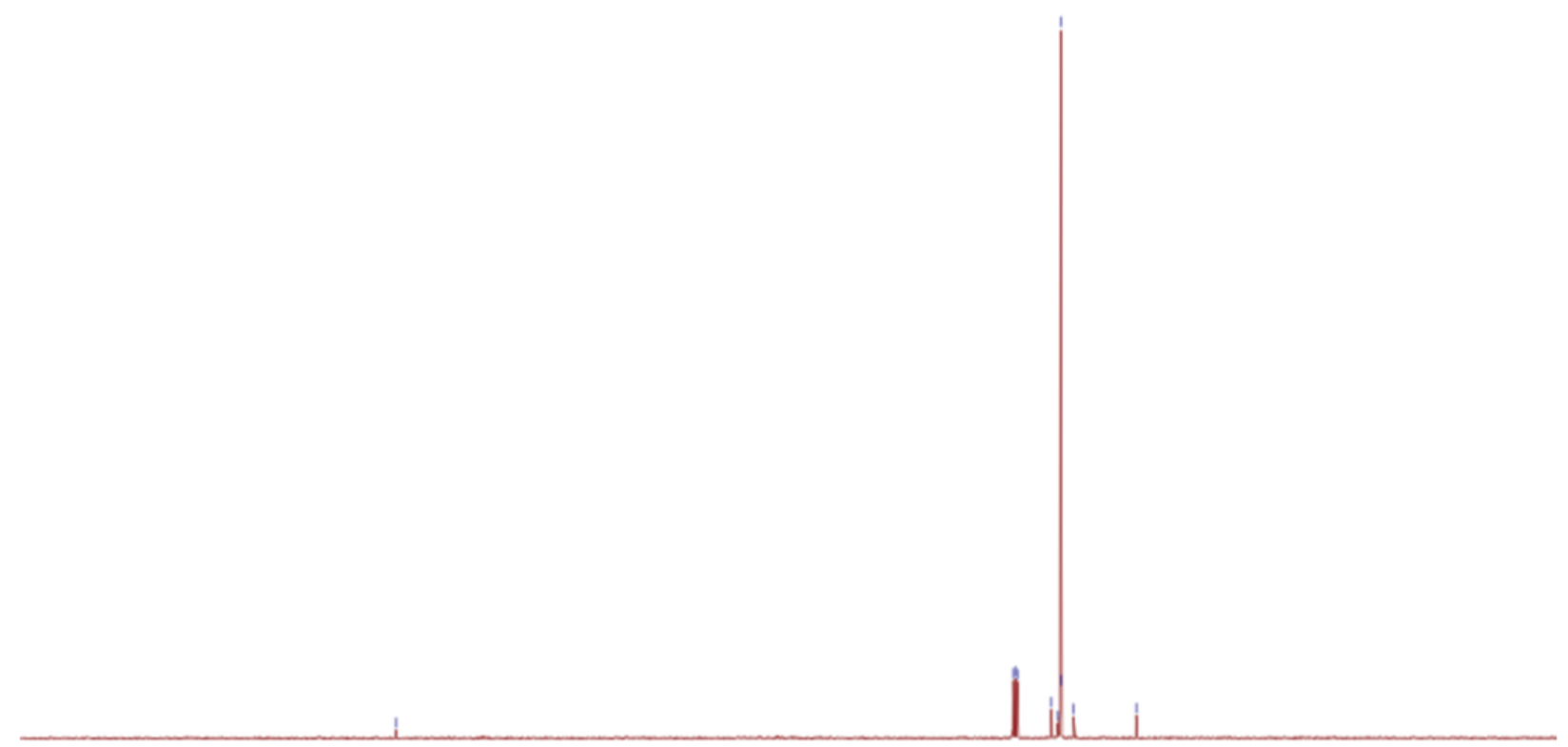

$\begin{array}{lllllllllllllllllllllll}220 & 210 & 200 & 190 & 180 & 170 & 160 & 150 & 140 & 130 & 120 & \left.\begin{array}{l}110 \\ \mathrm{fl}(\mathrm{ppm})\end{array}\right) & 100 & 90 & 80 & 70 & 60 & 50 & 40 & 30 & 20 & 10 & 0\end{array}$ 
-MS, $0.3 \mathrm{~min} \# 16$

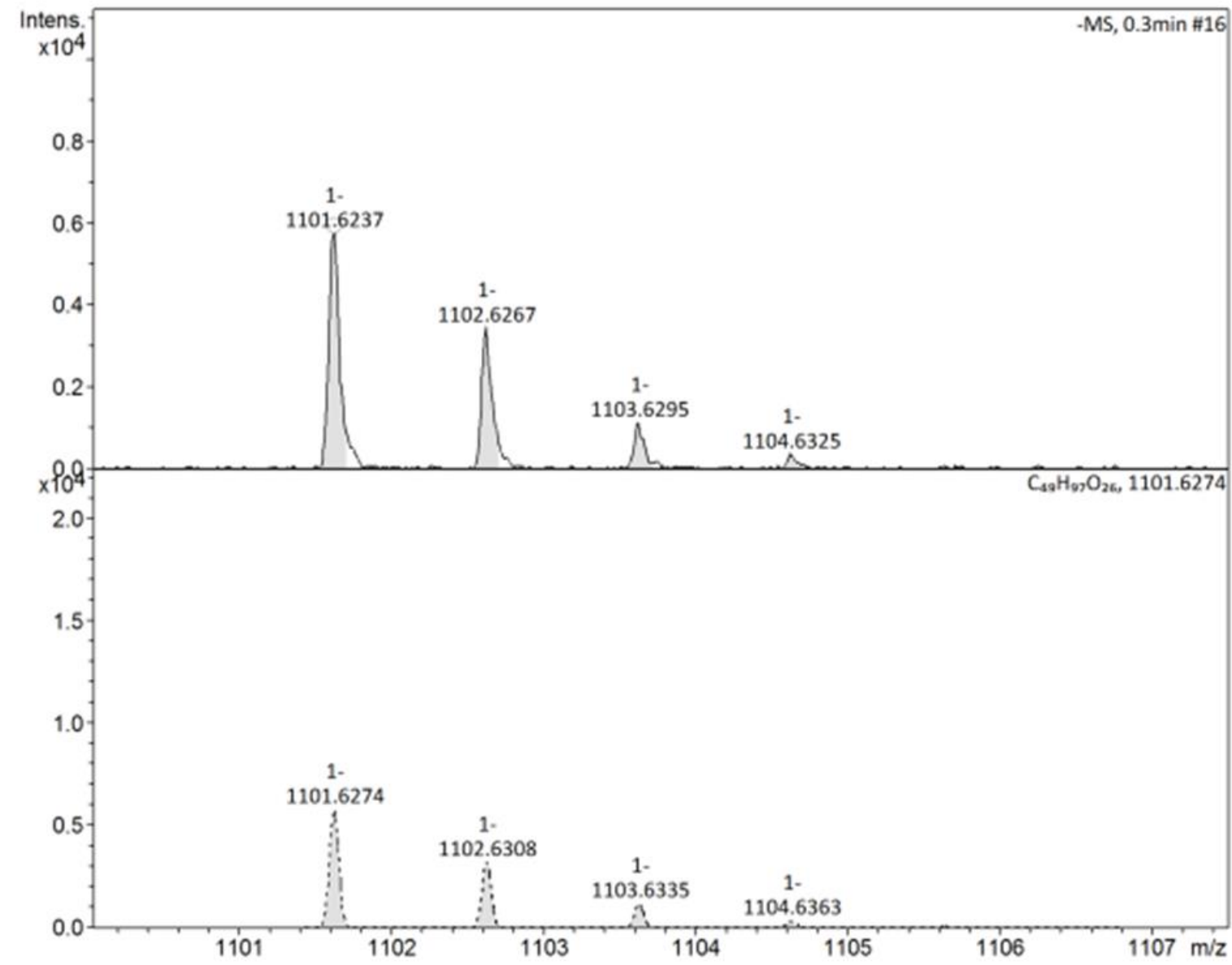

D0150420-jiarsex-7

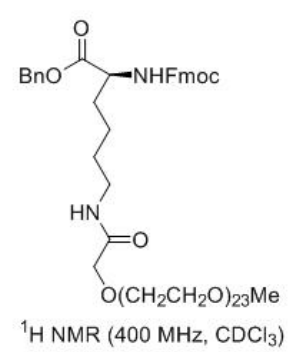

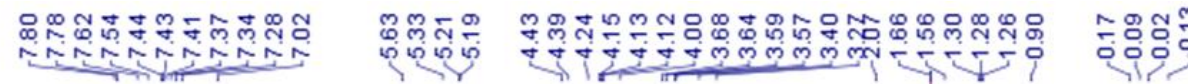

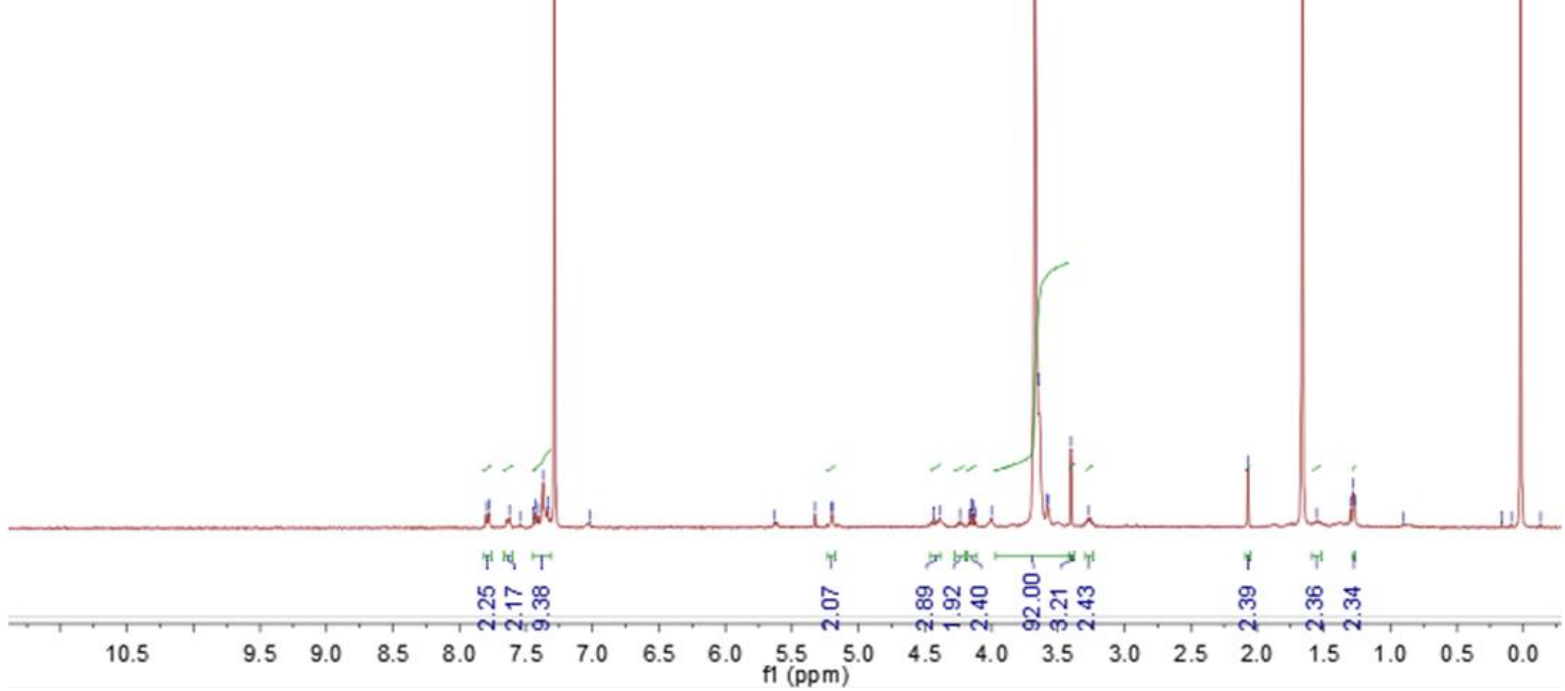




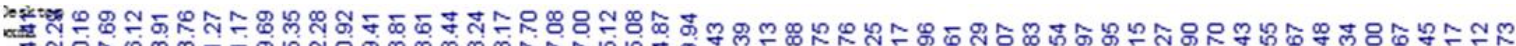

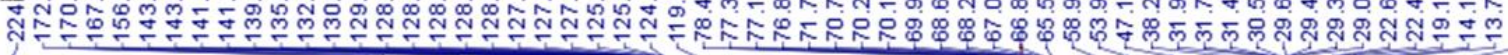

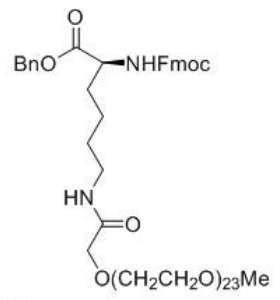

${ }^{13} \mathrm{C} \mathrm{NMR}\left(126 \mathrm{MHz}, \mathrm{CDCl}_{3}\right)$

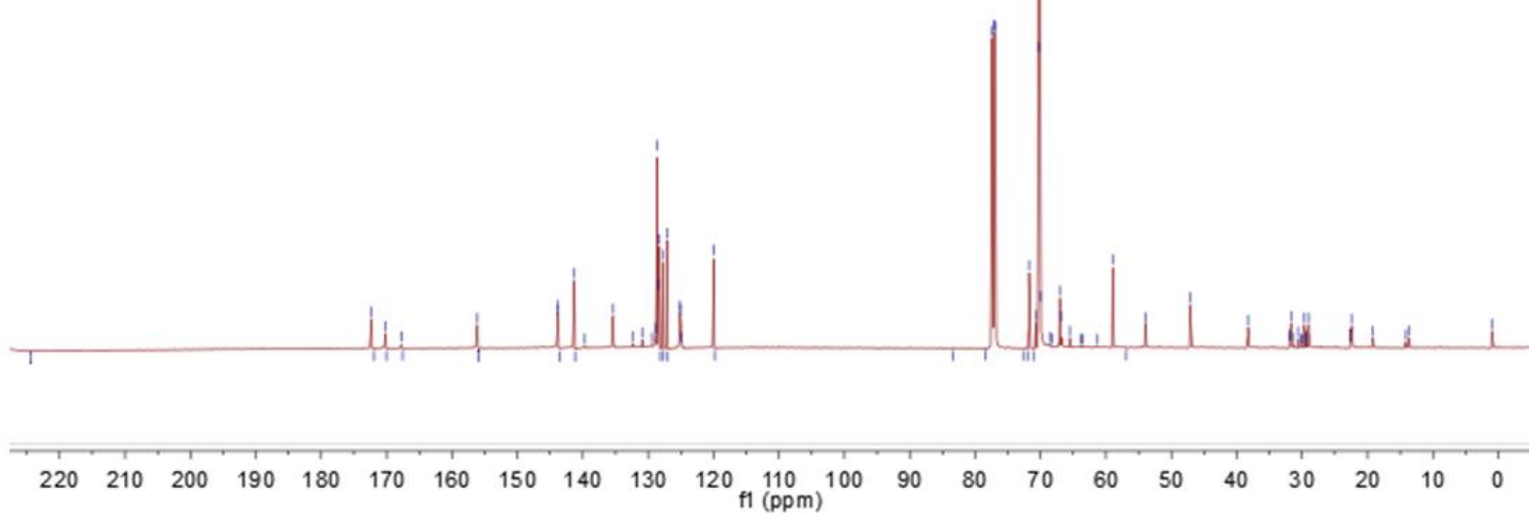

+MS, $0.8 \mathrm{~min} \# 48$

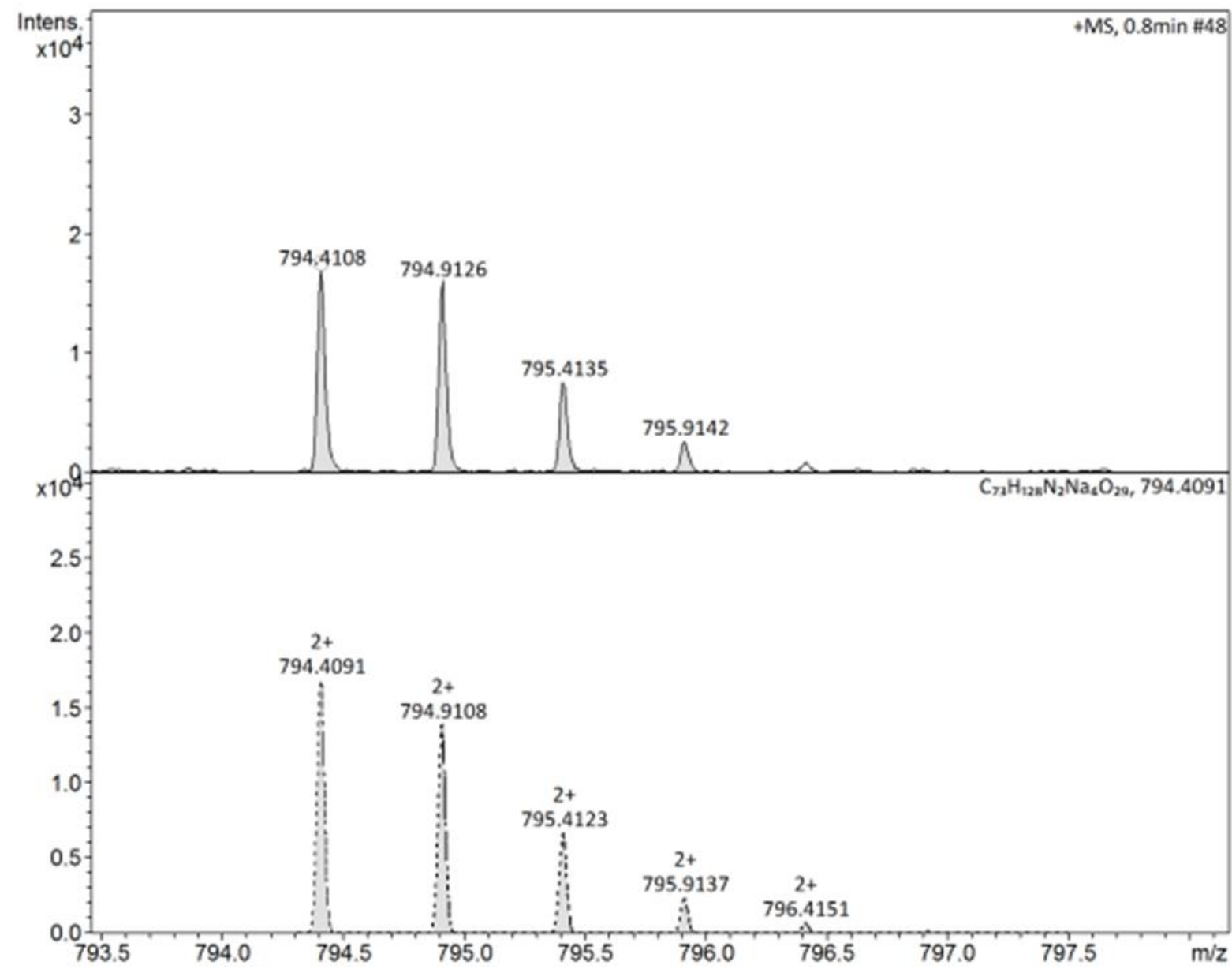



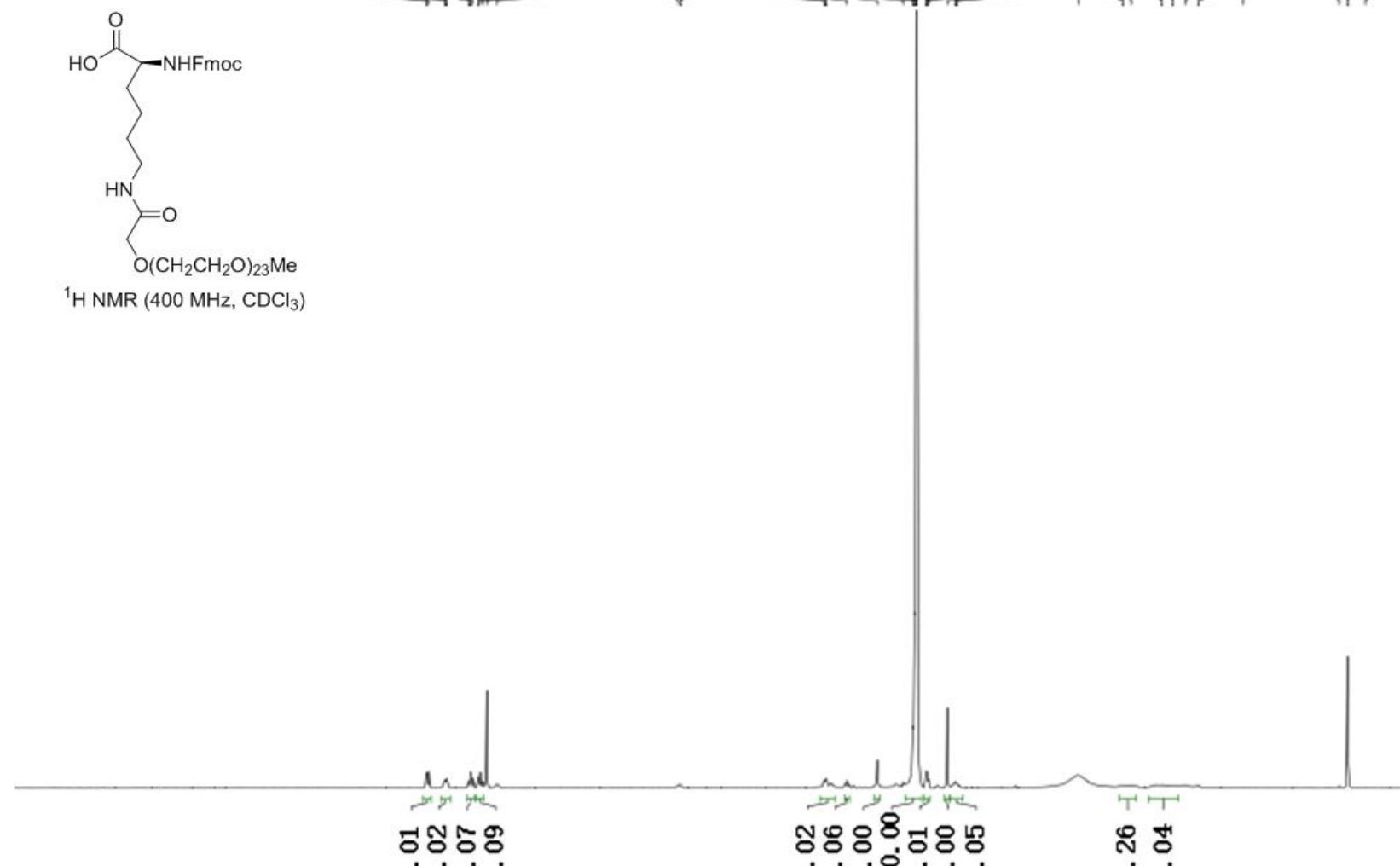

11.0 10.0 9.0 8. 0 7.0 6.0 5.0 4. 0 3.0 2.

1.0 0.0

D191031-jiarsex-10

$\mathrm{f} 1(\mathrm{ppm})$

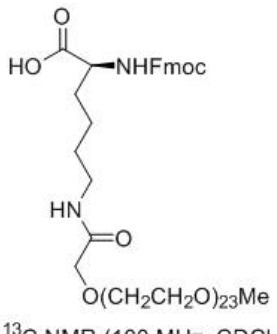

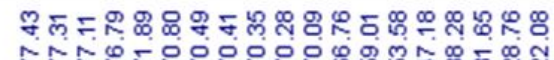

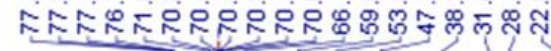

${ }^{13} \mathrm{C} \mathrm{NMR}(100 \mathrm{MHz}, \mathrm{CDCl})$

$\begin{array}{llllllllllllllllllllll}220 & 210 & 200 & 190 & 180 & 170 & 160 & 150 & 140 & 130 & 120 & \begin{array}{l}110 \\ \mathrm{f} 1\end{array}(\mathrm{ppm}) \\ 100 & 90 & 80 & 70 & 60 & 50 & 40 & 30 & 20 & 10 & 0\end{array}$ 
$-\mathrm{MS}, 0.3 \min \# 19$

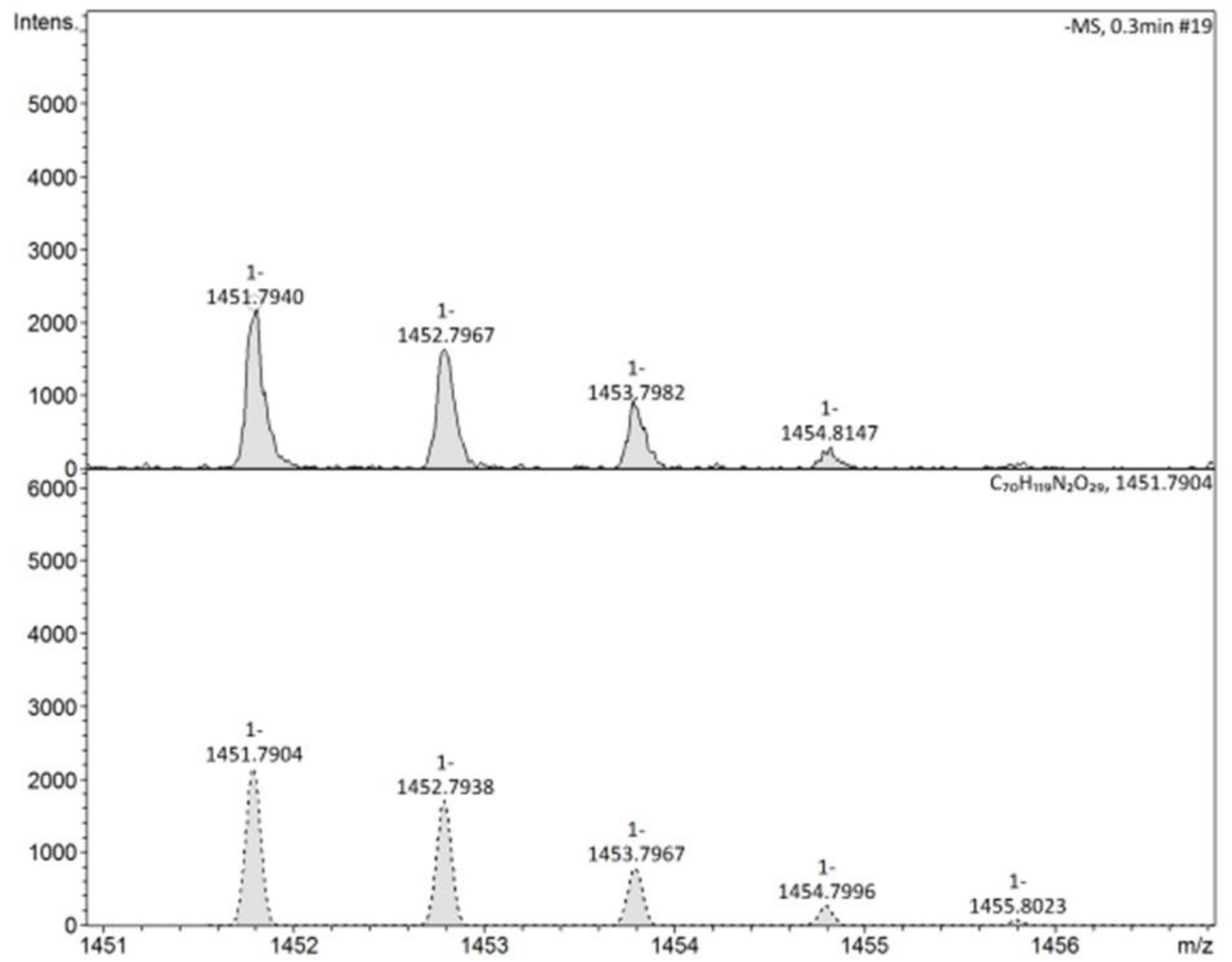

20151031-jiarsex-11

$\mathbf{P}_{7}-8$

${ }^{1} \mathrm{H}$ NMR $\left(400 \mathrm{MHz}, \mathrm{CD}_{3} \mathrm{OD}\right)$

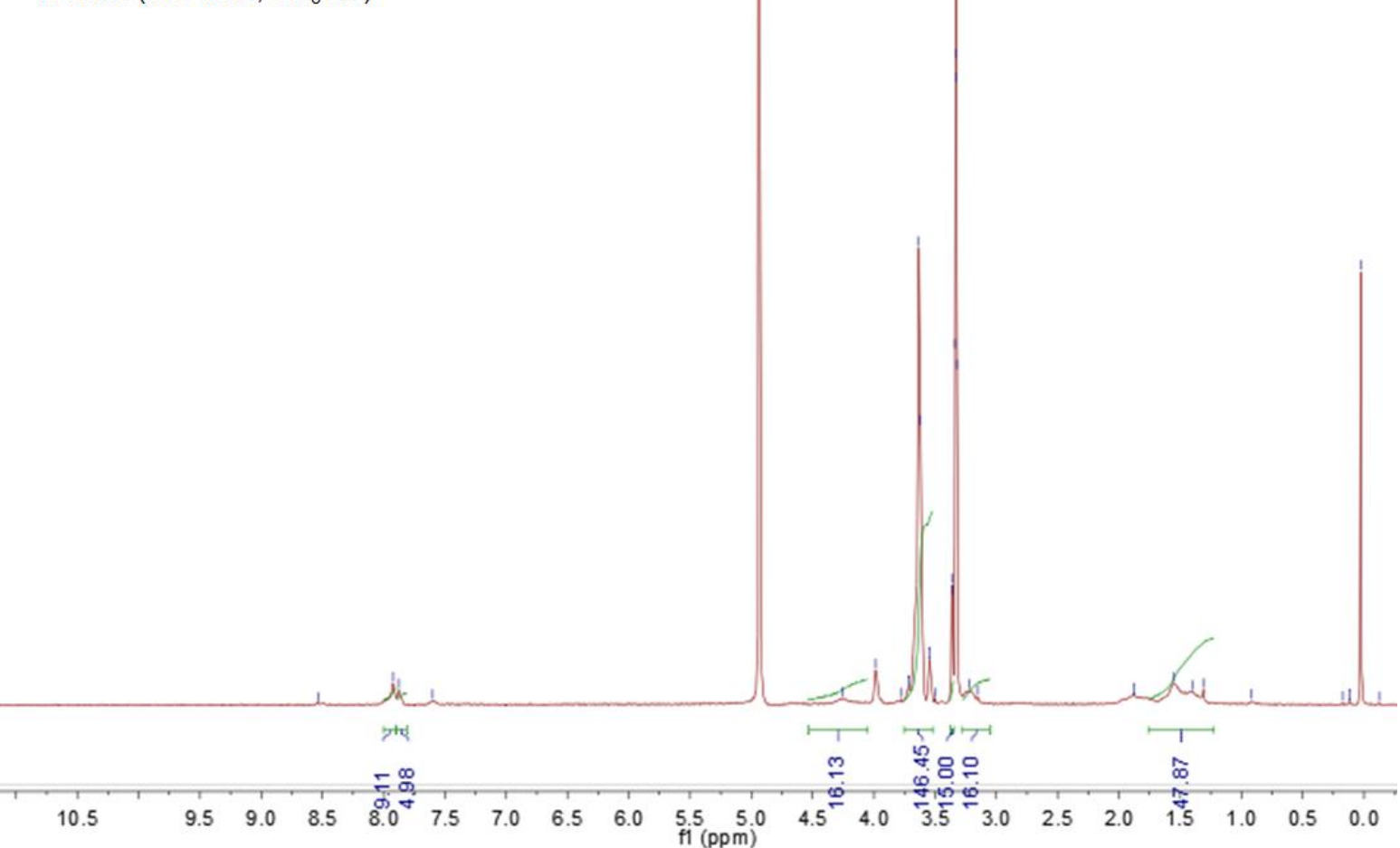


Do181210-jiarszx-5

$$
P_{7}-8
$$

${ }^{19} \mathrm{~F} \operatorname{NMR}\left(376 \mathrm{MHz}, \mathrm{D}_{2} \mathrm{O}\right)$

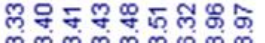

ب⿻

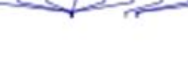

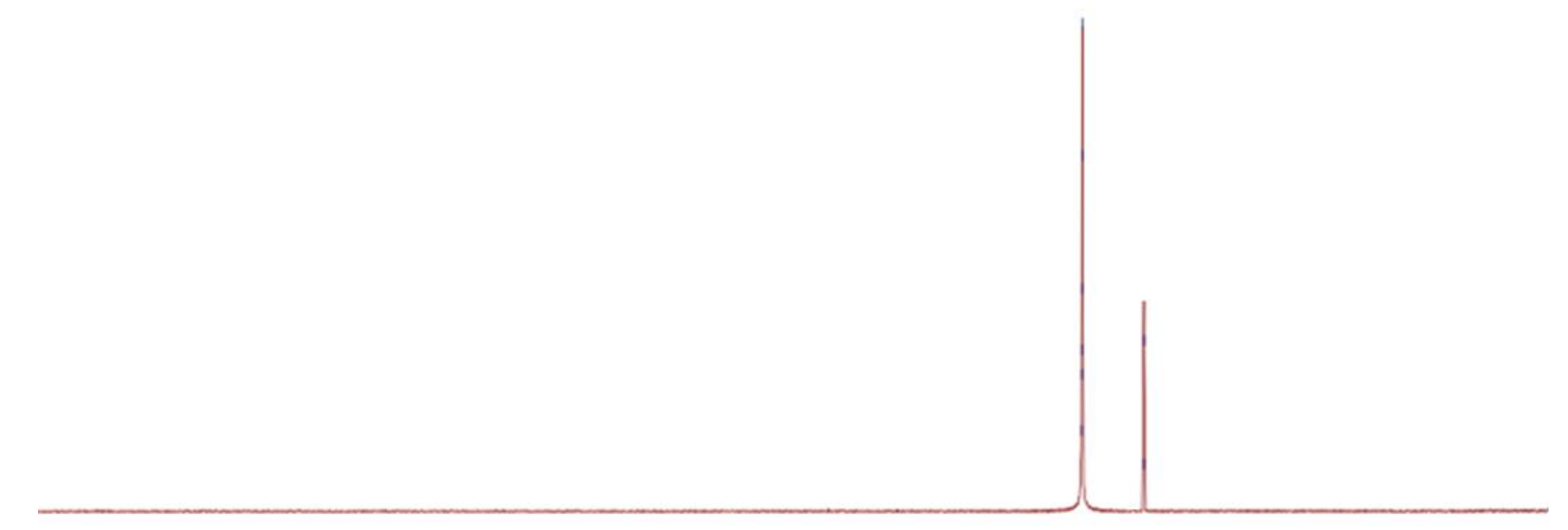

\begin{tabular}{llllllllllllllll}
\hline & 170 & 140 & 110 & 80 & 60 & 40 & 20 & 0 & 0 & -30 & -60 & -90 & -120 & -160 & -1
\end{tabular}

MS (MALDI)

MALDI-TOF,CCA,1,20180917

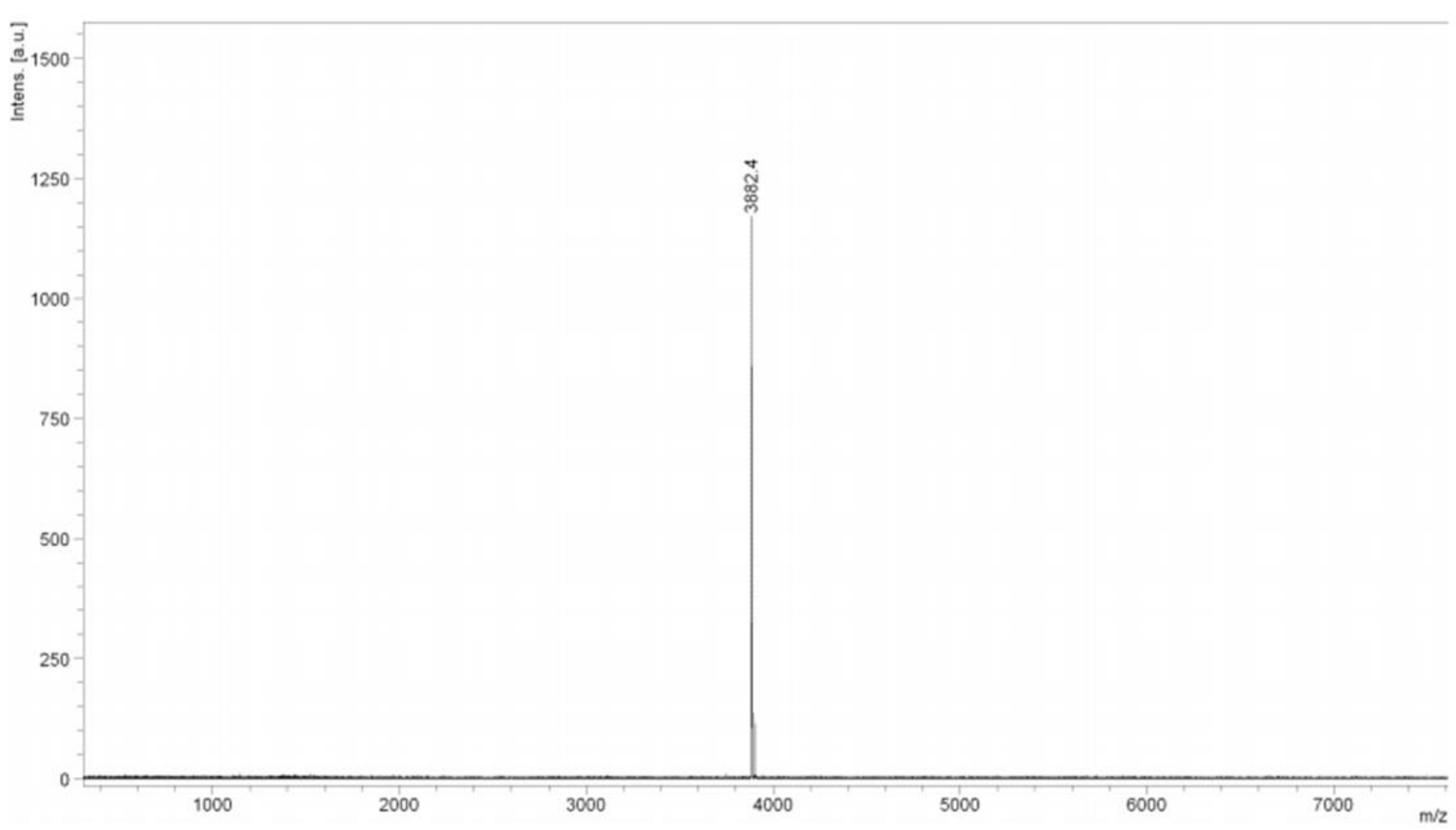




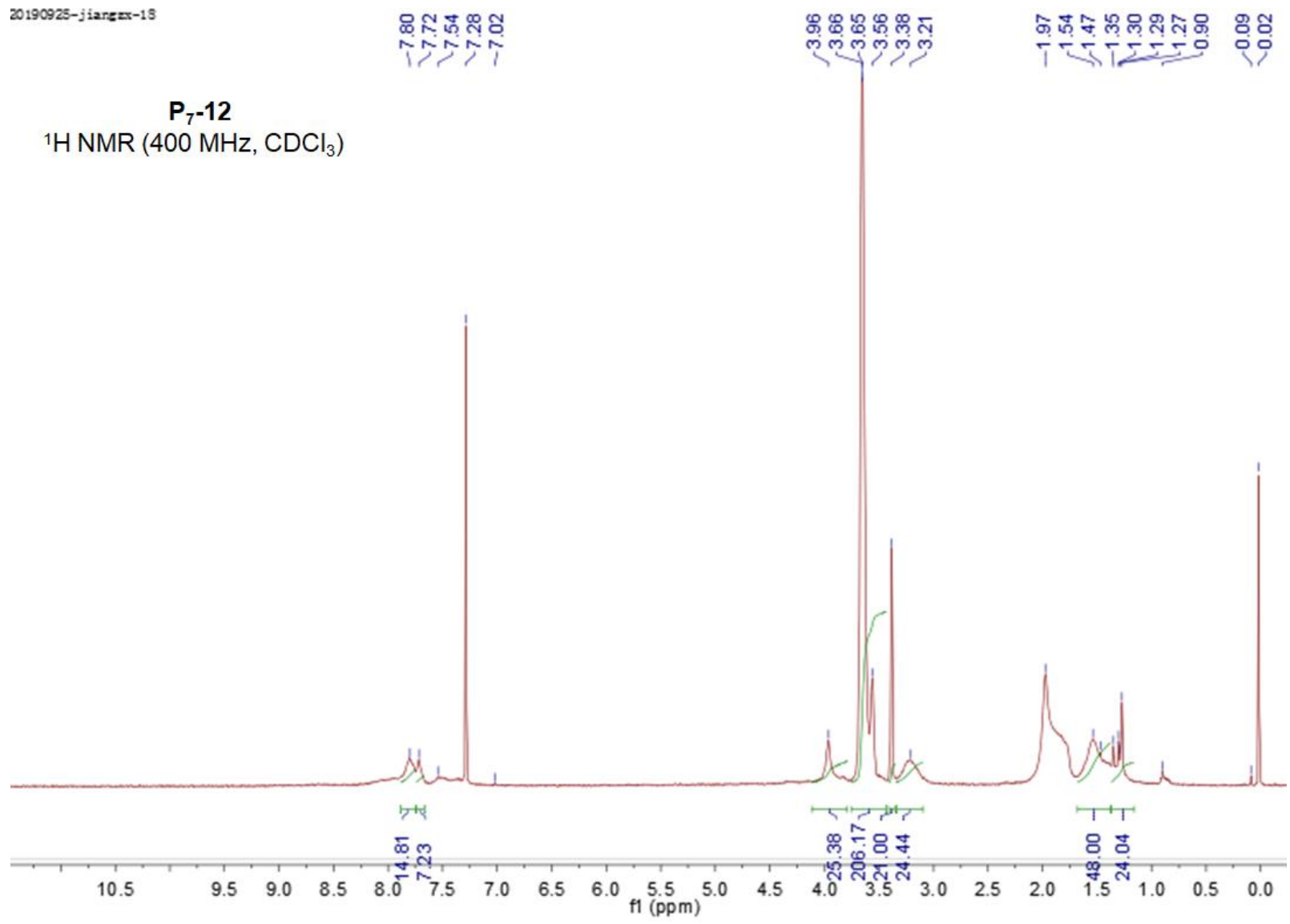
$20131210-j$ iarsex -10

$$
P_{7}-12
$$

भुำ

$m$

${ }^{19} \mathrm{~F} \mathrm{NMR}\left(376 \mathrm{MHz}, \mathrm{D}_{2} \mathrm{O}\right)$
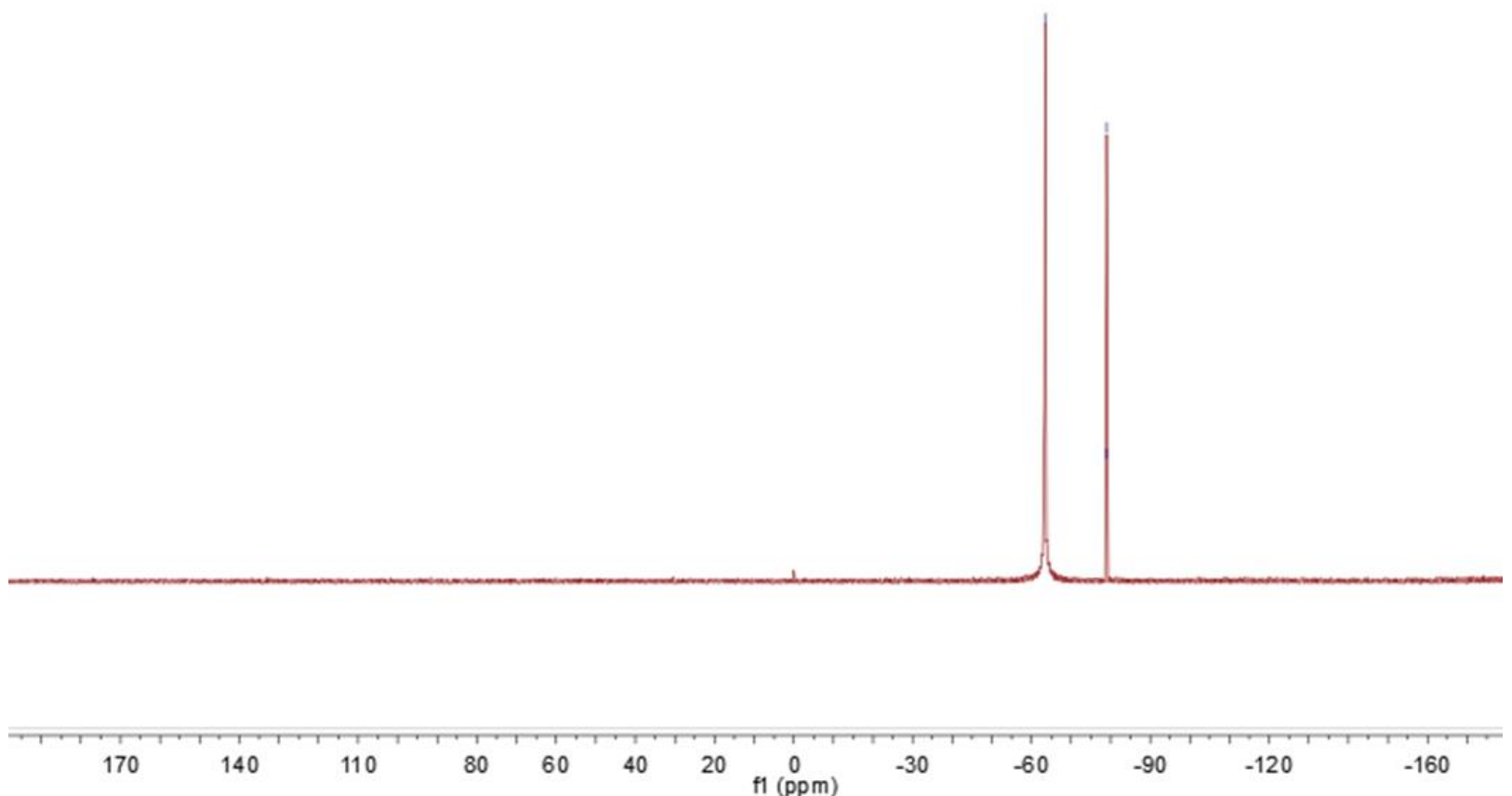


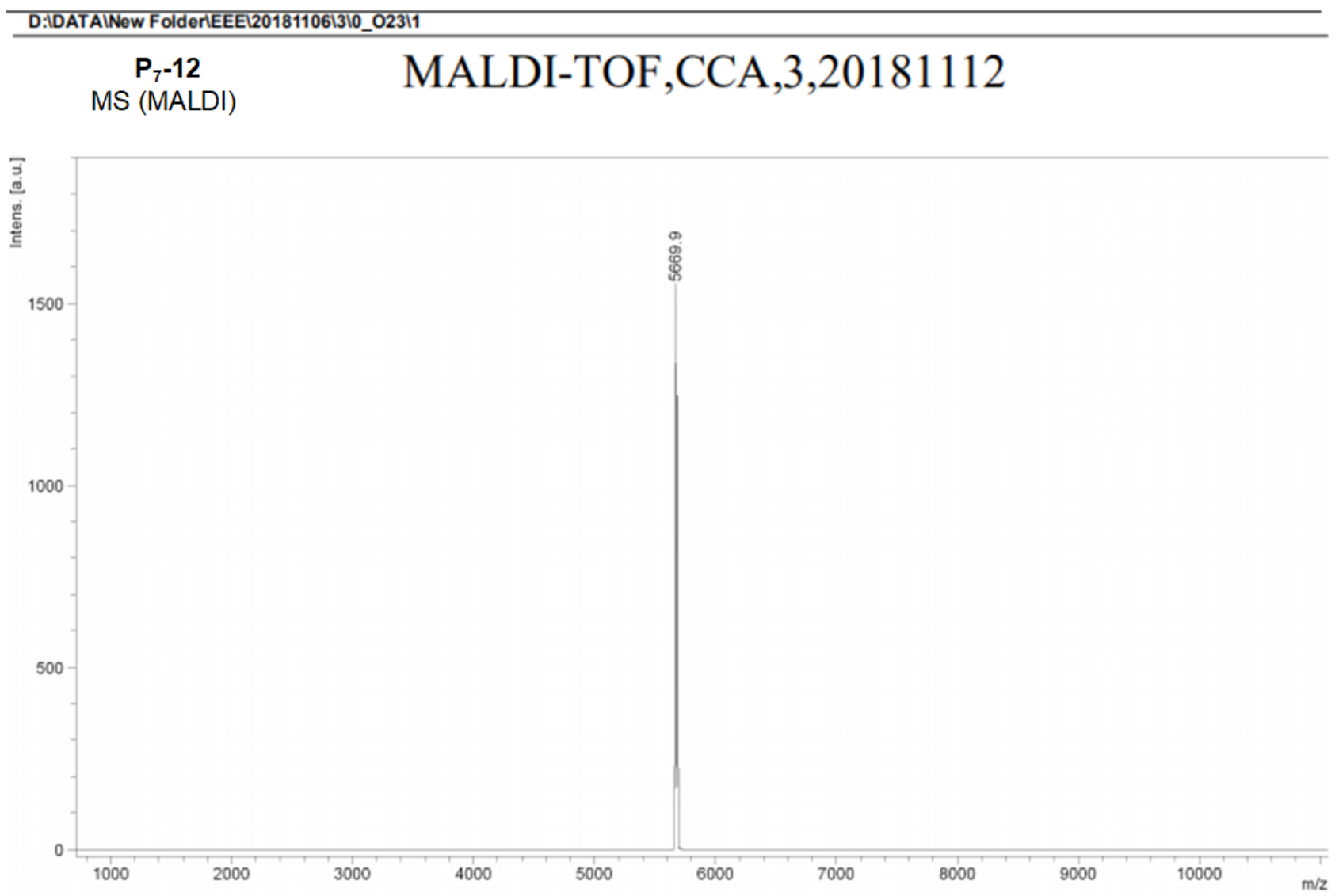

20190925-jiarzax-19

$\mathbf{P}_{11}-8$

${ }^{1} \mathrm{H} \mathrm{NMR}\left(400 \mathrm{MHz}, \mathrm{CDCl}_{3}\right)$

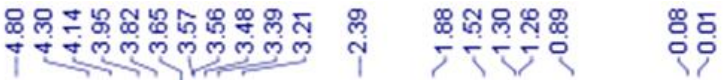

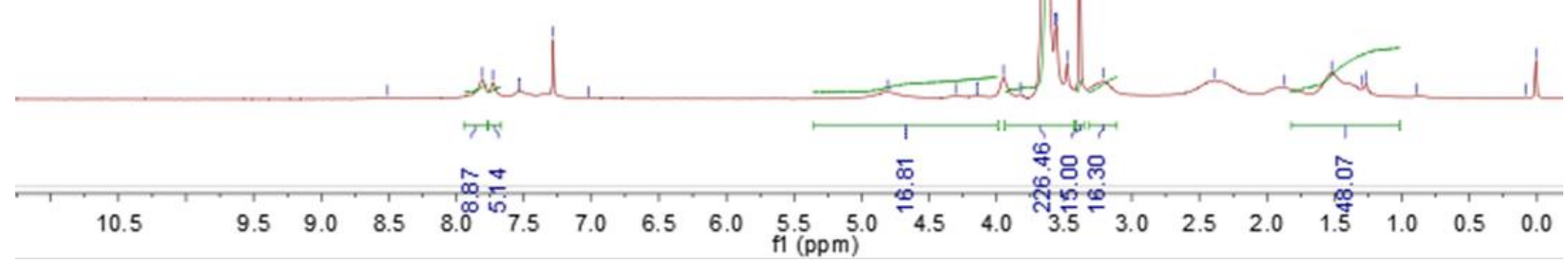


D $131210-j$ iarszx-15

$$
\mathbf{P}_{11-8}
$$

${ }^{19} \mathrm{~F}$ NMR $\left(376 \mathrm{MHz}, \mathrm{D}_{2} \mathrm{O}\right)$
कृष्ले

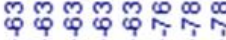

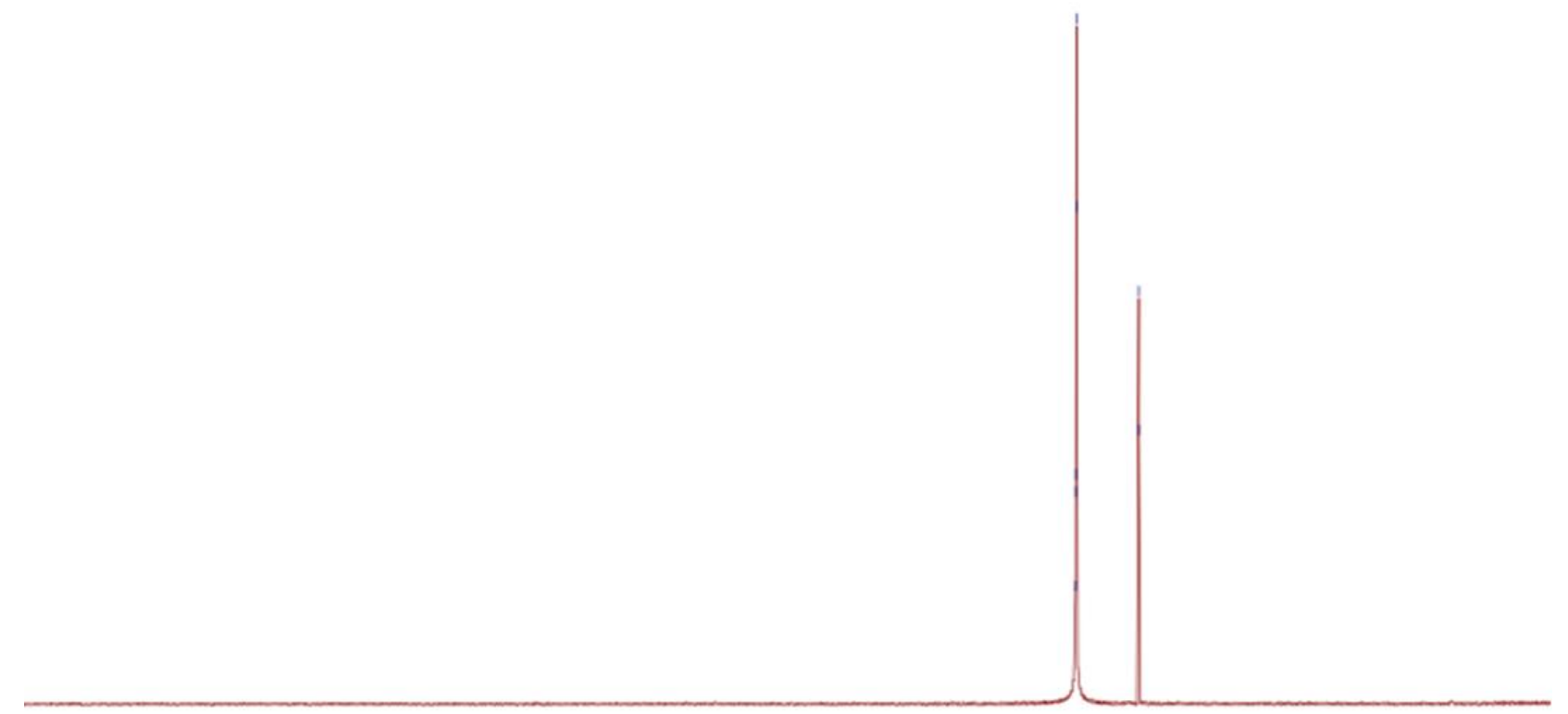

\begin{tabular}{lllllllllllllll}
\hline 170 & 140 & 110 & 80 & 60 & 40 & 20 & 0 & -30 & -60 & -90 & -120 & -160 &
\end{tabular}

$P_{11}-8$

MALDI-TOF,CCA,4,20181112

MS (MALDI)

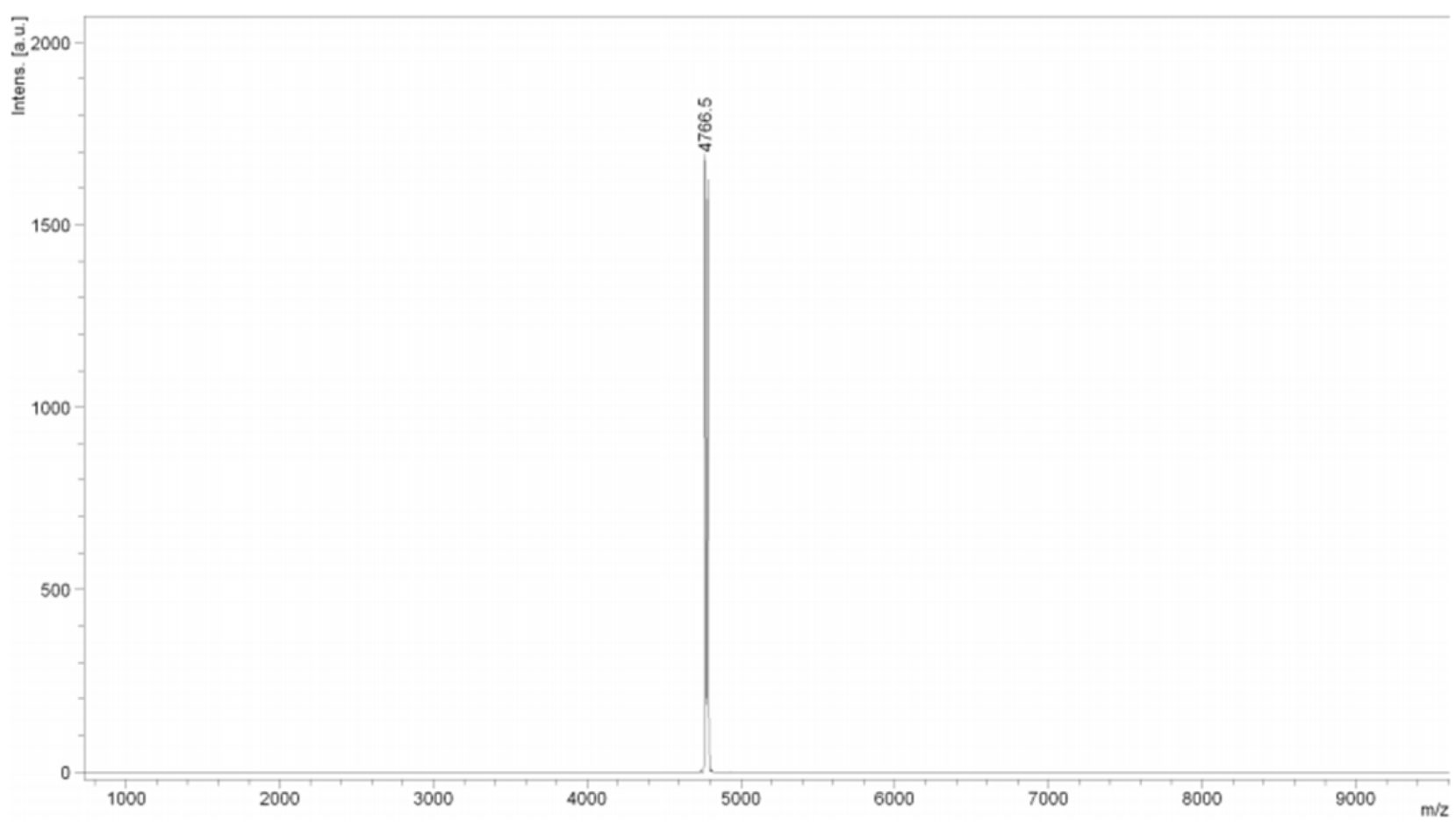




$$
P_{11}-12
$$

${ }^{1} \mathrm{H} \mathrm{NMR}\left(400 \mathrm{MHz}, \mathrm{CDCl}_{3}\right)$

(

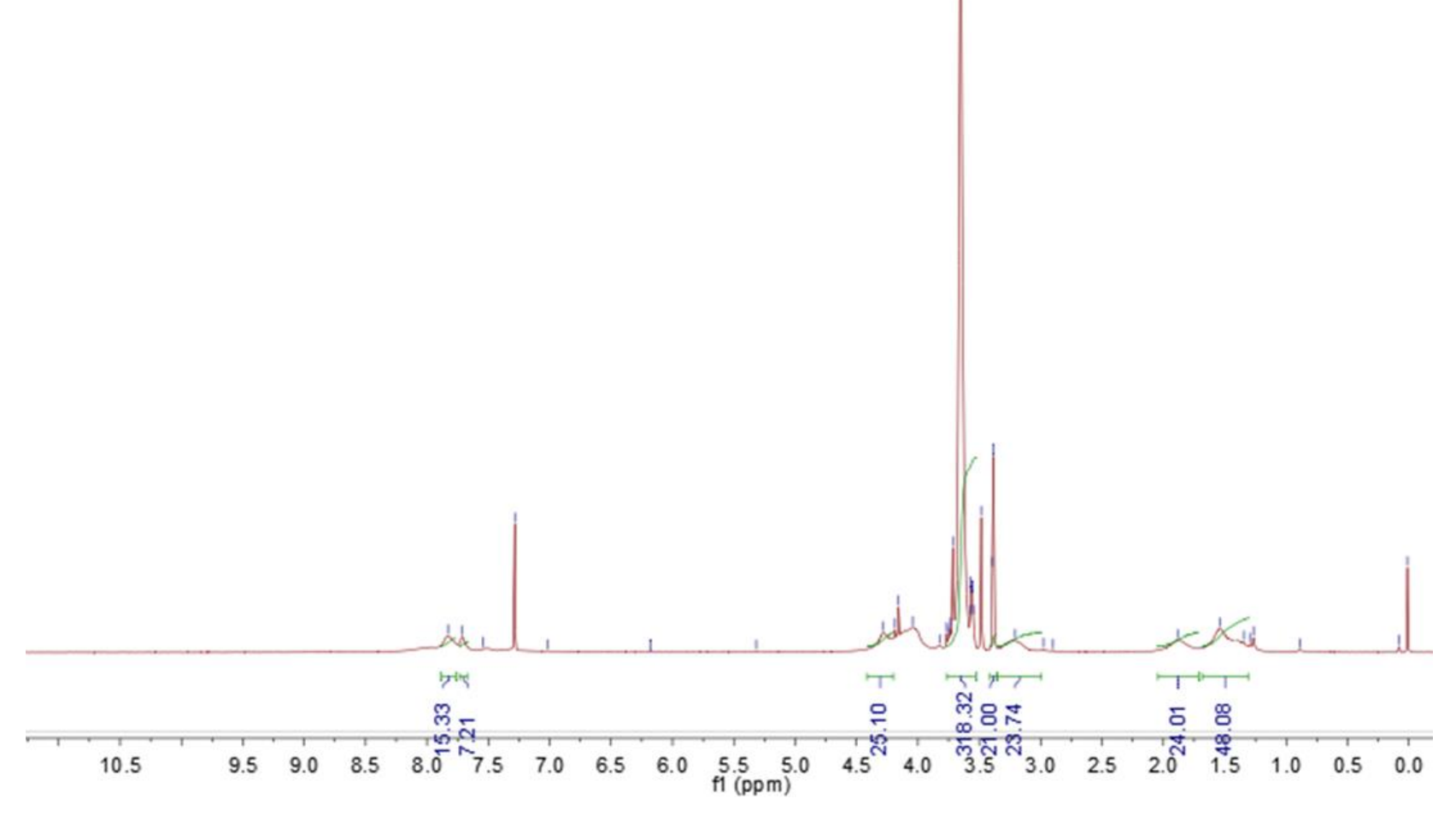

Co181610-J12rszex- 20

$$
P_{11}-12
$$

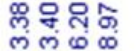

एँ⿻

${ }^{19} \mathrm{~F} \operatorname{NMR}\left(376 \mathrm{MHz}, \mathrm{D}_{2} \mathrm{O}\right)$

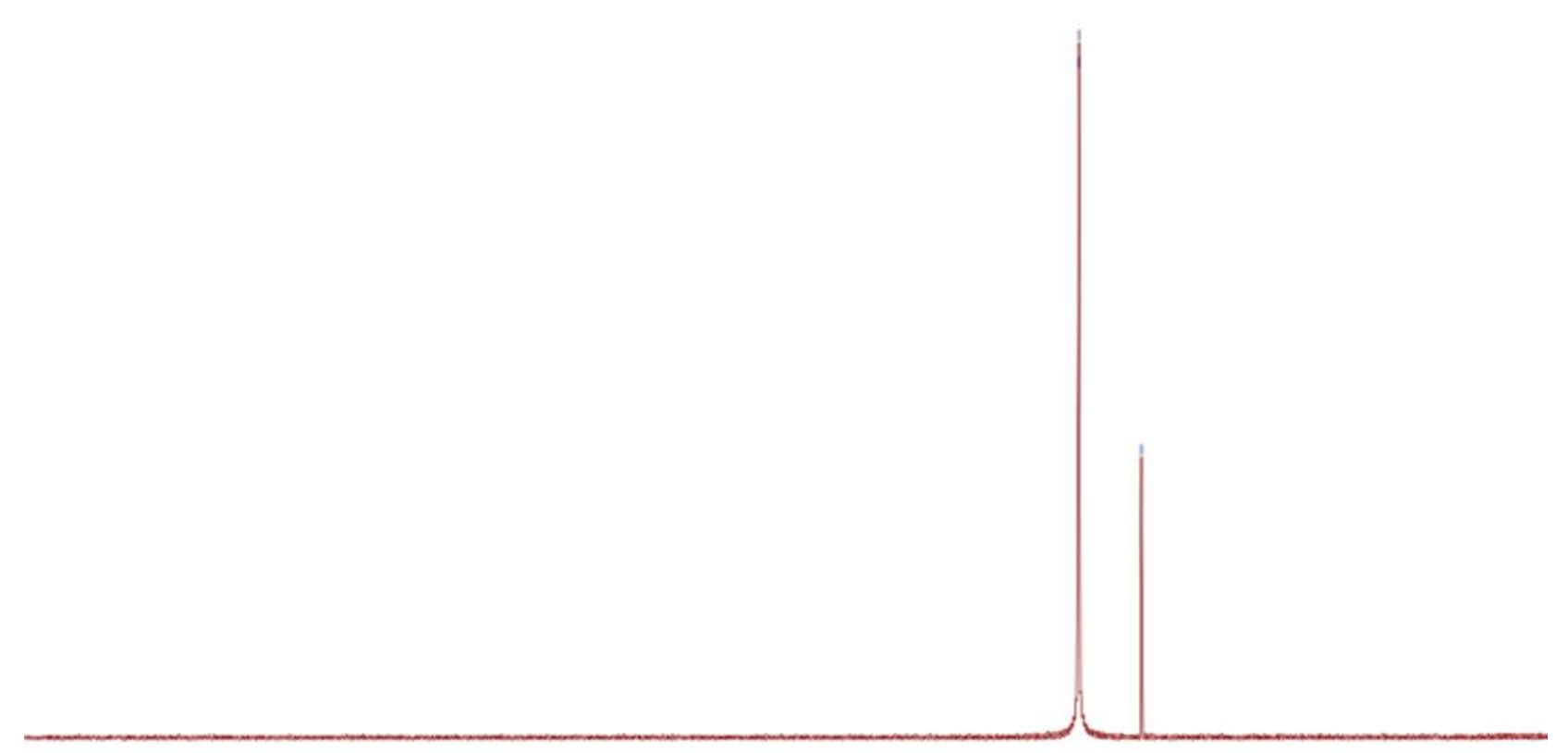


$P_{11}-12$

MS (MALDI)

MALDI-TOF,CCA,2,20181220

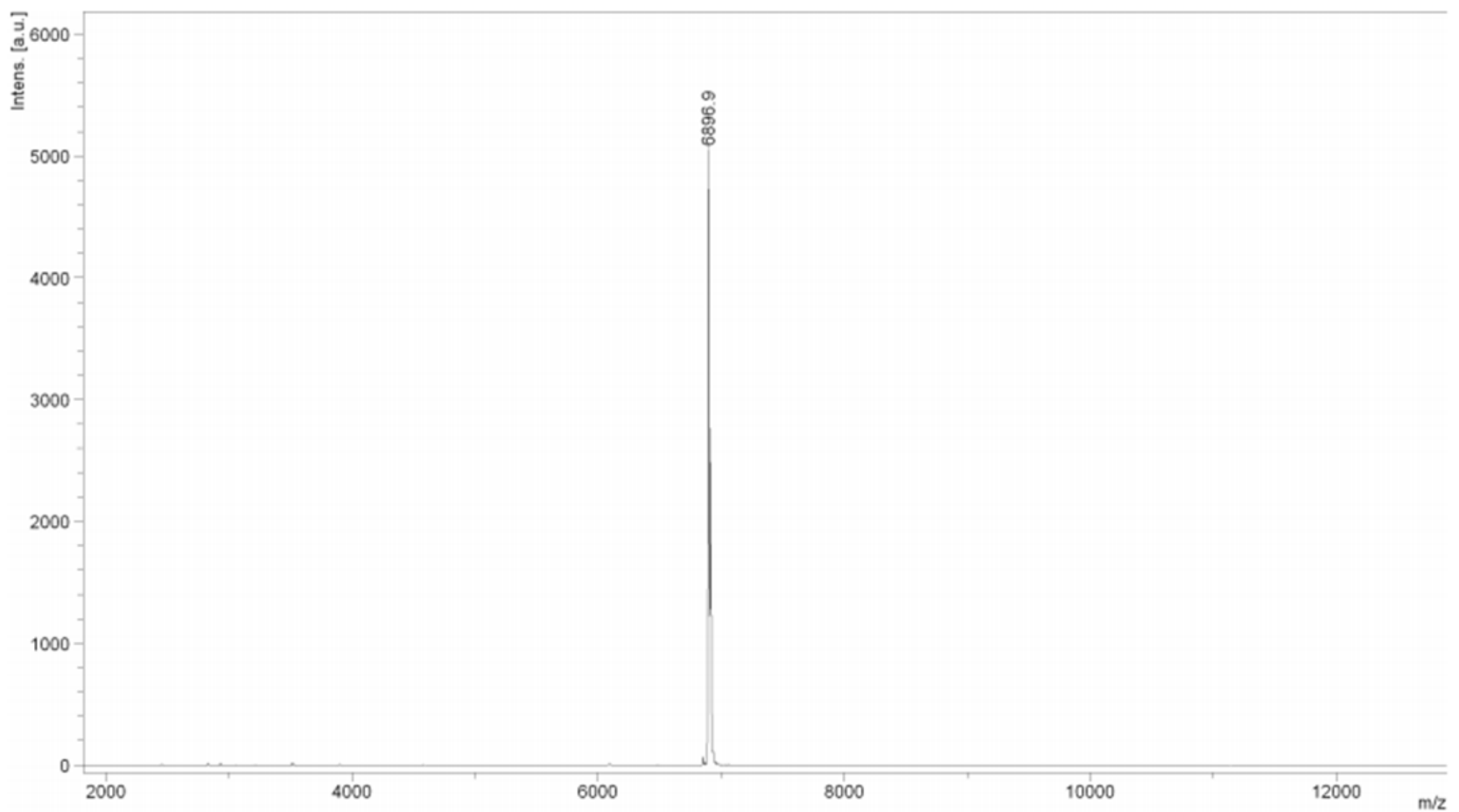

20190925-jiarzzx-21

लำ

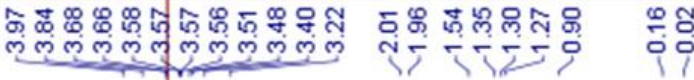

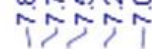

\section{$\mathrm{P}_{23}-8$}

${ }^{1} \mathrm{H} \mathrm{NMR}\left(400 \mathrm{MHz}, \mathrm{CDCl}_{3}\right)$

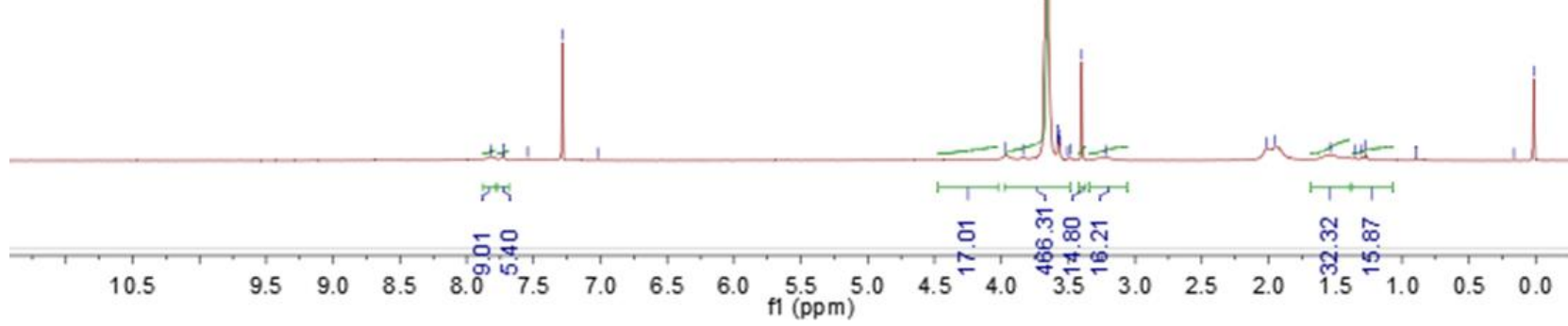


$20131210-j$ iarsex-25

$$
P_{23}-8
$$

${ }^{19} \mathrm{~F}$ NMR $\left(376 \mathrm{MHz}, \mathrm{D}_{2} \mathrm{O}\right)$

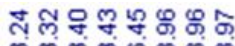

लूल

प

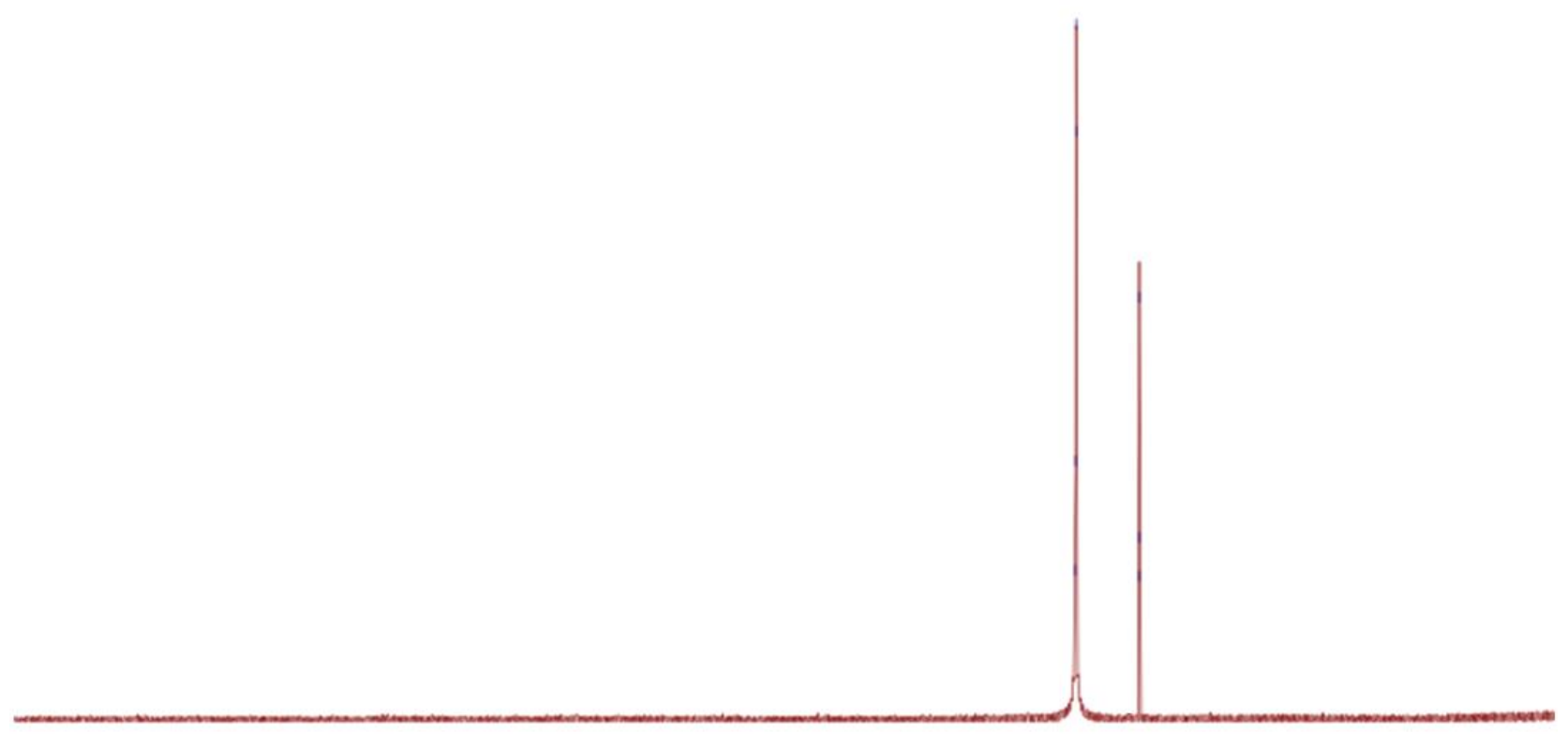

$\begin{array}{lllllllllllllllll}170 & 140 & 110 & 80 & 60 & 40 & 20 & 0 & 0 & -30 & -60 & -90 & -120 & -160 & \end{array}$
D:LATAINeW FolderlNow Folderl20181310_P71

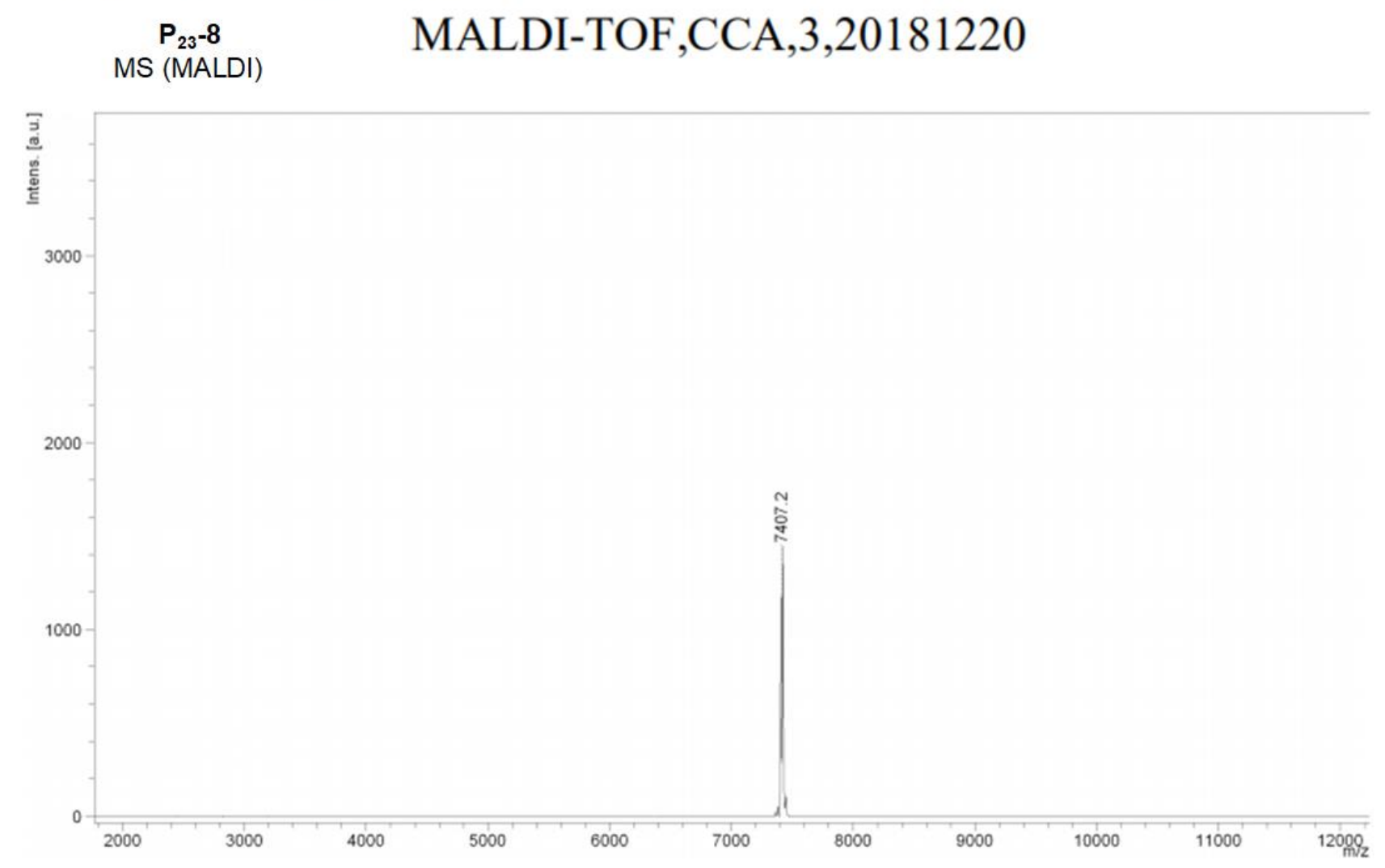

